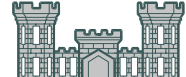

U.S. Army Corps of Engineers

Portland District

\title{
Evaluation of the Fish Passage Effectiveness of the Bonneville I Prototype Surface Collector using Three-Dimensional Ultrasonic Fish Tracking
}

FINAL REPORT

May 2001

Contract DE-AC06-76RLO1830 Related Services

Pacific Northwest National Laboratory

P.O. Box 999

K6-85

Richland, Washington 99352 


\title{
DISCLAIMER
}

This report was prepared as an account of work sponsored by an agency of the United States Government. Neither the United States Government nor any agency thereof, nor Battelle Memorial Institute, nor any of their employees, makes any warranty, express or implied, or assumes any legal liability or responsibility for the accuracy, completeness, or usefulness of any information, apparatus, product, or process disclosed, or represents that its use would not infringe privately owned rights. Reference herein to any specific commercial product, process, or service by trade name, trademark, manufacturer, or otherwise does not necessarily constitute or imply its endorsement, recommendation, or favoring by the United States Government or any agency thereof, or Battelle Memorial Institute. The views and opinions of authors expressed herein do not necessarily state or reflect those of the United States Government or any agency thereof.

\author{
PACIFIC NORTHWEST NATIONAL LABORATORY \\ operated by \\ BATTELLE \\ for the
}

UNITED STATES DEPARTMENT OF ENERGY

under Contract DE-AC06-76RLO1830 


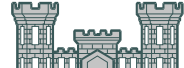

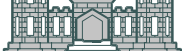

U.S. Army Corps of Engineers

Portland District

\section{Evaluation of the Fish Passage Effectiveness of the Bonneville I Prototype Surface Collector using Three-Dimensional Ultrasonic Fish Tracking}

\section{FINAL REPORT}

Prepared by:

D. M. Faber

M. A. Weiland

R. A. Moursund

T. J. Carlson

(Pacific Northwest National Laboratory)

N. Adams

D. Rhondorf

(U.S. Geological Survey, Biological Resources Division)

May 2001

Contract DE-AC06-76RLO1830 Related Services

Pacific Northwest National Laboratory

P.O. Box 999

K6-85

Richland, Washington 99352 


\section{Executive Summary}

This report describes tests conducted at Bonneville Dam on the Columbia River in the spring of 2000. The studies used three-dimensional (3D) acoustic telemetry and computational fluid dynamics (CFD) hydraulic modeling techniques to evaluate the response of outmigrating juvenile steelhead (Oncorhynchus mykiss) and yearling chinook (O. tshawytscha) to the Prototype Surface Collector (PSC) installed at Powerhouse I of Bonneville Dam in 1998 to test the concept of using a deep-slot surface bypass collector to divert downstream migrating salmon from turbines. The study was conducted by Pacific Northwest National Laboratory (PNNL), the Waterways Experiment Station of the U.S. Army Corp of Engineers (COE), Asci Corporation, and the U.S. Geological Survey (USGS), and was sponsored by COE's Portland District. The goal of the study was to observe the three-dimensional behavior of tagged fish (fish bearing ultrasonic micro-transmitters) within 100 meters $(\mathrm{m})$ of the surface flow bypass structure to test hypotheses about the response of migrants to flow stimuli generated by the presence of the surface flow bypass prototype and its operation. Research was done in parallel with radio telemetry studies conducted by USGS and hydroacoustic studies conducted by WES \& Asci to evaluate the prototype surface collector.

Based on the 3D acoustic telemetry and CFD modeling results, we can make the following general observations about the movements of tagged yearling spring chinook and steelhead in the immediate vicinity of the PSC.

We observed that fish tended to follow the river thalweg (main flow) as they approached the dam with the majority of the fish first encountering the dam and PSC at Powerhouse I Units 4 through 6. However, only about half of these fish passed the dam at Turbine Units 5 and 6, the other half passed to the south through Turbine Units 1 and 2.

In contrast to the difference between the horizontal distribution of approach and the units through which tagged fish passed, fish were more likely to maintain the same vertical distribution during approach and passage into or under the PSC. During approach to the PSC, tagged fish were more surface oriented in the daytime than at night.

We grouped fish into three categories based on three distinct types of observed passage behavior: 1) direct passage - fish that passed through the forebay and into the PSC or turbine units in less than an hour, 2) searching - fish that actively searched for an exit along the face of the dam for 1 to 4 hours before exiting through the PSC or turbines, and 3) milling - fish that traveled about the forebay for more than 4 hours before passing through the PSC or turbines or moving back upstream out of the forebay. The percentages of fish in each category (direct passage, searching, or milling) changed by diel period. Steelhead were twice as likely to mill during the day as during the night. Chinook were equally likely to mill at day or night. Steelhead were 10 times more likely to direct pass at night than during the day. Chinook were twice as likely to direct pass at night as during the day.

The 3D behavior observations were integrated with the output of a CFD model developed by PNNL (Rakowski et al. 2000), which showed that both juvenile steelhead and yearling chinook were more apt to follow flows greater than $\sim 3.0 \mathrm{ft} / \mathrm{s}(\sim 0.9 \mathrm{~m} / \mathrm{s})$ and their behavior was less directed in flows less than $3 \mathrm{ft} / \mathrm{s}$. 



\section{Acknowledgments}

We sincerely acknowledge the cooperation, assistance, and hard work of the following:

- Rock Peters and Blaine Ebberts of the U.S. Army Corps of Engineers, Portland District

- Shon Zimmerman of Mevatec and Joel Luchesi of USGS-BRD for mastering fish tracking and giving them a story to tell

- Jennifer Sturgill, COE staff at Bonneville Dam

- Sue Darland, Michelle Beeman, and Anne Vendetti, U.S. Geological Survey, Biological Resources Division (BRD), administrative staff

- Marshall Richmond, John Serkowski, and Cindy Rakowski, Battelle scientific staff

- Lisa Wright, Ken Gates, and Paul Powers, the BRD Tagging Crew

- Gene Ploskey, Charlie Escher, and Craig Smith, Waterways Experiment Station of the U.S. Army Corps of Engineers

- Pete Bevelacqua and Miguel Vilchez, Associated Western Universities fellows

- Gayle Dirkes, Terrie Bear, Al Garcia, Kathy Lavender, and Cindy Stevens, Battelle administrative and contracts staff. 



\section{Contents}

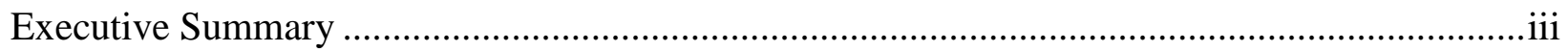

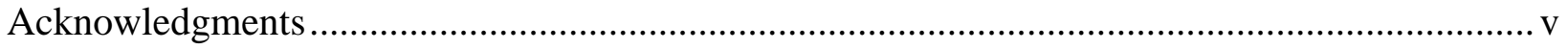

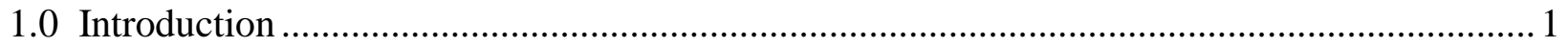

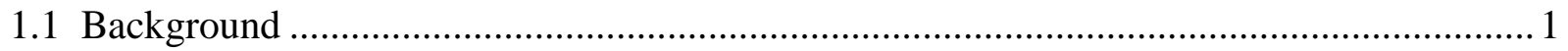

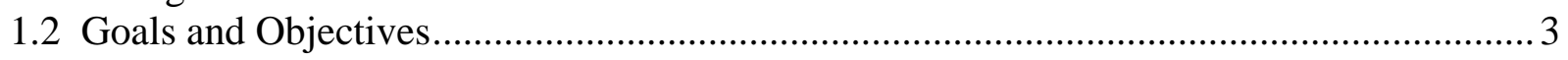

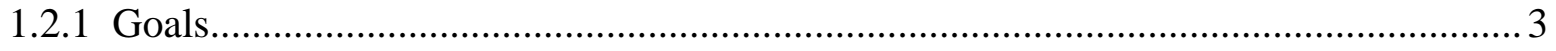

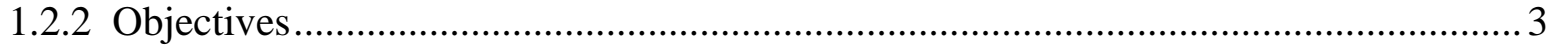

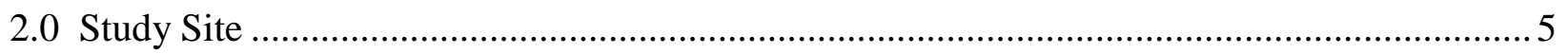

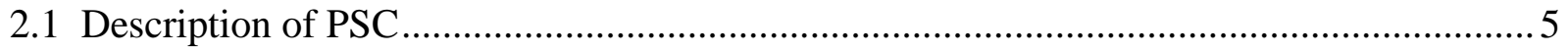

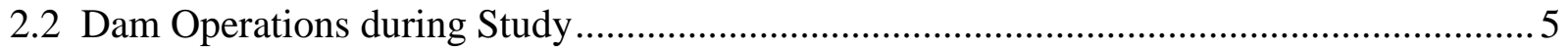

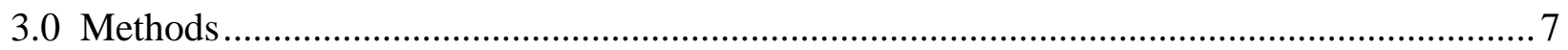

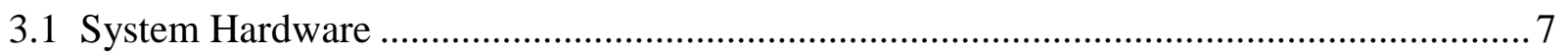

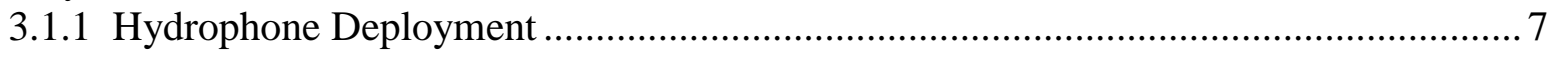

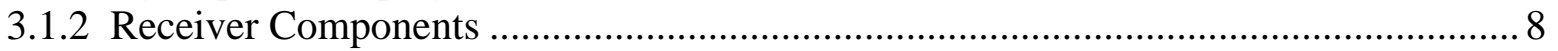

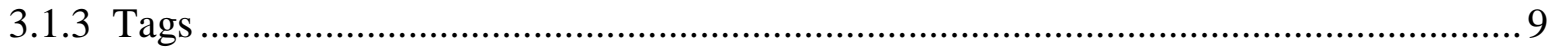

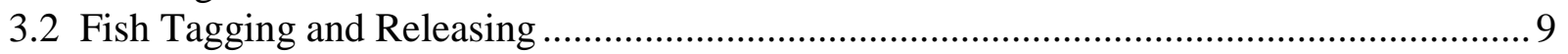

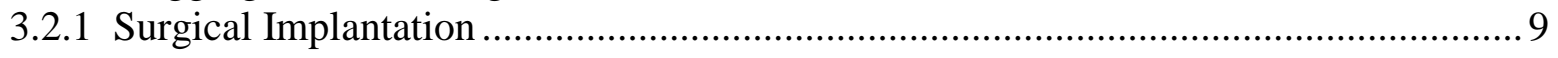

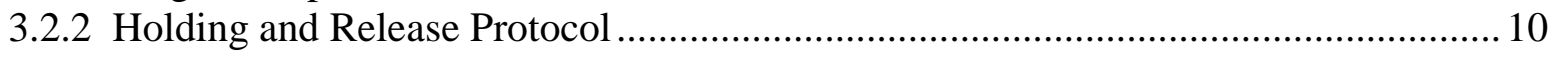

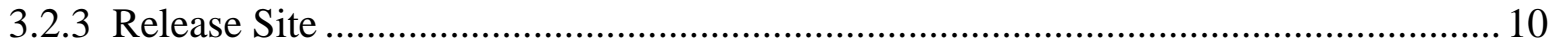

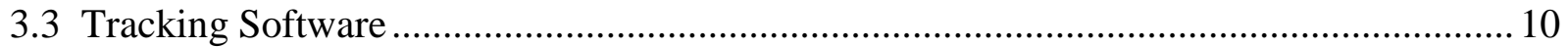

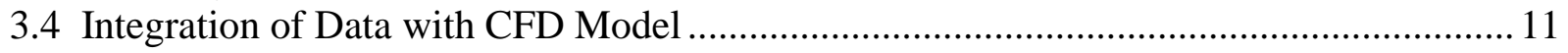

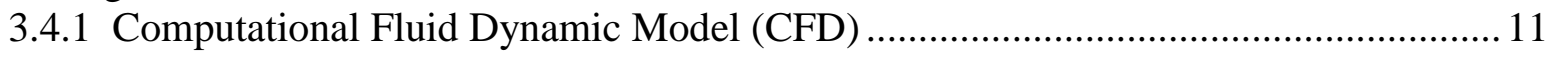

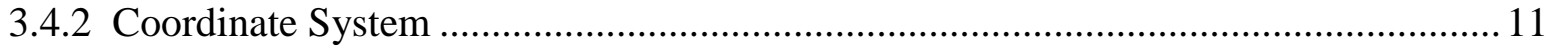

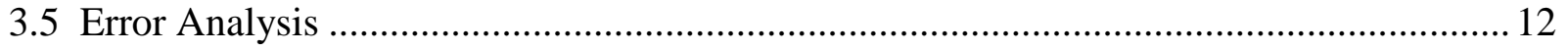

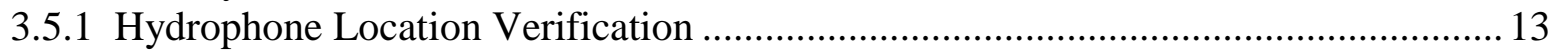

3.5.2 Speed of Sound Estimation ...................................................................... 13

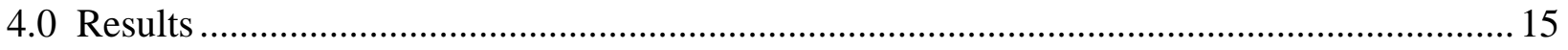

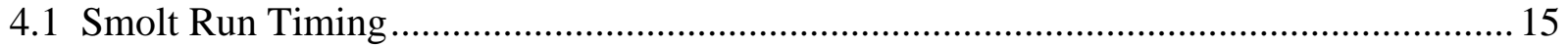

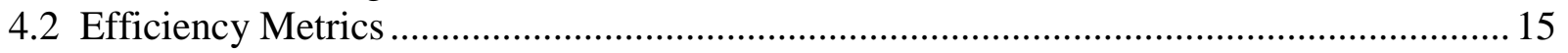

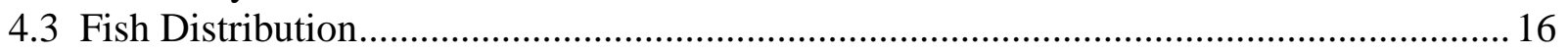

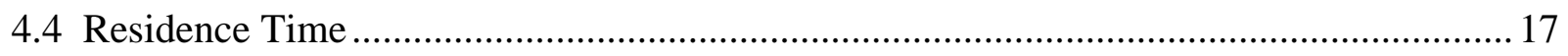

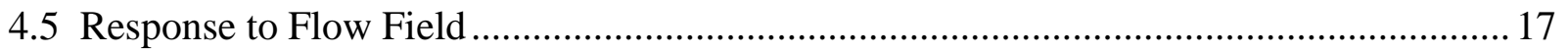

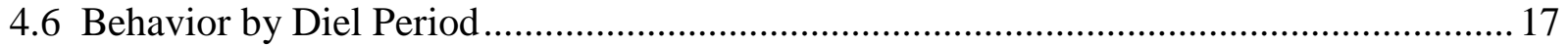




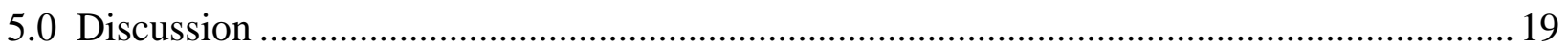

5.1 Past Studies and Fish Tracking Technology Overview ……………………………....... 19

5.2 Fish Approach Distribution and Passage Distribution ....................................................... 19

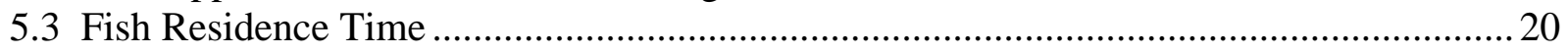

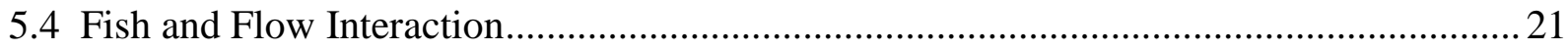

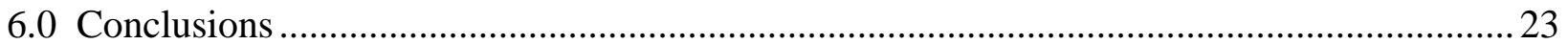

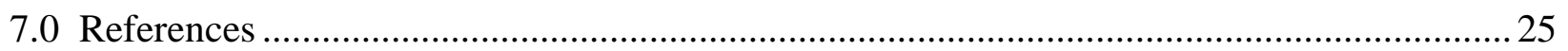

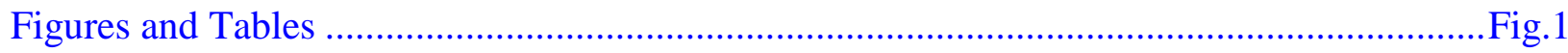




\section{Figures}

Figure 1. Study Area Shown at Bonneville Dam, Powerhouse I on the Columbia River. Fig.1

Figure 2. An Aerial Photograph of Bonneville Dam on the Columbia River Showing Powerhouse II, the Spillway, Powerhouse I, and the Navigation Lock

Figure 3. Powerhouse I with PSC Fig.3

Figure 4. Flow Data by Hour at Bonneville Dam, Powerhouse I during Estimated Times of Greatest Fish Passage

Figure 5. Hydrophone Array in Powerhouse I Forebay

Figure 6. Ideal Array of Hydrophones to Receive Ultrasonic Signals for 3D Positioning of Fish Fig.6

Figure 7. Baseline Hydrophone Array at Powerhouse I Showing a Tracked Juvenile Salmon as It Enters the Array....

Figure 8. Fixed Hydrophone Mount Fig.8

Figure 9. Ultrasonic Tag Fig.9

Figure 10. Surgical Incision of Yearling Chinook. Fig.10

Figure 11. Parameters for Using 3D Positioning Algorithm Fig.11

Figure 12. Water Velocity Output from CFD Model Fig.12

Figure 13. Absolute Value of Elevation Bias for Position Estimates at the 70-ft Elevation Fig.13

Figure 14. Deployment of GPS Drogue with Ultrasonic Tag Attached below Flow Vane..... Fig.14

Figure 15. Predicted Bias in Positioning Estimates for Easting (A) and Northing (B) at the 70-ft Elevation from University of Washington's Monte Carlo Simulation. Fig.15

Figure 16. Average Daily Passage at Bonneville Dam by Species from 1995-1999 Fig.16

Figure 17. Total Smolt Passage Index for Juvenile Salmon and Steelhead at Bonneville Dam from April 1 to September 1, 2000

Figure 18. Average Daily Passage Indices by Species at Bonneville Dam from 1995 to 1999 and Run Timing by Species at Bonneville Dam from April 1 to September 1, 2000

Figure 19. Average Daily Passage Indices by Species at Bonneville Dam from 1995 to 1999 Fig.19 
Figure 20. Approach and Passage Distribution of All Tracked Juvenile Steelhead and Yearling Chinook.

Figure 21. Horizontal Distribution of Juvenile Steelhead and Yearling Chinook Entering the Forebay of Bonneville Dam, Powerhouse I

Figure 22. Horizontal Distribution of Yearling Chinook Entering the Forebay of Bonneville Dam, Powerhouse I

Figure 23. Horizontal Distribution of Juvenile Steelhead Entering the Forebay of Bonneville Dam, Powerhouse I.

Figure 24. Horizontal Distribution of Juvenile Steelhead and Yearling Chinook Entering the Forebay of Bonneville Dam, Powerhouse I, during Daylight Hours.

Figure 25. Horizontal Distribution of Juvenile Steelhead and Yearling Chinook Entering the Forebay of Bonneville Dam, Powerhouse I, during Night Hours

Figure 26. Horizontal Distribution of Yearling Chinook Entering the Forebay of Bonneville Dam, Powerhouse I, during Daylight Hours

Figure 27. Horizontal Distribution of Yearling Chinook Entering the Forebay of Bonneville Dam, Powerhouse I, during Night Hours

Figure 28. Horizontal Distribution of Juvenile Steelhead Entering the Forebay of Bonneville Dam, Powerhouse I, during Daylight Hours

Figure 29. Horizontal Distribution of Juvenile Steelhead Entering the Forebay of Bonneville Dam, Powerhouse I, during Night Hours

Figure 30. Vertical Distribution and Passage of Tagged Juvenile Steelhead at the PSC for Daytime and Nighttime Hours for April, May, and June 2000

Figure 31. Vertical Distribution of Yearling Spring Chinook and Juvenile Steelhead Approaching the PSC at Bonneville Dam during Daylight Hours

Figure 32. Vertical Distribution of Yearling Spring Chinook and Juvenile Steelhead Approaching the PSC at Bonneville Dam during Night Hours

Figure 33. Vertical Distribution of Juvenile Steelhead Approaching the PSC at Bonneville Dam during Daylight Hours

Figure 34. Vertical Distribution of Juvenile Steelhead Approaching the PSC at Bonneville Dam during Nighttime Hours.

Figure 35. Vertical Distribution of Yearling Spring Chinook Approaching the PSC at Bonneville Dam during Daylight Hours 
Figure 36. Vertical Distribution of Yearling Spring Chinook Approaching the PSC at Bonneville Dam during Nighttime Hours

Figure 37. Migrating Yearling Spring Chinook Exiting South Side of Powerhouse I at Bonneville Dam during Daylight Hours

Figure 38. Migrating Yearling Spring Chinook Exiting South Side of Powerhouse I at Bonneville Dam during Night Hours

Figure 39. Migrating Juvenile Steelhead Exiting South Side of Powerhouse I at Bonneville Dam during Daylight Hours

Figure 40. Migrating Juvenile Steelhead Exiting South Side of Powerhouse I at Bonneville Dam during Night Hours

Figure 41. Angular Difference in Water Velocity Direction from Fish Direction for Direct Pass Fish (A), Searching Fish (B), and Milling Fish (C)

Figure 42. Modeled Water Velocity Contours Showing Steady Turbine Loading Unit 8 Off and Steady Turbine Loading Unit 8 On (B)

Figure 43. Milling Fish Movement with Respect to Flow (A) and Water Velocity Magnitude Output from CFD Model (B)

Figure 44. Sample Tracks of Fish Behavior Types in the Forebay of Bonneville Dam, Powerhouse I

Figure 45. Daytime (A) and Nighttime (B) Average Residence Times of Both Yearling Chinook and Juvenile Steelhead

Figure 46. Modeled Water Velocity Contours showing Steady Turbine Loading Unit 8 On as well as Milling Fish Movement Separated by $10 \mathrm{ft}$ x $10 \mathrm{ft}$ Grid Unit; Fish Heading with Respect to Water Velocity Heading

Figure 47. Daytime (A) and Nighttime (B) Average Fish Speed of both Yearling Chinook and Steelhead 
Evaluation of Fish Behavior at the PSC at Bonneville Powerhouse I 


\section{Tables}

Table 1: Fate of Yearling Chinook and Juvenile Steelhead Entering Powerhouse I

3D Hydrophone Array at Bonneville Dam ...................................................................... 48

Table 2: Migrating Yearling Chinook and Juvenile Steelhead Exiting South Side of

Powerhouse I at Bonneville Dam during Daylight Hours.

Fig.48

Table 3: Migrating Yearling Chinook and Juvenile Steelhead Exiting South Side of

Powerhouse I at Bonneville Dam during Night Hours

Table 4: Summary of Acoustic Telemetry Data Relative to Bonneville Dam, Powerhouse 1 and the PSC 


\subsection{Introduction}

This report describes a study conducted at Bonneville Dam on the Columbia River in the spring of 2000. The study used three-dimensional (3D) acoustic telemetry and computational fluid dynamics (CFD) hydraulic modeling to evaluate the response of outmigrating juvenile steelhead (Oncorhynchus mykiss) and yearling chinook (O. tshawytscha) to the Prototype Surface Collector (PSC) installed at Powerhouse I of Bonneville Dam (see Figure 1) in 1998 to test the concept of using a deep-slot surface bypass collector to divert downstream migrating salmon from turbines. The study was conducted by Pacific Northwest National Laboratory (PNNL), the Waterways Experiment Station (WES) of the U.S. Army Corp of Engineers (COE), Asci Corporation, and the U.S. Geological Survey (USGS) and was sponsored by COE's Portland District. Research was done in parallel with radio telemetry studies conducted by USGS and hydroacoustic studies conducted by WES and Asci to evaluate the prototype surface collector. This is one of several studies conducted over the last five years for the Corps to evaluate prototype surface bypass structures that have been installed at COE Dams on the Columbia and Snake Rivers, including Lower Granite and Bonneville Powerhouse I and II.

This report presents information on the movements of tagged yearling spring chinook salmon and steelhead in the immediate vicinity of the PSC. Data was obtained at high spatial and temporal resolution using 3D-acoustic telemetry techniques (3DAT) and related to modeled CFD flow. We also provide estimates of PSC fish passage performance measures and observations of the response of tagged fish to forebay hydraulic conditions.

\subsection{Background}

Surface flow bypass and downstream migrant collection systems are being tested at hydroelectric dams in the Columbia River Basin as a potential means of improving the survival of seaward migrating salmon smolts passing through the dams, thereby assisting the recovery of threatened and endangered Pacific Northwest salmon stocks. At Bonneville Dam Powerhouse I, COE's is evaluating two smolt bypass approaches: surface flow bypass and extended-length submersible bar screens. The year 2001 has been scheduled for a decision on which suite of smolt passage measures to emphasize for long-term smolt protection at Bonneville Dam Powerhouse I. The COE is preparing a special report, called the Decision Document, to present the results of an assessment of the relative merits of surface bypass and other passage alternatives for Powerhouse I.

In 1998 the COE installed a Prototype Surface Collector (PSC) at Bonneville Dam's Powerhouse I that extended into the forebay in front of Turbine Units 3 through 6 (see Johnson and Giorgi 1999 for a review). This PSC configuration was evaluated in 1998. In 1999, limited research was performed to prepare for a comprehensive suite of tests of PSC fish bypass performance to be conducted in 2000. Prior to the spring of 2000, the PSC, which had covered Units 3 through 6, was extended to cover Units 1 and 2 because a noticeable number of smolts were observed in 1998 and 1999 to move obliquely from north to south across the forebay of the PSC. A thorough evaluation of the PSC was conducted in 2000 as part of the Anadromous Fish Evaluation Program (AFEP). The general objectives for surface bypass research at Bonneville Powerhouse I in 2000 were to 1) confirm the positive results of proof-of-concept tests for surface flow bypass at Powerhouse I that were observed in 1998, 2) estimate PSC performance metrics 
for the PSC configuration and powerhouse operations tested in 2000, and 3) study fish behavioral processes and mechanisms that affect fish bypass performance to aid future surface bypass designs.

The 2000 PSC evaluation emphasized PSC performance, i.e., collection efficiency, as well as characterization of fish behavior during approach through the dam forebay to the PSC and response upon encountering the PSC. Surface collector efficiency (a measure of the ability of a structure to collect juvenile fish) has been linked to flow characteristics immediately upstream of the entrances to a bypass facility. It is believed that hydraulic conditions leading to the bypass entrances significantly influence the ability of fish to discover a bypass entrance and the response of fish to the bypass entrance. Recently, it has been suggested that smolts may respond to fine-scale flow field characteristics, such as turbulence, during their migration and that a collection system could use these attributes of flow to better collect juvenile salmon. For example, Coutant (1998) speculated that low levels of turbulence at the entrance to the bypass collector may attract juvenile salmon and Haro et al. 1998 found a relationship between surface water acceleration and success in drawing salmon into collectors.

Previous studies on the PSC using hydroacoustic and radio telemetry found high fish passage efficiencies. Ploskey et al. (1999), using hydroacoustics, found collection efficiencies of $85 \%$ with the PSC open $20 \mathrm{ft}$ in 1999. Hansel (1998), using radio telemetry, found collection efficiencies of $89 \%$ for juvenile steelhead and $93 \%$ for yearling chinook with the PSC open $20 \mathrm{ft}$ in 1998. (They tested 20 feet and 5 feet openings in 1998-1999 and only 20-ft openings in the 1999-2000 study.) (Passage efficiency is the number of fish passing into the PSC relative to the total number passing into and under the PSC). However, an estimate of entrance efficiencies (i.e., the number entering divided by the total number within $20 \mathrm{ft}$ of a slot) was much lower (Johnson et al. 1999). A desire to reconcile these seemingly inconsistent observations and obtain continuous fish behavior information upstream of the PSC entrances led to interest in the application of 3DAT techniques.

In previous years, traditional fixed radio-telemetry has provided general observations of the behavior of fish immediately upstream of surface-oriented dam passage routes. However, fine-scale continuous threedimensional information on fish behavior cannot be easily obtained using traditional radio telemetry techniques. Advances in micro-electronic devices have permitted the design of ultrasonic microtransmitters small enough for implantation in juvenile fish. In conjunction with standard 3DAT techniques, it is possible to observe the three-dimensional behavior of fish within a tracking baseline. In 2000, we conducted the field studies described here using 3DAT at Bonneville Dam on the Lower Columbia River. As part of a broader program to test the feasibility of surface collection at all of the Columbia Basin dams, steady-state three-dimensional CFD models have been developed that describe flow fields and associated turbulence and acceleration gradients upstream of the PSC. The CFD model output can be analyzed in conjunction with fish behavior data to permit evaluation in three dimensions of potential relationships between fish behavior and flow field characteristics.

There is also special interest in learning more about how juvenile downstream migrant salmonids detect and respond to sensory stimuli generated by the bypass entrances (such as flow gradients). Over the past 20 years, a variety of methods have been used to observe downstream migrant behavior. Of these methods, fisheries sonar (hydroacoustics) and radio telemetry have had the widest application. However, these methods lack the ability to completely characterize fish response to flow field stimuli due to the scales at which the methods function. Hydroacoustics can be used to observe fine-scale movements of unidentified fish within a volume defined by the characteristics of the systems' transducers, which typically limits observations to a small region immediately in front of bypass entrances. Radio-telemetry mobile tracking offers broader scale movements of a known (tagged) individual fish, but, in most cases, is limited to two dimensions and relatively infrequent location estimates, which limits the possibility of observing a tagged fish's response to small changes in flow fields and other habitat features. 3DAT has 
the ability to track an individual tagged fish on temporal and spatial scales fine enough to observe responses to microhabitat changes within a large enough volume and over a long enough time period to comprehensively characterize its approach and other aspects of behavior upon exposure to a known stimulus such as an entrance to the PSC. With better understanding of fish behavior to flow field characteristics, we may be able to gain insights that will aide the development of surface flow bypass devices on Columbia River hydropower dams.

\subsection{Goals and Objectives}

The goals and objectives of this study were as follows:

\subsubsection{Goals}

1. Observe in three dimensions and time the behavior of ultrasonically tagged juvenile steelhead and yearling chinook salmon smolts during approach to the Bonneville Powerhouse I PSC, their response upon discovery of the PSC, and their route of passage past the powerhouse.

2. Estimate measures of the fish passage effectiveness of the PSC for juvenile steelhead and yearling chinook salmon smolts.

3. Investigate potential relationships between features of the flow field in the forebay of Bonneville Powerhouse I and the region immediately in front of the PSC estimated using a 3D CFD model and observations of the behavior of tagged juvenile steelhead and Chinook smolts.

\subsubsection{Objectives}

1. Acquire high temporal- and spatial-resolution three-dimensional observations of juvenile steelhead trout and chinook salmon smolt during residence within the intermediate and near field of the prototype surface flow bypass using ultrasonic tracking methods.

2. Establish behavioral criteria, using high-resolution three-dimensional ultrasonic tracking methods, to identify fish rejection of surface flow bypass entrances by ultrasonically tagged juvenile salmonids.

3. Provide population distribution data as it relates to species, flow, and categorical behavior type within the hydrophone array. 



\subsection{Study Site}

Bonneville Dam on the Columbia River is located at river mile $146(\mathrm{~km} \mathrm{245).} \mathrm{(See} \mathrm{Figure} \mathrm{2.)} \mathrm{The} \mathrm{dam} \mathrm{is}$ composed of two powerhouses and a single spillway, separated by islands. Powerhouse I has 10 turbine units and is located on the south side of the river between a navigation lock located on the Oregon shore and Bradford Island. Powerhouse II has 8 turbine units and is located on the north side of the river between the Washington shore and Cascade Island. The dam's spillway located between Bradford Island and Cascade Island; consists of 18 spill gates. The first powerhouse and spillway were completed in 1937 and, to meet growing energy requirements in the Pacific Northwest, the second powerhouse was added and completed in 1981. The depth of the forebay for Powerhouse I is $78 \mathrm{ft}$.

\subsection{Description of PSC}

The PSC is attached to the upstream face of Powerhouse I (Figure 3). The PSC is a steel structure that was retrofitted to a portion of the face of Powerhouse I in 1998 and extended in 2000. In 2000 it spanned Turbine Units 1 through 6. It has openings at the center module (B intake bay) of each turbine unit extending $50 \mathrm{ft}(15.2 \mathrm{~m})$ below the water surface. The PSC entrances are designed to be either $5 \mathrm{ft}$ or 20 $\mathrm{ft}$ wide. In 2000 all PSC entrances were set to their 20-ft width. The entire PSC structure slopes with the powerhouse pier noses at an angle of approximately $11^{\circ}$. Water is drawn through PSC openings by operating the turbines. The PSC is a façade without a conveyance channel so that water that passes through PSC entrances exits the PSC façade by passing into turbine intakes. Intakes for turbine Units 1 through 6 and 7 through 10 are separated by a concrete wing wall, which extends perpendicularly from the face of the powerhouse approximately $140 \mathrm{ft}(42.7 \mathrm{~m})$ upstream.

\subsection{Dam Operations during Study}

During the study, operation of the Powerhouse I turbines and sluiceway was limited to one operational scenario and the forebay elevation was controlled within $\pm 1 \mathrm{ft}$. Furthermore, the PSC was limited to one entrance configuration (all entrances were $20 \mathrm{ft}$ wide) throughout the study. These operation and configuration restrictions were required to maximize the sample size of test fish for a single flow field condition. PSC evaluation studies conducted in 1998 and 1999 had focused on evaluation of PSC operation alternatives. The 2000 evaluation used the PSC configuration and powerhouse operations found to optimize PSC fish passage performance. Limiting study conditions to one PSC configuration and powerhouse operation scenario limited the variables in our study, thereby permitting larger sample sizes for estimation of PSC fish passage performance metrics and investigation of relationships between flow field features and migrant behavior.

While it was possible to maintain the PSC configuration and forebay elevation to specifications through the study, there was some variability in powerhouse operations. During the study outages at Units 8 and 10 were necessary to perform needed turbine maintenance. As a result of these outages we ended up with four powerhouse operating scenarios: 1) steady turbine loading all units, 2) steady turbine loading with Unit 8 offline, 3) steady turbine loading with Unit 10 offline, and 4) steady turbine loading with both Units 8 and 10 offline. In order to better estimate forebay flow field conditions, individual CFD model runs were performed for the first two powerhouse operating scenarios (Figure 4). 



\subsection{Methods}

To accomplish the study goals and objectives, the following steps were taken:

1. Deploy the ultrasonic tracking baseline in the Bonneville Dam Powerhouse I forebay.

2. Collect and tag fish.

3. Release and track fish.

4. Analyze observations of migrant behavior within the context of flow field estimates obtained using a 3D CFD model of the Bonneville Powerhouse I forebay.

\subsection{System Hardware}

The 3DAT system hardware consisted of 16 hardwired hydrophones and receivers, which were positioned around the Bonneville I forebay and an ultrasonic micro-transmitter that was implanted in the test fish. The system hydrophones were arranged in the forebay in a configuration that permitted transmissions from the ultrasonic micro-transmitters implanted in the test fish to be received on a minimum of four hydrophones. A large number of hydrophones were required to provide adequate coverage in the dam forebay because maximum detection ranges for the micro-transmitter transmissions were on the order of 300 feet. The 3D tracking method used required time-of-arrival data from a minimum of four hydrophones within the tracking array to estimate the 3D location of the transmitter.

\subsubsection{Hydrophone Deployment}

The 16 tracking baseline hydrophones were positioned in the forebay of Bonneville Powerhouse I to provide 3D coverage of the whole forebay volume out to a distance of approximately $400 \mathrm{ft}(125 \mathrm{~m})$ from the face of the PSC. The acoustic detection zone extended horizontally the length of Powerhouse I, vertically from the water surface to the bottom, and longitudinally from the powerhouse upstream about $125 \mathrm{~m}$. Figure 5 shows the deployment of the hydrophones within the forebay.

We followed a tracking baseline deployment design used at Rocky Reach Dam in 1998 and 1999. This design positioned hydrophones at the corners of adjacent volumes, which were roughly rectangular in shape with surface dimensions of $100 \mathrm{~m}$ by $100 \mathrm{~m}$ (Steig et al. 1998). (See Figure 6.) The tracking system baseline was designed so that detailed tracking of tagged test fish could begin as they crossed into the upstream edge of the study area (125 m upstream of the PSC). In addition, tagged fish were tracked upstream of the study zone at a lower temporal and spatial resolution to document their direction of approach and to anticipate their arrival in the study area.

Hydrophones were placed at various elevations along the PSC. Twelve of the hydrophones were hard mounted to dam structures including the concrete wing wall and the old navigation wall; four of the hydrophones were attached to "clump" anchors set on the river bottom (Figures 7 and 8). The clump anchors consisted of a crosshatched iron I-beam base and a mast to support the hydrophone. The portion of the forebay to the south of the wing wall in front of the PSC and Turbine Units 1 through 6 was the region where detailed observations of fish behavior were most important to aid evaluation of PSC fish passage performance. Therefore 13 of the 16 tracking baseline hydrophones were placed in this region to optimize our ability to observe the behavior of test fish as they approached and responded to the PSC. Four hydrophones were positioned on the north side of the wing wall (Units 7 through 10). 
The positions of the 12 hard-mounted hydrophones were determined using traditional survey techniques and a Nikon Laser Surveyor Total Station. Surveying with these methods and equipment allowed us to make position estimates accurate to about the nearest inch $(2.54 \mathrm{~cm})$. We used the hard-mounted elements of the tracking baseline to estimate the positions of the four clump anchor-mounted hydrophones. This method required the clump-mounted hydrophones to be operated as projectors. Projector positions were estimated by triangulation using time-of-arrival data from the hard-mounted elements of the tracking baseline, measurements of the projectors' depth, and speed-of-sound estimates.

Hydrophones attached to dam structures were attached by mounts designed to reduce multipath (acoustic reflections from dam structures or other boundaries which are one source of error in position estimates). The hydrophone mounts were designed so that the hydrophones were placed a minimum distance of $5 \mathrm{ft}$ $(1.7 \mathrm{~m})$ from dam structures. This placement of hydrophones permitted micro-transmitter pulses that were reflected from a hard structure (i.e., concrete wall, PSC wall) to be separated from those transmissions arriving at the hydrophone directly from the micro-transmitters in the test fish. All of the hard-mounted hydrophones were fixed to dam structures that did not move.

\subsubsection{Receiver Components}

The receiver system was capable of continuously monitoring up to 16 separate channels with one channel assigned to each hydrophone. Received signals were synchronized so that the time of arrival for each detected tag pulse could be used to position the tag in three dimensions. Hydrophones were connected by underwater cables to the receiver system. The hydrophones have a receive directivity of $290^{\circ}$ (vertical slice through spherical directivity pattern) $3 \mathrm{~dB}$ down, which is almost omni-directional. The $70^{\circ}$ blind spot in the receive directivity is directly behind the ceramic element (tip of the hydrophone). Typically the hydrophones are deployed so that the blind spot is oriented away from regions where fish are expected. The receiver channels each have a micro-processor and hard drive which were, in turn, networked to a separate monitoring computer using an Ethernet networking interface. Signals received from the hydrophones were recorded onto the hard drive of the monitoring computer in files each containing the results from an hour of monitoring. Raw data files were downloaded and backed up daily.

The receiving system was designed to receive an acoustic band centered on the transmit frequency of the micro-transmitters (tags) implanted in the test fish. The tags transmitted at a frequency of 307.5 kilo Hertz (kHz) with a pulse width of 0.5 milliseconds (ms) and varying time between pulses, which was uniquely set for each fish in a release group. This pulse repetition rate encoding permitted each fish in a release group to be individually identified. The receive gains for each channel of the system receiver were individually set with gains ranging from 46 to $60 \mathrm{~dB}$ (depending on location of hydrophones and other factors unique to each hydrophone). The receiving system had thresholds of 0.2 volts minimum for a received micro-transmitter pulse and a signal-to-noise ratio of three for detection of micro-transmitter pulses. Thresholds on signal to noise and the amplitude of received micro-transmitter pulses were necessary to discriminate against other acoustic signals that were present in the study area. There were several studies concurrent with this study that used active hydroacoustic devices to acquire various types of data in the forebay of Powerhouse I, all of which could be detected on our hydrophones. The system we deployed and the criteria we selected for detection of micro-transmitter pulses was robust enough to discriminate known tag codes (micro-transmitter pulses from individual fish) from other acoustic noise. 


\subsubsection{Tags}

We used ultrasonic tags that transmitted a 0.5-ms tone burst (pulse) at a carrier frequency of $307.5 \mathrm{kHz}$. The time between tone bursts was uniquely set by changing the inter tone burst timing by a minimum of 1 ms for each micro-transmitter implanted in a release group of test fish. The micro-transmitters had exterior dimensions of 20 millimeters $(\mathrm{mm})$ in length and $7.1 \mathrm{~mm}$ in diameter (Figure 9). The average tag dry weight was 2.5 grams (ranging from 2.3 grams to 3.0 grams). The excess mass of the transmitter in water was estimated to be 2.1 grams. This weight gave an average tag weight-to-fish weight percentage of $4.14 \%$ for all tagged yearling chinook salmon and $2.47 \%$ for all tagged steelhead. The inter-tone burst times that were used ranged from $264 \mathrm{~ms}$ to $500 \mathrm{~ms}$ ( $3.8 \mathrm{pings} / \mathrm{s}$, to 2 pings/s). The micro-transmitters' expected life was 11 to 12 days from start of activation.

\subsection{Fish Tagging and Releasing}

We followed procedures outlined in Adams et al. (1998) for surgically implanting the ultrasonic tags in the test fish. Juvenile steelhead and yearling chinook over $155 \mathrm{~mm}$ in length were collected at Bonneville Dam collection facilities, at the downstream migration channel at Powerhouse I, and at the juvenile bypass facility at Powerhouse II. Only fish larger than $155 \mathrm{~mm}$ were selected for tagging so that the tagto-fish weight ratio did not exceed 5\%. Collection at either facility was dependent on numbers of fish available for tagging. A total of 34 fish were desired for each release (22 juvenile steelhead and 12 yearling chinook), although this number fluctuated based on fish availability at the collection sites. Releases were scheduled every other day from April 26 through June 12, 2000. Fish were transported to the tagging area located at the juvenile bypass collection facility and held for 18 to 24 hours before their tags were surgically implanted.

\subsubsection{Surgical Implantation}

Tags were coded (inter ping [tone burst] timing set) and activated a minimum of 1 hour (and maximum of 3 hours) prior to surgical implantation and placed in a sterile saline solution. A unique tag code was assigned to each fish; codes varied from $264 \mathrm{~ms}$ to $500 \mathrm{~ms}$ between pings and codes were repeated every 12 days (the expected life of the tag). Fish were placed in an anesthetic tank prior to surgery and kept in the tank for no longer than $150 \mathrm{~s}$. Tricaine Methanesulfonate (MS-222) in quantities of 5.5 to 7.0 millileters per 10 liters $(\mathrm{ml} / 10 \mathrm{l})$ was used as the anesthetic. After a fish lost equilibrium in the anesthetic tank it was immediately weighed to the nearest $0.1 \mathrm{~g}$ and measured to the nearest millimeter. The fish was then placed on a surgical table and given anesthesia through rubber tubing from a gravity-fed bucket in the form of MS-222 in quantities of $0.2 \mathrm{ml} / \mathrm{l}$ until 1 minute before the surgical procedure was completed, whereupon the anesthetic mixture was changed to fresh river water.

With the fish's ventral side up, a 10-mm incision was made $3 \mathrm{~mm}$ from and parallel to the mid-ventral line between the pelvic girdle and anal fin (Figure 10). The ultrasonic micro-transmitter was then inserted through the incision into the fish's body cavity, while species, weight, fork length, and tag code were recorded. Oxytetracycline was injected into the incision at a concentration of $100 \mathrm{mg} / \mathrm{ml}$ in an amount of $50-\mathrm{mg} / \mathrm{kg}$ body weight. The incision was sutured immediately following the oxytetracycline injection with three stitches. Antibacterial cream was applied to the stitches using a Q-tip. After surgery, fish were placed into a recovery tank with fresh oxygenated river water and monitored to ensure they recovered equilibrium. After recovering equilibrium, fish were placed into a larger holding tank for $24 \mathrm{~h}$ before transport. 


\subsubsection{Holding and Release Protocol}

After the 24-hour holding period, fish were transported to the Hood River release site. During transport, fish were given a constant supply of oxygen and their holding tanks were covered to reduce stress. Fish were moved to holding tanks at the Hood River marina by boat. The boat was driven to the center of the Columbia River under the Hood River Bridge (24.5 miles, 39.4 km, upstream of Bonneville Dam). The implanted micro-transmitters were then tested to verify that they were transmitting and the fish were released one at a time. Tag operation was verified using a hydrophone and receiver designed for that purpose. Another receiver system was used to log the release of each fish and verify the tag code upon release. A total of 494 ultrasonically tagged fish were released between April 26 and June 12, 2000 (331 steelhead and 163 yearling chinook salmon).

\subsubsection{Release Site}

The Hood River Bridge (24.5 miles upstream of Bonneville Dam) was selected as the release site to allow tagged fish sufficient time to distribute naturally in the river before they encountered Bonneville Dam, which gave them an equal opportunity to enter the forebay of Powerhouse I, the spillbay, or the forebay of Powerhouse II. From previous radio-telemetry studies, we expected the fish to arrive in the forebay of Bonneville dam in 12 to 16 hours after release. We also expected about one-third of the fish to enter the Powerhouse I forebay.

\subsection{Tracking Software}

Procedures to estimate the 3D position of a fish involved three steps: 1) finding the tag code specific to an individual fish in the raw acoustic echo files, 2) manually tracking the tag code record on each of 16 hydrophones, and 3) running the manually tracked files through a 3D tracking program (Figure 11).

Files were first browsed for sequences of transmissions from tagged fish bearing the micro-transmitters with the tag codes expected to arrive in the forebay 8 to 18 hours after fish were released at Hood River Bridge. A directory was created for each fish found in that time period so that raw echo files associated with each fish could be placed in the directory. Raw echo files for each unique tag code and each hydrophone where the transmitter was detected were then manually tracked with the aid of a software program. Upon completion of the manual tracking process, a database was created for each fish tag code. From this database, another software program was run to estimate the location of the transmitter for each detected transmission. Sequences of such individual location estimates formed a 3D position track for each test fish detected within the tracking baseline. Processing criteria used within the tracking software included a planar separation of at least $10 \mathrm{ft}(3 \mathrm{~m})$ (e.g., planes that are created by the four-hydrophone combination had to be $10 \mathrm{ft}$ apart). The fish position estimation software used multiple combinations of hydrophones to estimate a fish's position (not necessarily the first combination of four). Other criteria included the following: the gap between manual tracks could be no greater than $40 \mathrm{~s}$; fish swim-speed was limited to $5 \mathrm{ft} / \mathrm{s}(1.5 \mathrm{~m} / \mathrm{s})$; and the 3D track was interpolated to a maximum gap of $20 \mathrm{~s}$ with a limit of $5 \mathrm{ft}(1.5 \mathrm{~m})$ for a position change from the last 3D position (HTI 2000).

Selection of transmitter position estimation software program parameters was aided by data acquired by tracking drogues equipped with Global Positioning System (GPS) receivers above water and microtransmitters suspended below the drogues' underwater vanes at known depths through the tracking baseline array. Parameters selected for the 3D tracking program that minimized the difference between the estimated 3D track (sequence of position estimates for the micro-transmitter) for 14 drogue releases to the actual track of the drogue (known northing, easting, and elevation) were used to process the data files for test fish. Possible factors that may have had an influence on the accuracy with which we tracked the 
3D position of the fish were noise, multipath, estimation of speed of sound, and the method used to estimate micro-transmitter position.

\subsection{Integration of Data with CFD Model}

Several observed behavioral attributes of the test fish were analyzed with the forebay flow field characteristics as estimated by a CFD model. These included 1) the horizontal and vertical distribution of fish as they swam through the tracking baseline and encountered the dam, 2) residence time within the tracking baseline volume, and 3) fish swimming direction and speed relative to flow field vectors.

Behavioral attributes were organized by species, diel period, and behavior category. Horizontal and vertical distribution estimates were categorized by using the fish approach path with respect to vertical reference planes parallel to the dam face. When the approach path of a fish passed through a reference plane, an observation of the vertical and horizontal location of the fish at the time of passage was recorded for that reference plane. In this way, the vertical and horizontal distribution of the population of test fish by species was estimated for each reference plane. Only the first record of the fish crossing a reference plane was recorded. In addition to the distribution information for each reference plane, residence time, fish speed, and fish heading with respect to water heading were integrated over depth and expressed as the average value in a $10 \mathrm{ft} \times 10 \mathrm{ft}(3 \mathrm{~m} \mathrm{x} 3 \mathrm{~m})$ grid unit by species for all test fish. Grid units were distributed equally over the study area and the value in each grid unit was expressed as a color to facilitate visualization of fish behavior relative to flow field characteristics.

We examined fish tracks by grouping them into three categories: species, diel period, and behavior type. Juvenile steelhead and yearling chinook made up the species categories, diel periods were defined as daytime ( $8 \mathrm{am}-8 \mathrm{pm})$ and nighttime ( $8 \mathrm{pm}-8 \mathrm{am})$, and to categorize by behavior type, we used residence

time in the tracking baseline. Test fish were grouped into three categories: direct-passage fish, searching fish, and milling fish. Direct passage fish were those that stayed in the tracking baseline for less than 1 hour, moving into the PSC or turbine-units relatively quickly. Searching fish stayed in the tracking baseline between 1 and 4 hours; they tended to encounter the dam and then exhibited what we assumed was a "searching" behavior in that portion of the tracking baseline closest to the front of the dam. Milling fish stayed in the array for greater than 4 hours and most traveled on both sides of the wing wall before passing through the dam or back upstream.

\subsubsection{Computational Fluid Dynamic Model (CFD)}

Star $\mathrm{CD}^{\mathrm{TM}}$ was used to estimate flow field characteristics for the Bonneville I forebay. Example output is shown in Figure 12. The model output was exported from Star CD into Tecplot ${ }^{\mathrm{TM}}$, a commercially available data visualization software package. PNNL developed an application named Tecplot Model Viewer (TMV) that researchers could use to view and manipulate the output of the Star CD model (Rakowski et al. 2000). Flow field characteristics for the specific 3-D locations estimated for fish could be extracted from the CFD model output (which was very large) by using TMV.

\subsubsection{Coordinate System}

The coordinate system used for all 2000 studies at Powerhouse I, both hydraulic and fish related, was the Oregon State Plane North zone referenced to the North American Datum, 1927 (NAD27) horizontal datum and the National Geodetic Vertical Datum, 1929 (NGVD29) vertical datum. Use of the same reference coordinate system allowed for seamless integration of the CFD model output with 3D fish position estimates. Therefore, each fish position could be linked to a water attribute from the CFD model output (e.g., velocity, acceleration, turbulence intensity). 


\subsection{Error Analysis}

Error in acoustically tracked position estimates was continuously variable, in three dimensions, throughout the tracking baseline volume. The vertical (elevation) position estimate $(\mathrm{z})$ had the most error (Figure 13). Error for the easting (X) and northing (Y) position estimates was generally less than $3 \mathrm{ft}$ $(1 \mathrm{~m})$ throughout the hydrophone array at the 70 -ft elevation we tested. The position estimate of a fish was dependent on several factors, which included 1) the accuracy and precision of speed of sound estimates, 2) the geometry of the tracking baseline hydrophone array, 3) the density of the tracking baseline hydrophone array, 4) the accuracy of hydrophone position estimates, and 5) the 3D tracking process (software). The error in 3D position estimates was evaluated using various methods; these included fixed location beacons, global positioning drogues, and ultrasonic test tags that we fixed at points and moved in transects throughout the array. The data acquired using these methods enabled us to map the bias component of total error for a single elevation, $70 \mathrm{ft}$ (Figure 13-A).

The data used to estimate tracking bias were acquired tracking a GPS drogue (Figure 14) equipped with a micro-transmitter positioned below the drogue underwater vane at a depth of approximately $5 \mathrm{ft}$ through the tracking baseline. Estimates of the vertical position of the micro-transmitter (which was constant) were compared with those estimated using tracking system hardware and software. Estimates of horizontal position obtained using the drogue's GPS receiver were compared with horizontal position estimates obtained using the tracking system (Figure 13-A.)

As an element of tracking error analysis, a numerical model was developed to estimate tracking error due to hydrophone geometry and various other sources of error. John Skalski and Jose A. Perez-Comas of the University of Washington developed a Microsoft Excel ${ }^{\mathrm{TM}}$ Solver application that used Monte Carlo simulation to estimate position estimation error at discrete points throughout the volume monitored by the 3DAT tracking baseline. Input variables for estimation of tracking error included speed of sound error, hydrophone position error, and the error in measurement of the time of acoustic signal arrival.

We used the tracking error estimation program to compute the expected error for the 70-ft elevation given a bias in hydrophone position of $0.2 \mathrm{ft}$, a bias in the speed of sound of approximately $4 \mathrm{ft} / \mathrm{s}$, and a clock speed in the hydrophone receivers of $12 \mathrm{kHz}$. We used the same hydrophone combinations as those for the empirical map, from which the minimum bias for those combinations (41 hydrophone combinations total) was extracted and mapped. The bias in easting (X) and northing (Y) estimates was predicted to be low throughout the array and was consistent with measurements taken with the GPS drogue and fixed tags (Figure 15 - A, B). However, the predicted bias in elevation $(\mathrm{Z})$ at the $70 \mathrm{ft}$ elevation was not as close to the observed bias in vertical position estimates (Figure 15, B). The patterns of vertical position estimate bias were similar, but the scale for the measured bias was greater than the calculated error by about a factor of three. Therefore, we have concluded that there is a source of error that has not yet been incorporated into the theoretical model of position estimate error. We have not identified this source of error but possible candidates are the algorithm used to estimate the vertical component of transmitter position given time-of-arrival data, some other problem such as multipath, or errors in the numerical model. For example, the program does not account for the propagation of positioning error when one hydrophone in the combination of four hydrophones is outside the bounds of the pre-set positioning error. This propagation of error from one hydrophone combination to the next would be extremely difficult to predict, due to the resultant combination generating a completely separate and different error map. This may be resolved in field tests of positioning error planned for 2001 . 


\subsubsection{Hydrophone Location Verification}

Twelve of the 16 hydrophones were attached to fixed structures underwater or to surface mounts such that they could not move. The locations of these 12 hydrophones were determined using traditional surveying methods. Survey reference points were located on structures to which hydrophones were mounted, and the relative positions of each hydrophone in NAD1927 Oregon North State plane were derived from the surveyed positions. The remaining four hydrophones were placed on the bottom of the riverbed using clump anchors. The clump-mounted hydrophone positions were estimated using that portion of the tracking baseline attached to dam structures. Using this method, termed "ring-a-round," the hydrophone being positioned was operated as a projector and its transmissions were detected by the hard-mounted hydrophones. Differences in the time-of-arrival of the pulses transmitted by the hydrophone and triangulation were used to estimate the horizontal position of the hydrophone. The depth of the hydrophones was estimated at the time of their deployment. We checked the position of the clumpmounted hydrophones using ring-a-round periodically throughout the study. No significant position shift was observed for any of the clump-mounted hydrophones.

\subsubsection{Speed of Sound Estimation}

Accurate and precise speed-of-sound estimates were needed to estimate micro-transmitter 3D position. The positions of hydrophones in a tracking baseline array, time-of-arrival differences for microtransmitter pulses received at hydrophones, and the speed of sound are the primary variables that are used to estimate the 3D position of a fish bearing an ultrasonic micro-transmitter. Transmitter position estimates are particularly sensitive to the accuracy of speed of sound estimates. In addition to the basic variable affecting the accuracy and precision of $3 \mathrm{D}$ transmitter position estimates, speed of sound is the most variable. Speed of sound is a function of temperature, salinity, and pressure. In our study, because it was conducted in fresh water, water temperature fluctuations over short time periods (i.e., 24 hours) and spatially within the tracking volume were the critical factor influencing speed of sound. A difference of $1^{\circ} \mathrm{C}$ changes the speed of sound by approximately $15 \mathrm{ft} / \mathrm{s}(4.5 \mathrm{~m} / \mathrm{s})$.

During the early stages of the study we thought it might be possible to use published relationships between water temperature, salinity, pressure, and speed of sound. We quickly learned that these relationships did not provide speed of sound estimates that were accurate enough to meet our requirements of $<1 \mathrm{~m}$ absolute transmitter position accuracy. Therefore, we used several different methods to estimate speed of sound. These included ultrasonic beacons, thermisters, and ring-around the baseline tracking array.

- Ultrasonic beacon: Two slightly modified micro-transmitters of the same basic design as those implanted into test fish were positioned on either side of the forebay and were left to transmit continuously throughout the study. The locations of the beacons were known to the same level of accuracy as the hard-mounted elements of the tracking baseline hydrophone array. The pulses from the beacons were received on several baseline hydrophones located at varying, but known, distances from the beacons. Difference in time of arrival of beacon pulses between pairs of baseline hydrophones along with the distance between these same pairs provided the basic time and distance information required to estimate speed of sound. The beacons transmitted once every two seconds. Speed of sound estimates were processed in 1-hour blocks throughout the study. However, the primary use of the beacon speed of sound estimates was to obtain a relationship between speed of sound and temperature, which turned out to be easier to integrate into the processing of other data to estimate fish 3D position. 
- Thermisters were used to obtain accurate estimates of forebay water temperature. The thermisters used were manufactured by Yellow Springs Instruments (YSI) and were calibrated to an accuracy of $0.025^{\circ} \mathrm{C}$. Thermister temperature measurement and speed of sound estimates from ultrasonic beacons were used to derive a relationship between temperature and speed of sound used to estimate fish 3D positions. We did not take into consideration the salinity (conductivity) of the water or other factors that may have also influenced speed of sound. Therefore the relationship between water temperature and speed of sound we derived should not be extrapolated to other fresh water environments. Speed of sound estimates were validated for our purposes in this study by comparing 2D drogue micro-transmitter position estimates obtained using our estimates of speed of sound with 2D drogue position estimates obtained using undithered GPS.

- We also used ring-around within the tracking baseline hydrophone array to estimate speed of sound. This method was similar to that for the ultrasonic beacons, the main difference being we knew when the hydrophone selected as the transmitter for the ring-around was transmitting. Since we could estimate the time between transmission and reception of sound pulses between the transmitting hydrophone and other receiving hydrophones in the array and we knew the distance between hydrophones, we could directly estimate speed of sound. This method was simple and reliable but had two major disadvantages. The most significant disadvantage was that it was not possible to perform ring-around and monitoring for tagged fish simultaneously and because of the rapid fluctuations in forebay water temperature it was necessary to estimate speed of sound essentially continuously. The second disadvantage was that this method of speed of sound estimation was not automated and required considerable operator and data handling time to implement.

We compared our speed-of-sound estimates, which we validated using GPS drogue data, with speed of sound estimates obtained using published equations for estimation of speed of sound given water temperature, salinity, and pressure. The results were not consistent for any speed of sound in water equation that we used (Medwin, Greenspan, Del Grosso). Since the dependence of speed of sound on water temperature, salinity, and pressure is well known, we assumed that we did not have enough information, particularly that for salinity (or conductance) to characterize the water in the forebay of Bonneville I and use the published relationships to estimate speed of sound. Therefore we used a relationship between water temperature measured using thermisters and speed of sound estimated using ultrasonic beacons, validated using GPS drogue observations, to estimate speed of sound for our study. This relationship was used to fill in any missing data we could not obtain from ultrasonic beacon-based estimates of speed of sound, because beacon data extraction was a time-consuming manual process whereas extracting thermister data was automated and relatively simple. Beacon-based estimates of speed of sound were extracted at set intervals throughout the study, and the thermister-speed of sound relationship was used to fill data gaps between those periods. The speed of sound was averaged over 1-hour periods and the average speed of sound was used in the 3D algorithm for each hour-long fish tracking file. 


\subsection{Results}

\subsection{Smolt Run Timing}

We timed our test fish releases to coincide with peak outmigration for both juvenile steelhead and yearling chinook salmon (Figures 16-19). Our study began April 26 and ended June 12. We released groups of test fish every other day from the last week in April through May. This release strategy, while not random, ensured that our test fish experienced the range of biotic and abiotic factors that might influence their migration to Bonneville I and their behavior as they were tracked through the monitored volume within the Bonneville I forebay.

\subsection{Efficiency Metrics}

Several metrics have been developed by the CE to describe the fish passage performance of the PSC. These metric have been established as standards so that researchers may compare results even through they are using different measurement methods (e.g., 3DAT, radio telemetry, hydroacoustics). The metrics we will report are as follows:

1) travel time, the time it takes a tagged fish to reach the study site from the release site

2) percent contact, or the number of fish detected within the tracking baseline out of the number released

3) PSC collection efficiency, which is the percent of fish entering the PSC out of the total number that pass into and under the PSC (This metric is relative to Turbine Units 1 through 6 only.)

4) PSC discovery efficiency, or the number of fish that come within $9.8 \mathrm{ft}(3 \mathrm{~m})$ of the entrance to the PSC compared to all tagged fish that pass Powerhouse I through the PSC or turbines

5) PSC passage effectiveness, which is the collection efficiency divided by the proportion of water entering the PSC (or a specific PSC entrance) out of the total water passing the dam

6) forebay residence time, which is the average time that tagged fish spend in the forebay (Table 1).

The mean travel time for yearling chinook salmon from Hood River Bridge to Powerhouse I was 18 hours and 22 min (median 14 hours); for juvenile steelhead trout, it was 17 hours and 9 min (median 14 hours).

The percent of test fish by species contacted in the Powerhouse I array was $19 \%$ ( 31 of 163 fish released) for yearling chinook and 42\% (139 of 331 fish released) for juvenile steelhead. All tagged fish had an equal opportunity to pass Bonneville Dam at Powerhouse I, the Spillbay, or Powerhouse II. Travel times and species detections at Powerhouse I were consistent with previous years' radio-telemetry results (Hensleigh et al. 1998).

The entrance efficiency to the PSC for acoustically tracked fish was higher than that reported for radio telemetry tracked fish (Evans et al. 2001). The entrance efficiency for acoustically tracked fish was 58\% for yearling chinook and $67 \%$ for juvenile steelhead. 
We estimated a passage efficiency of $96 \%$ for yearling chinook salmon (22 of the 23 that came within 3 meters of the PSC actually passed through the PSC) and 88\% for juvenile steelhead (70 of the 80 that came within 3 meters of the PSC actually passed through the PSC).

PSC discovery efficiency for was $82 \%$ yearling chinook (23 out of 28 test fish) and $67 \%$ for juvenile steelhead (74 our of 110 test fish).

Passage effectiveness was 2.87 for yearling chinook and 2.63 for juvenile steelhead. In other words, the number of fish per unit volume of water was higher for water passed through the PSC than for water that passed under the PSC, or the PSC made more effective use of water for passing fish than did the turbines.

The mean residence time was 6 hours and 56 minutes for yearling chinook salmon and 11 hours and 37 minutes for juvenile steelhead. All discovery and passage metrics are presented in Table 1.

\subsection{Fish Distribution}

Distribution and residence times were examined by species and diel period. Graphical displays were generated to display differences between species and time periods. The horizontal distributions of steelhead and chinook when they initially entered the tracking volume are shown in Figures 20 through 29. The vertical distributions of test fish corresponding to the horizontal distributions are shown in Figures 30 through 36 . The horizontal distributions show the entire forebay, while the vertical distributions are only for test fish in the portion of the tracking volume south of the forebay wing wall in front of the PSC and Turbine Units 1 through 6. The horizontal distribution of both species was very similar at $400 \mathrm{ft}(120 \mathrm{~m})$ from the dam where the median of the distribution was slightly south of the forebay thalweg. As the test fish progressed in their approach to the dam, the median of their horizontal distribution moved slightly to the north and became more centered on the forebay thalweg where it remained until they were immediately in front of the dam, which placed the distribution median centered on Turbine Units 5 and 6 immediately south of the forebay wingwall (Figure 21). In general the horizontal distribution of the individual species was similar to that for the population of test fish during both day and nighttime periods (Figures 23-29). The exception was the daytime distribution of juvenile steelhead where the median was strongly oriented toward the south along the navigation lock wall at entry to the tracking volume (Figure 28). However, by the time they had reached $200 \mathrm{ft}$ from the dam, the median of their horizontal distribution was near the forebay thalweg.

In contrast to horizontal distribution where the two species behaved quite similarly, their vertical distribution varied with species and diel period (Figures 30-36). The daytime distribution of juvenile steelhead was skewed to the upper $20 \mathrm{ft}(6 \mathrm{~m})$ of the water column and to the upper $30 \mathrm{ft}(9 \mathrm{~m})$ of the water column for yearling chinook salmon for all reference planes except the 5-ft plane (Figure 36). At the 5-ft-reference plane, yearling chinook salmon were evenly distributed in the upper $40 \mathrm{ft}(12 \mathrm{~m})$ of the water column during the daytime while steelhead were more evenly distributed in the upper $50 \mathrm{ft}(15 \mathrm{~m})$. Too few yearling Chinook were observed in the tracking volume at night to estimate their vertical distribution.

While most test fish encountered the dam at Units 4, 5, and 6, the majority of test fish that passed into the PSC entered through the entrances in front of Turbine Units 1, 2, and 5 (Table 2-4). In general, test fish were more evenly distributed vertically in the water column at night than during daytime, which was reflected in dam passage route selection where more steelhead exited the dam under the PSC at night (9 fish) than during the day (1 fish, Figures 30, 37-40, Tables 2-4). Juvenile steelhead appeared to maintain their vertical distribution during approach to the PSC, while the yearling chinook appeared to redistribute more deeply in the immediate vicinity of the PSC. 


\subsection{Residence Time}

Residence time was used to describe migrant behavior. Three distinct residence time behaviors were observed. These were direct-passage, searching, and milling. Direct passage fish were those that stayed in the tracking volume for less than 1 hour then moved into the PSC or turbine units and passed the dam relatively quickly. Searching fish stayed in the tracking volume between 1 and 4 hours and tended to approach the dam then displayed what appeared to be searching behavior. Perhaps these fish were searching for an exit past the dam. Milling fish stayed in the array for more than 4 hours and most visited both sides of the wing wall before passing into the PSC or the turbines or swimming against prevailing currents and exiting the tracking volume upstream.

Forebay residence time was longer for juvenile steelhead (mean, 11 hours and 37 minutes) than for yearling chinook (mean 6 hours and 56 minutes). The diel distribution of residence time for the population of test fish is shown in Figure 45, A and B. The figures show test fish that entered the array during each diel period and residence time within the tracking volume. During the day, test fish aggregated in front of the dam on both sides of the forebay wing wall and resided in these areas for long periods of time. During the night, residence times in front of the PSC were significantly shorter than during the day. The contrast between day and night residence times was less pronounced north of the wing wall. It appears that the PSC may have reduced forebay residence for test fish during the night while fish continued to "hold" or at least show longer residence time in that portion of the dam without a PSC.

\subsection{Response to Flow Field}

The direction of movement of test fish by behavior category (direct pass, searching, and milling) in relation to the direction of water flow is shown in Figure 41 A-D. Direct passage fish tended to move more in the direction of flow than the other two behavior types. Areas where direct passage fish swam into flow were at the entrances to the PSC above Turbine Units 2 and 3. Searching fish swam into and across flow $\left(90^{\circ}-180^{\circ}\right.$ angular difference) in the immediate vicinity of the PSC and north of the forebay wing wall in front of Turbine Unit 9. Milling fish tended to swim into flow at the north and south edges of the tracking volume, while they showed a tendency to follow flow in the center of the tracking volume in the region extending south of the wing wall in front of Turbine Units 4, 5, and 6. Test fish appeared to follow flow when water velocity was higher than $3 \mathrm{ft} / \mathrm{s}(0.9 \mathrm{~m} / \mathrm{s}$, Figures $41-43)$ and showed a net movement against or orthogonal to flow when water velocity was lower than $3 \mathrm{ft} / \mathrm{s}(0.9 \mathrm{~m} / \mathrm{s}$, Figure 30$)$.

\subsection{Behavior by Diel Period}

During the night $52 \%(39 / 75)$ of the population of test fish showed direct passage behavior, $37 \%$ showed (28/75) milling behavior, and the remainder, $11 \%$, showed searching behavior. During the day only $8.4 \%$ of test fish showed direct passage behavior, $64 \%$ showed milling behavior, and $26.6 \%$ showed searching behavior.

The contrast in behavior between day and night was most pronounced for juvenile steelhead. During the night $54 \%$ of juvenile steelhead showed direct passage behavior while only $5 \%$ exhibited this type of behavior during the day. This was in contrast to yearling chinook where $40 \%$ showed direct passage behavior during the night and 19\% during the day (Figure 44). 



\subsection{Discussion}

\subsection{Past Studies and Fish Tracking Technology Overview}

The first comprehensive assessment of information available to assist development and evaluation of surface flow bypass systems at Bonneville Dam was completed by Giorgi and Stevenson in 1995. They concluded that information necessary to identify the preferred design, location, and operation of a surface flow bypass at Bonneville Dam was lacking. They also concluded "a design that increases opportunity for discovery may be the most fruitful strategy." They observed "Although there is a general belief that smolt reaction to velocity changes may be an important dynamic to consider in collector design, we saw no obvious insight on this matter provided in the collective studies we reviewed....It may be easier to obtain and interpret this type of water velocity/smolt reaction interaction in a laboratory rather than in field experiments. In the field, too many competing conditions may be affecting the response, conditions we can neither control, isolate, or perhaps even recognize."

Since the review by Giorgi and Stevenson, several years of mobile and fixed aspect radio telemetry and hydroacoustic studies have been performed to observe fish distribution and behavior at Bonneville Dam (Hensleigh et al. 1999; Holmberg et al. 1998; Johnson et al. 1999; Hansel et al. 1999; Ploskey et al. 1999). Mobile radio tracking typically provides information about the two-dimensional behavior of a sub-population of test fish bearing radio transmitters as they move down river and through the forebays of dams. Subsampling of the total migrant population is required to select species, age groups, and individuals large enough for implantation of radio transmitters. Test fish bearing implanted radio transmitters are followed by boat after release. The two-dimensional accuracy and precision of position estimates is dependent upon detection of the radio transmissions and positioning the tracking boat over the suspected location of the transmitter. Detection probability is a function of transmitter characteristics, water conductivity, and the depth of the transmitter. In fixed location radio telemetry, radio receivers mounted in fixed locations at the dam provide additional information about the passage route of tracked fish. Acceptance of the assumption that transmitter-containing fish behave the same as the population at large is required to apply obtained behavioral observations to the population of migrants.

Three-dimensional tracking of test fish using ultrasonics is similar in some respects to both mobile and fixed location radio telemetry. While a boat isn't required to track test fish, the region within which tracking can occur is limited by the geometry of the tracking baseline array, the characteristics of the ultrasonic transmitters implanted in the test fish, and some environmental parameters. Typically it is possible to track test fish external to the volume contained within the tracking baseline in two dimensions and within the tracking baseline volume in three dimensions. The ability to track in three dimensions with high temporal and spatial accuracy and precision within a tracking baseline distinguished mobile radio telemetry and three-dimensional ultrasonic tracking. Using three-dimensional ultrasonic tracking it is possible to get very detailed and prolonged observations of test fish behavior within a tracking baseline. The observations of test fish exhibiting a wide range of behaviors, some of which were hours in duration, with very complex movement patterns (e.g., direct passage, searching, and milling) are examples of the tracking capability of three-dimensional ultrasonic tracking. However, a critical assumption for both methods is that fish bearing implanted transmitters behave the same as run-of-the-river fish without transmitters.

\subsection{Fish Approach Distribution and Passage Distribution}

We observed that as test fish of both species approached the dam, the median of their horizontal distribution followed the thalweg so that the majority of fish encounter the dam at Units 4 through 6 , the 
northern half of the PSC. During their approach, test fish of both species were more surface-oriented in the daytime than in the nighttime (Figures 20, 31-36). This was especially evident for juvenile steelhead. The vertical distribution of yearling chinook salmon remained largely unchanged during the daytime for most of their approach to the dam, but as they encounter the PSC (5 ft reference plane, Figures 31-36) they appeared to spread out vertically and become more evenly distributed (i.e., less distinctly surface oriented) in the water column.

The horizontal distribution of test fish at first contact with the dam did not determine the location of passage. We found that equal numbers of test fish passed the dam at Units 5 and 6 and at Units 1 and 2, which was not proportional to their horizontal approach path since the majority of test fish of both species initially contacted the dam at Turbine Units 4 through 6 . We were not able to identify the stimuli that determined where fish passed the dam; however, it is clear that a large proportion of test fish did not choose to pass the dam at the first passage opportunities, when they first encountered the dam. Presumably this is due to the lack of sufficiently attractive hydraulic conditions or some other sensory barrier that caused test fish not to enter the PSC and turbines at Units 4 through 6 in equal proportions to their arrival distribution. Units 1 and 2 may have been equally attractive, as the CFD flow field estimates indicate, or a combination of hydraulic and other stimuli may have resulted in test fish exploring the forebay prior to moving downstream past the dam. A significant finding was the large proportion of test fish south of the forebay wing wall that selected PSC entrances when they decided to move downstream. The PSC passage efficiency was $95.7 \%$ for yearling chinook and $87.5 \%$ for juvenile steelhead.

The vertical distribution of test fish appeared to be an important factor affecting whether they passed into PSC entrances or into turbines. For example, more juvenile steelhead were observed to pass under the PSC and directly into turbines at nighttime when they were more deeply distributed in the water column than during the daytime (Figures 37-40). The influence of vertical distribution during approach and immediately in front of bypass entrances on the efficiency of fish bypass alternatives has been observed in previous studies and is consistent with hydroacoustic and radio-telemetry data for the spring 2000 tests (Hensleigh et al. 1999; Ploskey 1999). Thus it would appear that while the horizontal distribution of test fish as they approach the dam does not predetermine where along the dam they will pass, their vertical distribution does influence whether they will pass through a surface-oriented bypass alternative or through turbines.

\subsection{Fish Residence Time}

We were able to estimate the residence time in the immediate vicinities of turbine intakes where the PSC was absent (north of the forebay wing wall) and compare these estimates of residence time and associated behavior to areas where the PSC was present (south of the forebay wing wall) for nighttime hours (Figure 45). While there was a significant change is residence time south of the wing wall in front of the PSC from day to night, the change in residence time was much less distinct day to night north of the wing wall in front of Turbine Units 7 through10 where these was no PSC but where turbine operating conditions and therefore many aspects of flow field conditions were similar. The analyses we have conducted to date do not explain why residence time was less in front of the PSC at night than during the day. We do not have comparable observations of residence time over diel periods with the PSC not present so we cannot conclude that the difference is due to the PSC. However, the contrast in the behavior of fish north and south of the wing wall does suggest that the presence of the PSC for some reason, one of which may by hydraulics, does appear to significantly change the nighttime behavior of test fish. Perhaps the change in flow field direction and the creation of nearer surface intake flows for water entering the PSC deep slots may have encouraged test fish to enter PSC entrances more easily than turbine entrances, which would require the fish to sound. The tendency for migrating juveniles to pass more directly when arriving at the dam at night in contrast to their tendency to hold and mill in the forebay if they arrive in the day (Figure 
44) has been observed in previous studies. While not as clearly described as the three-dimensional methods used in this study permitted, similar behavior has been indicated in previous behavior observations particularly in fixed-location radio telemetry observations (Hensleigh et al. 1999).

\subsection{Fish and Flow Interaction}

The relationship between fish behavior and the Bonneville I forebay flow field is complex and is a function of fish behavior types. Those test fish whose behavior was classified as "direct passage" appeared to follow flow during approach and passage. On the other hand, test fish behavior classified as "milling" showed a range of response to the forebay flow field. Milling fish tended to wander throughout the entire forebay and during this process defined specific zones where they followed flow and other regions where they swam into or at some angle to flow. As a group, test fish were observed to mostly follow flow along the thalweg of the forebay where water-velocity magnitudes were greater than $3.0 \mathrm{ft} / \mathrm{s}$ $(0.9 \mathrm{~m} / \mathrm{s}$, Figures 41,46$)$. Along the thalweg, the horizontal approach distribution of test fish of both species was densest (Figure 47).

Direct passage and searching fish primarily moved with the flow until they encountered entrances to the PSC Units 1 through 6 south of the forebay wing wall and Turbine Unit 9 north of the wing wall. It was at those locations that they first showed any signs of movement against flow (Figure 41). The flow field at the $20 \mathrm{ft}$ wide entrances to the PSC was below $3.0 \mathrm{ft} / \mathrm{s}$ for the upper $5 \mathrm{ft}$ of the water column and greater than $3.0 \mathrm{ft} / \mathrm{s}$ below elevation $70 \mathrm{ft}$ (Faber et al. 1999). Fish movement against flow was seen at the entrances to the collector units and in areas of surface draw (Turbine Unit 9). It was at these positions that fish may have sensed a change in hydraulic conditions and oriented themselves to oppose flow until they were ready to pass or until they chose another exit. Assuming that searching and direct passage fish follow the behavior of milling fish when migrating in flows greater than or less than $3.0 \mathrm{ft} / \mathrm{s}$, the fish that were moving against or at an angle to flow at the entrances were also likely to be in the upper $5 \mathrm{ft}$ of the water column. This is also consistent with the approach distribution of steelhead in that the main proportion of steelhead was in the upper 5 to $10 \mathrm{ft}$ of the water column (Figures 31-36). The conditions at these entrances need to be further examined, not only for differences in hydraulic or physical structure, but also for any other sensory stimuli that may affect the passage of juvenile salmon from PSC entrances. 



\subsection{Conclusions}

The results of our study of the three-dimensional paths of tagged juvenile steelhead and yearling chinook salmon in the forebay of Bonneville Dam Powerhouse I in front of the PSC can be summarized as follows:

- Juvenile steelhead and yearling chinook salmon followed flows greater than $\sim 3.0 \mathrm{ft} / \mathrm{s}(\sim 0.9 \mathrm{~m} / \mathrm{s})$, and their behavior was less directed in flows less than $3 \mathrm{ft} / \mathrm{s}$.

- The horizontal distribution of juvenile steelhead and yearling chinook salmon did not determine the location at which by passed the dam.

- The vertical distribution of juvenile steelhead was deeper during the night than during the day. The difference in passage efficiency between day and night for juvenile steelhead was correlated with their observed vertical distribution with higher passage efficiency during the day when they were distributed higher in the water column (33 juvenile steelhead went through the PSC during the day and 1 went under while at night 37 passed through the PSC and 9 went under).

- The vertical distribution of yearling chinook salmon was more consistent from day to night. During both day and night periods the yearling chinook redistributed from a nearer surface distribution to a more uniform distribution over a greater depth.

- Residence time in the vicinity of the PSC for both species of test fish was shorter during the night than during the day south of the forebay wing wall. North of the forebay wing wall, over that portion of the powerhouse without a PSC, residence time was the same day and night.

- The proportion of test fish exhibiting specific forebay behavior (direct passage, searching, milling) changed day to night. More direct passage behavior was seen for test fish arriving at the dam at night and more milling behavior was seen for test fish that arrived during the day.

- The estimated error in ultrasonic transmitter location estimate for easting (X) and northing (Y) was less than $3 \mathrm{ft}(1 \mathrm{~m})$ within the 70-ft elevation plane and met the needs of this study. However the error in transmitter position estimate in elevation $(\mathrm{Z})$ was more variable $(3 \mathrm{ft}$ to $30 \mathrm{ft}$ ) over the 70 -ft elevation of the tracking baseline volume and did not meet study needs. Research is needed to determine the reasons for this inadequate performance and to make adjustment in study methods to meet requirements for the elevation component of transmitter position estimates. 



\subsection{References}

Adams, N.S., D.W. Rondorf, S.D. Evans, J.E. Kelly, and R.W. Perry. 1998. "Effects of Surgically and Gastrically Implanted Radio Transmitters on Swimming Performance and Predator Avoidance of Juvenile Chinook Salmon (Oncorhynchus tshawytscha).” Can. J. Fish. Aquat. Sci. 55:781-787.

Blackman, S.S. 1986. Multiple Target Tracking with Radar Applications. Artech House.

Brookner, E. 1998. Tracking and Kalman Filtering Made Easy. John Wiley \& Sons, New York.

Coutant, C.C. 1998. Turbulent Attraction Flows for Juvenile Salmonids Passage at Dams. DE-AC0596OR22464. U.S. Department of Energy, Lockheed Martin Energy Research Corp.

Del Grosso, V.A. and C.W. Mader. 1972. "Speed of Sound in Pure Water." J. Acoustical Soc America. 52:1442-6.

Faber, D.M., D.W. Rondorf, M. Odeh, and S. Zimmerman. 1999. Water Velocity Profiles at Bonneville Dam Prototypes Surface Collector, Turbine Unit 5. U.S. Army Corps of Engineers. Portland, Oregon. Contract \# W66QKZ91652193.

Fisher, N.I. 1993. Statistical Analysis of Circular Data. Cambridge University Press, Cambridge UK.

Fisher, N.I., T. Lewis, and B.J.J Embleton. 1987. Statistical Analysis of Spherical Data. Cambridge University Press, Cambridge, UK.

Giorgi, A.E. and J.R. Stevenson. 1995. A Review of Biological Investigations Describing Smolt Passage Behavior at Portland District Corps of Engineer Projects: Implications to Surface Collection Systems. Report to the Portland District of the US Army Corps of Engineers, Portland, Oregon.

Greenspan, M. and C.E. Tschieg. 1959. "Tables of the Speed of Sound in Water." J Acoustical Soc. America. 31:75.

Hansel, H.C., R.S. Shively, J.E. Hensleigh, B.C. Liedtke, R.E. Wardell, R.H. Wertheimer, and T.P. Poe. 1998. Movement, Distribution, and Behavior of Radio-Tagged Juvenile Chinook Salmon and Steelhead in the Forebay of Bonneville Dam, 1998. Draft report to the Portland District of the US Army Corps of Engineers, Portland, Oregon.

Haro, A., M. Odeh, J. Noreika, and T. Castero-Santos. 1998. "Effect of Water Acceleration on Downstream Migratory Behavior and Passage of Atlantic Salmon Smolts and Juvenile American Shad at Surface Bypasses." Trans. Am. Fish. Soc. 127:118-127.

Hensleigh, J.E., R.S. Shively, H.C. Hansel, J.M. Hardiman, G.S. Holmberg, B.D. Liedtke, T.L. Martinelli, R.E. Wardell, R.H. Wertheimer, and T.P. Poe. 1999. Movement, Distribution and Behavior of RadioTagged Juvenile Chinook Salmon and Steelhead in John Day, The Dalles, and Bonneville Dam Forebays, 1997. Report to the Portland District of the US Army Corps of Engineers, Portland, Oregon.

Holmberg, G.S., R.S. Shively, H.C. Hansel, T.L. Martinelli, M.B. Sheer, J.M. Hardiman, B.D. Liedtke, L.S. Blythe, and T.P. Poe. 1998. Movement, Distribution, and Behavior of Radio-Tagged Juvenile 
Chinook Salmon in John Day, The Dalles, and Bonneville Forebays, 1996. Report to the Portland District of the US Army Corps of Engineers, Portland, Oregon

Johnson, R.L., R.A. Moursund, and M.A. Simmons. 1999. Fish Behavior in Front of the PSC at Bonneville Dam in 1998. Report to the Portland District of the US Army Corps of Engineers, Portland, Oregon.

Medwin, H. 1975. "Speed of Sound in Water for Realistic Parameters." J Acoustical Soc. America. 58:1818.

Ploskey, G.R., W.T. Nagy, L.R. Lawrence, D.S. Patterson, C.R. Schilt, P.N. Johnson, and J.R. Skalski. 1999. Hydroacoustic Evaluation of Juvenile Salmonids Passage through Experimental Routes at Bonneville Dam in 1998. Draft report to the Portland District of the U.S. Army Corps of Engineers, Portland, Oregon.

Rakowski, C.L., J.A. Serkowski, M.C. Richmond, and K.P. Recknagle. 2000. Development and Application of a 3D CFD Model for the Bonneville Project Powerhouse 1 and Powerhouse 2. Report submitted to U.S. Army Corps of Engineers, Portland District. Pacific Northwest National Laboratory, Richland, Washington.

Ransom, B.H., and T.W. Steig. 1995. "Comparison of the Effectiveness of Surface Flow and Deep Spill for Bypassing Pacific Salmon Smolts (Oncorhynchus spp.) at Columbia River Basin Hydropower Dams." Presented at Waterpower '95, July 1995, San Francisco.

Steig, T.W., R. Adeniyi, T.K. Iverson, and T.C. Torkelson. 1998. Using Acoustic Tags for Monitoring Fine-Scale Migration Routes of Juvenile Salmonids in the Forebay of Rocky Reach Dam in 1998. Draft report to Chelan County Public Utility District No. 1, Wenatchee, Washington.

Turchin, P. Quantitative Analysis of Movement: Measuring and Modeling Population Redistribution in Animals and Plants. Sinaur Associates, Sunderland Massachusetts. 
Figures and Tables 


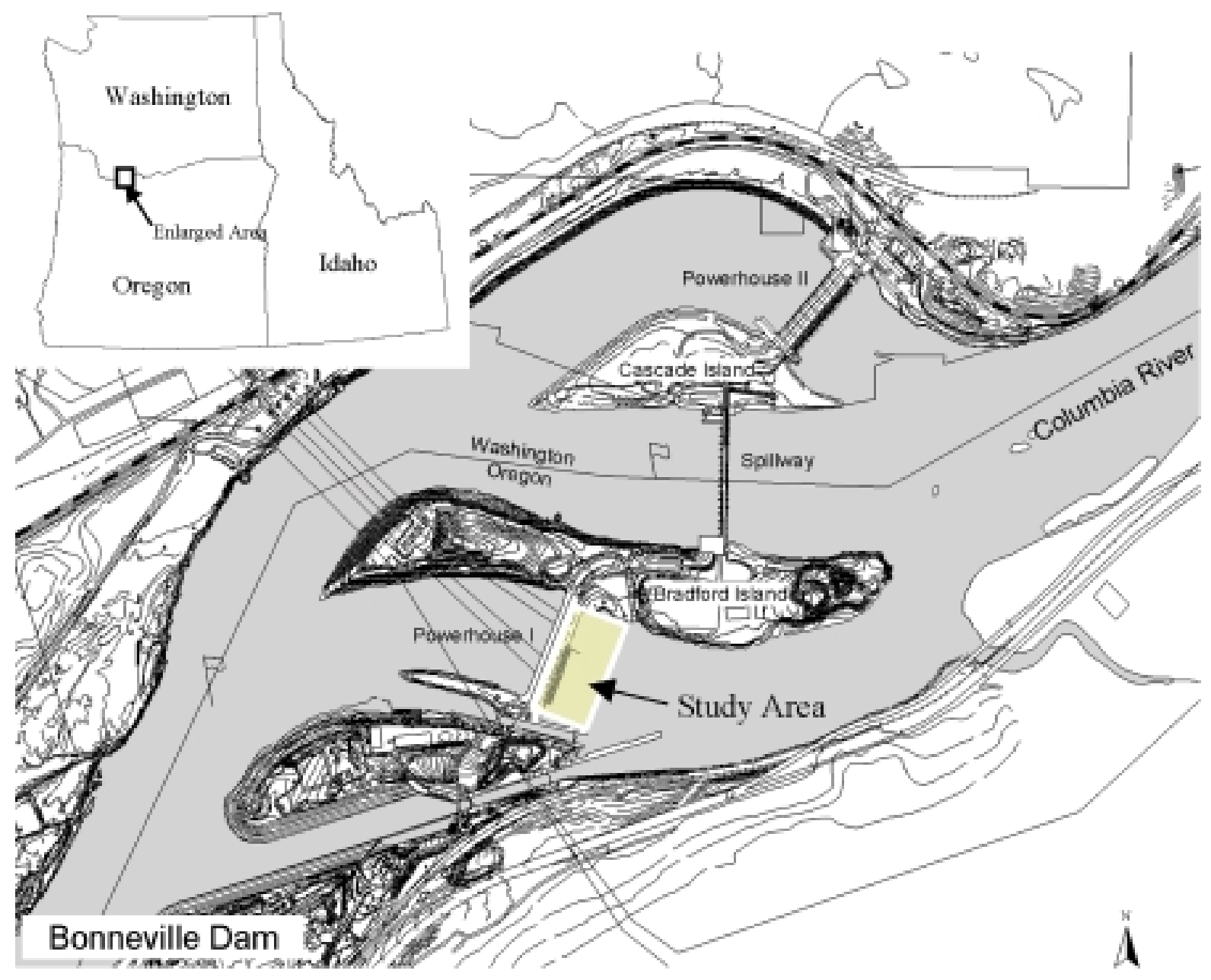

Figure 1. Study Area Shown at Bonneville Dam, Powerhouse I on the Columbia River. Bonneville Dam consists of three main structures, Powerhouse I, the Spillway and Powerhouse II; structures are separated by Bradford Island and Cascade Island. 


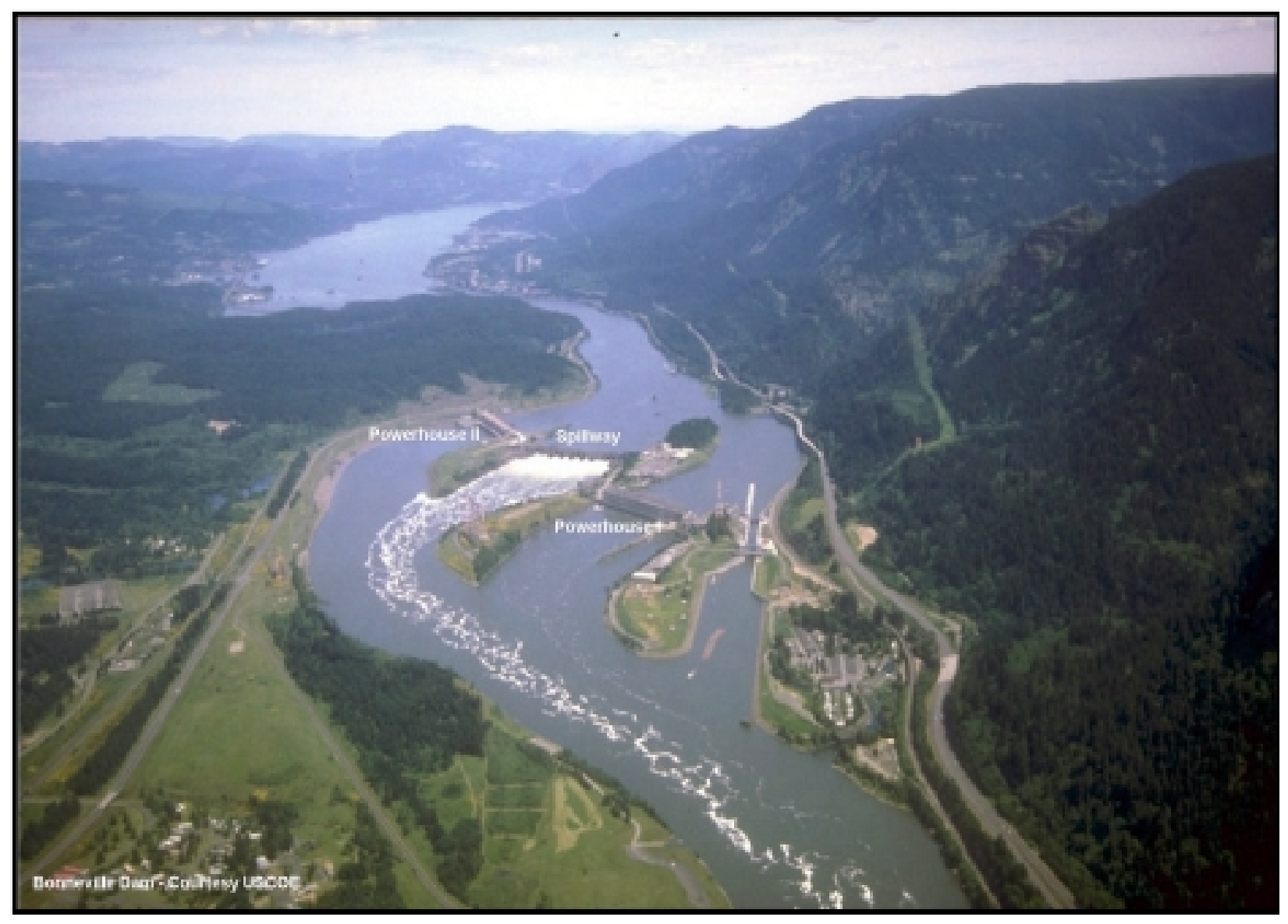

Figure 2. An Aerial Photograph of Bonneville Dam on the Columbia River Showing Powerhouse II, the Spillway, Powerhouse I, and the Navigation Lock 


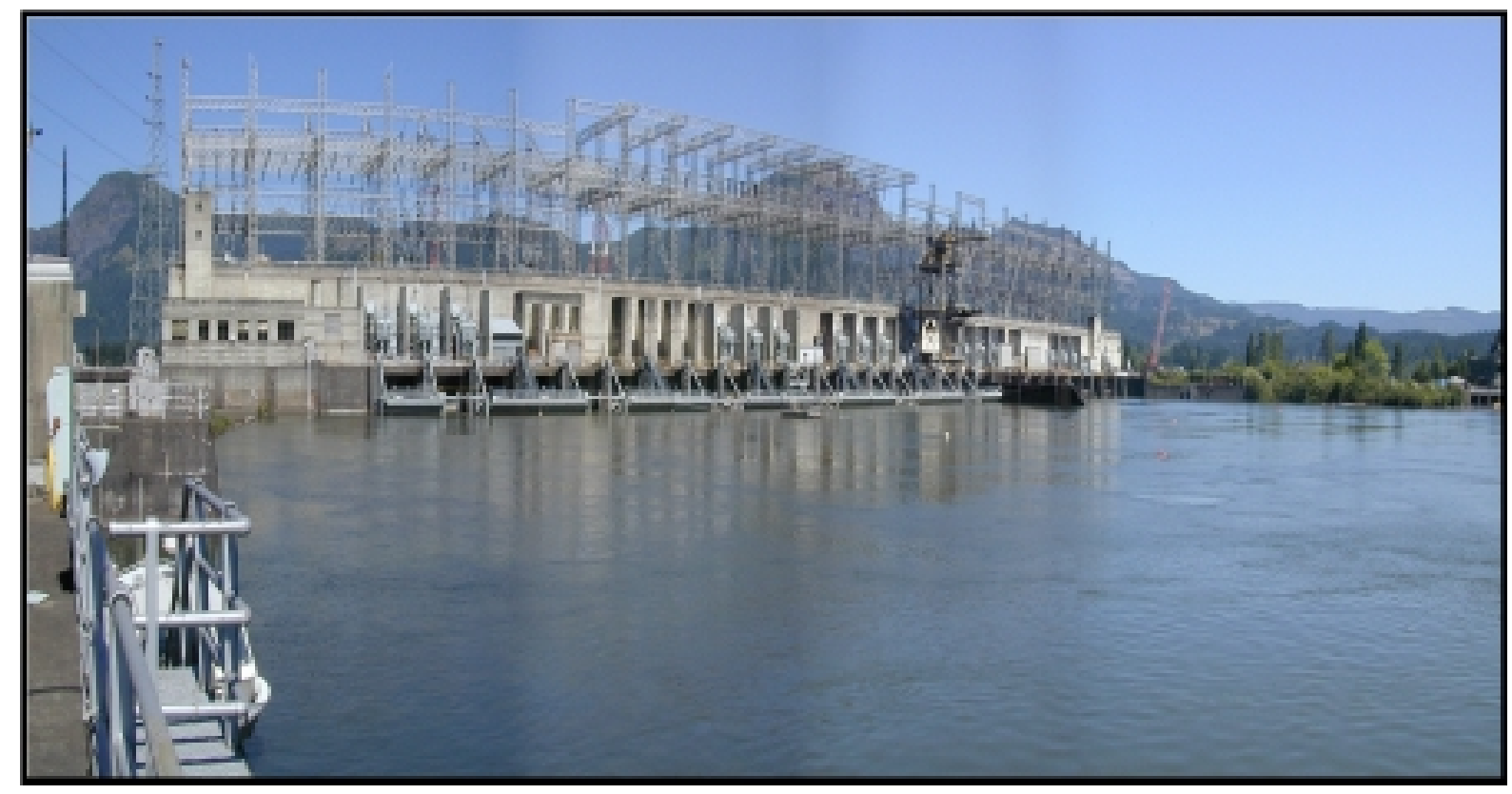

Figure 3. Powerhouse I with PSC

Fig.3 


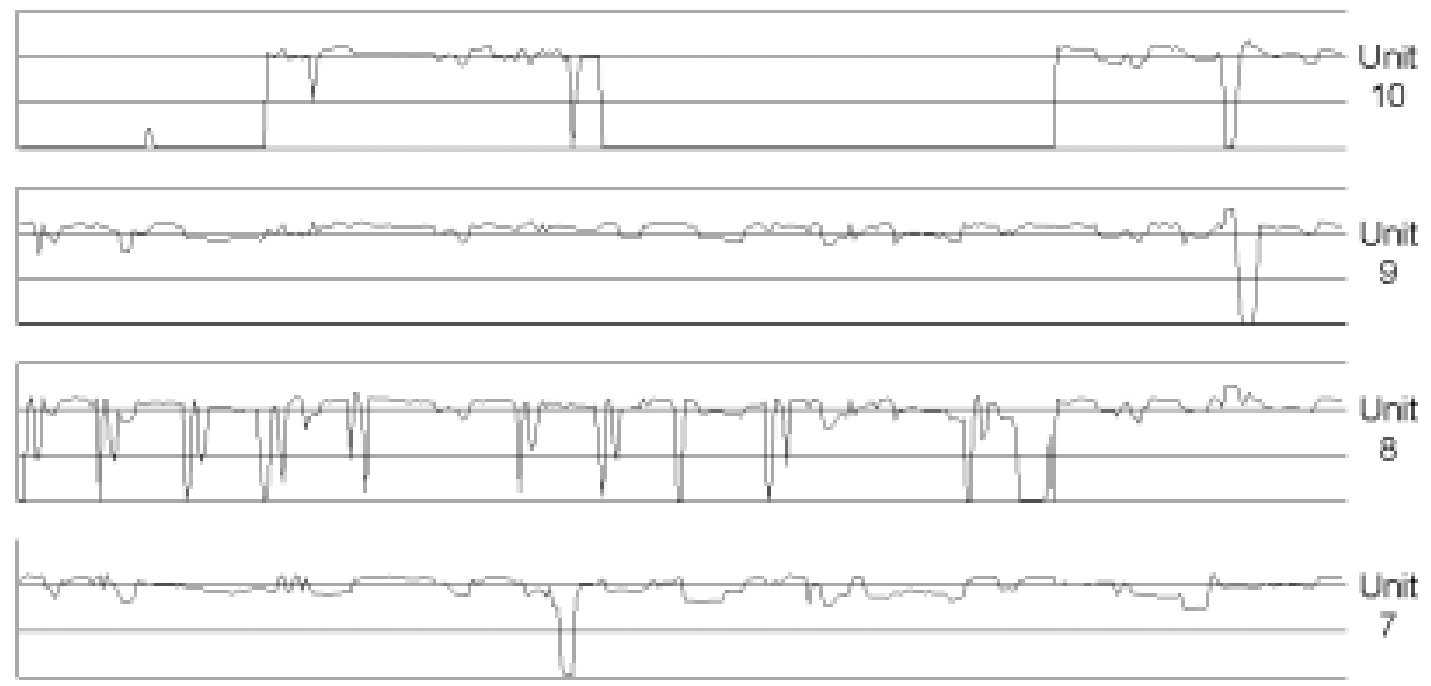

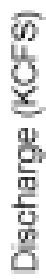
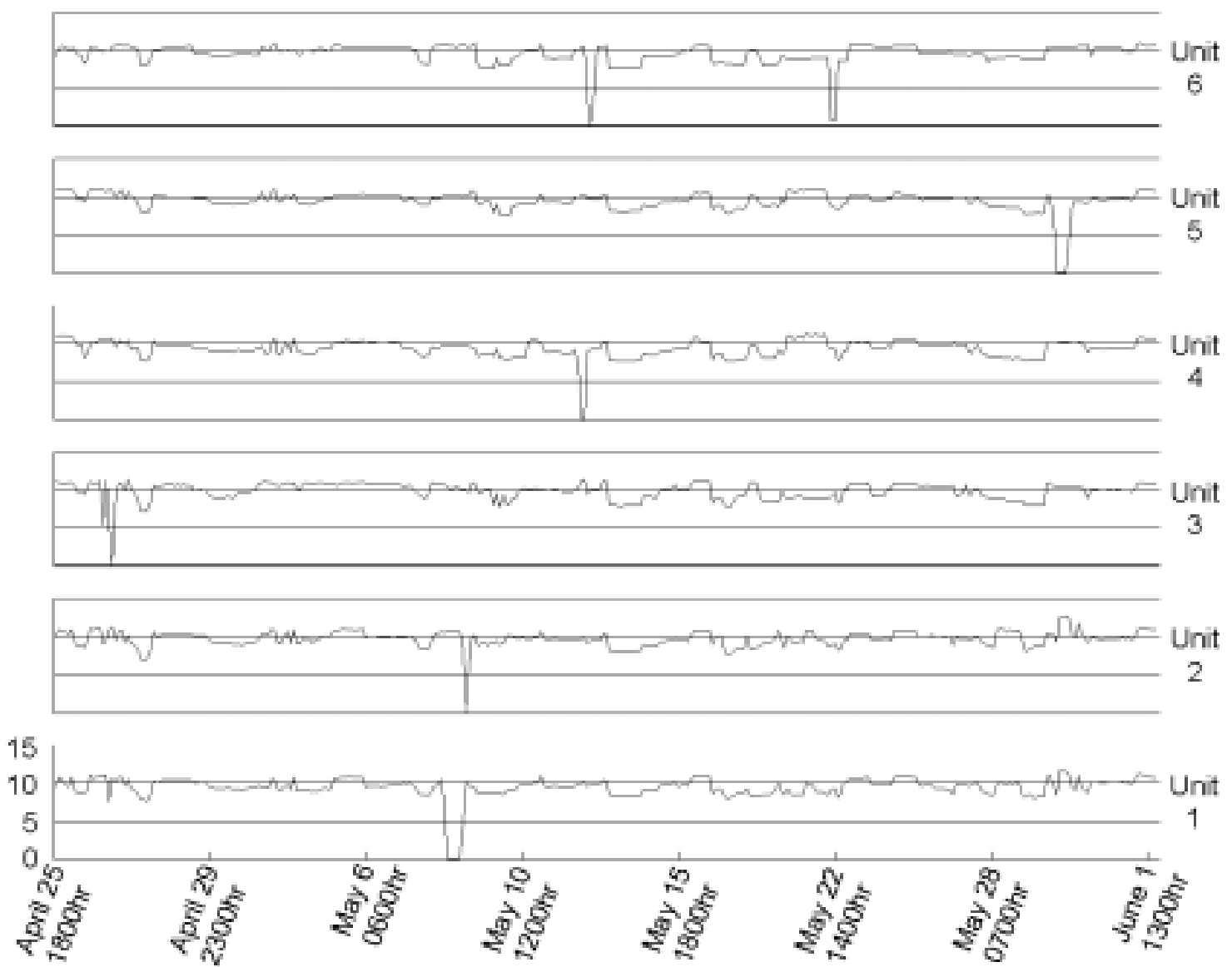

Figure 4. Flow Data by Hour at Bonneville Dam, Powerhouse 1, During Estimated Times of Greatest Fish Passage. Hours counted only include those during release sampling times. Measurements are in thousands of cubic feet per second (KCFS). Dates included are April 21 though June 6th. No Bonneville operations data were collected for May $3^{\text {rd }}$ 


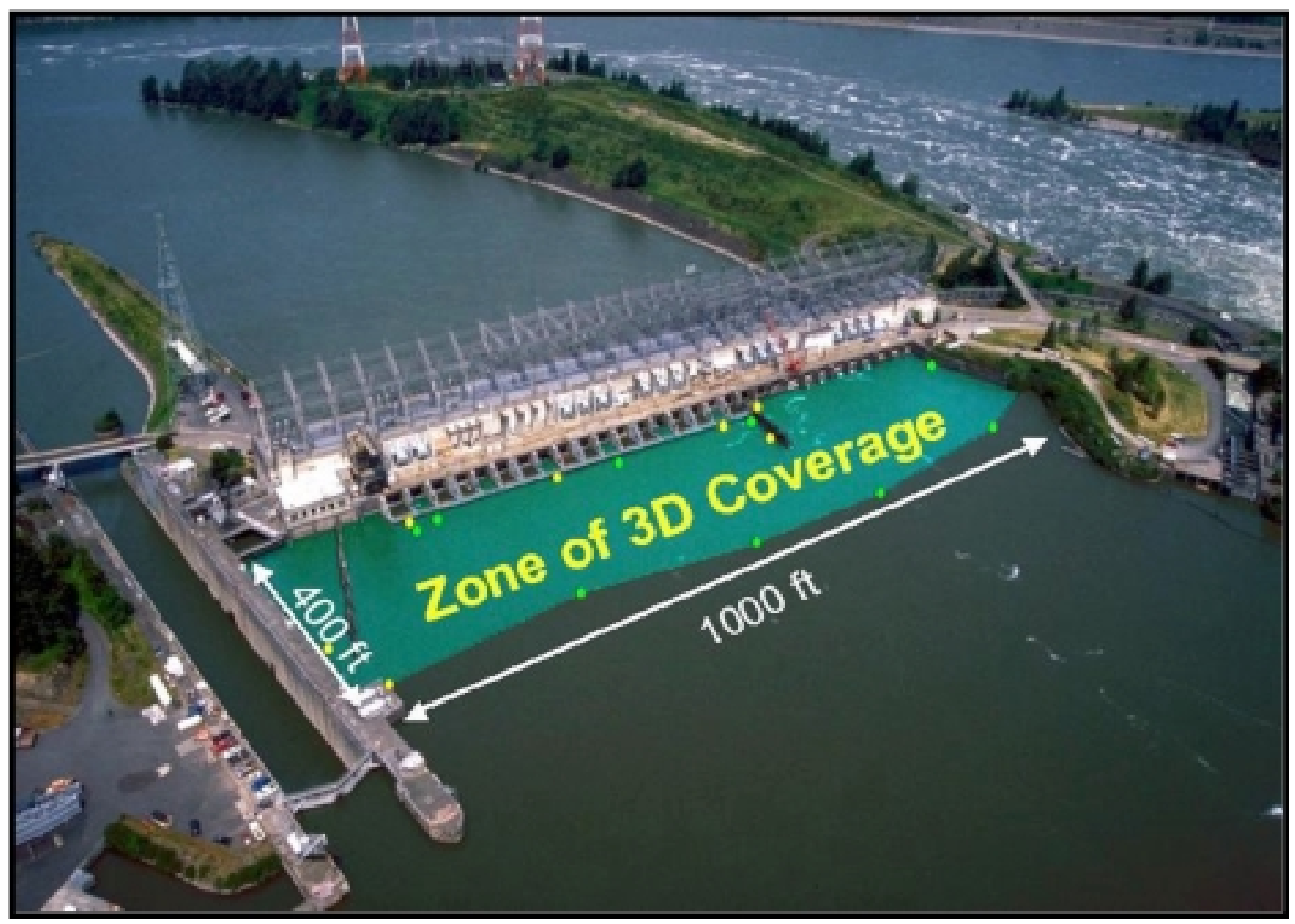

Figure 5. Hydrophone Array in Powerhouse I Forebay. Green dots show hydrophones anchored near the river bottom. Yellow dots are hydrophones mounted near the water surface. 


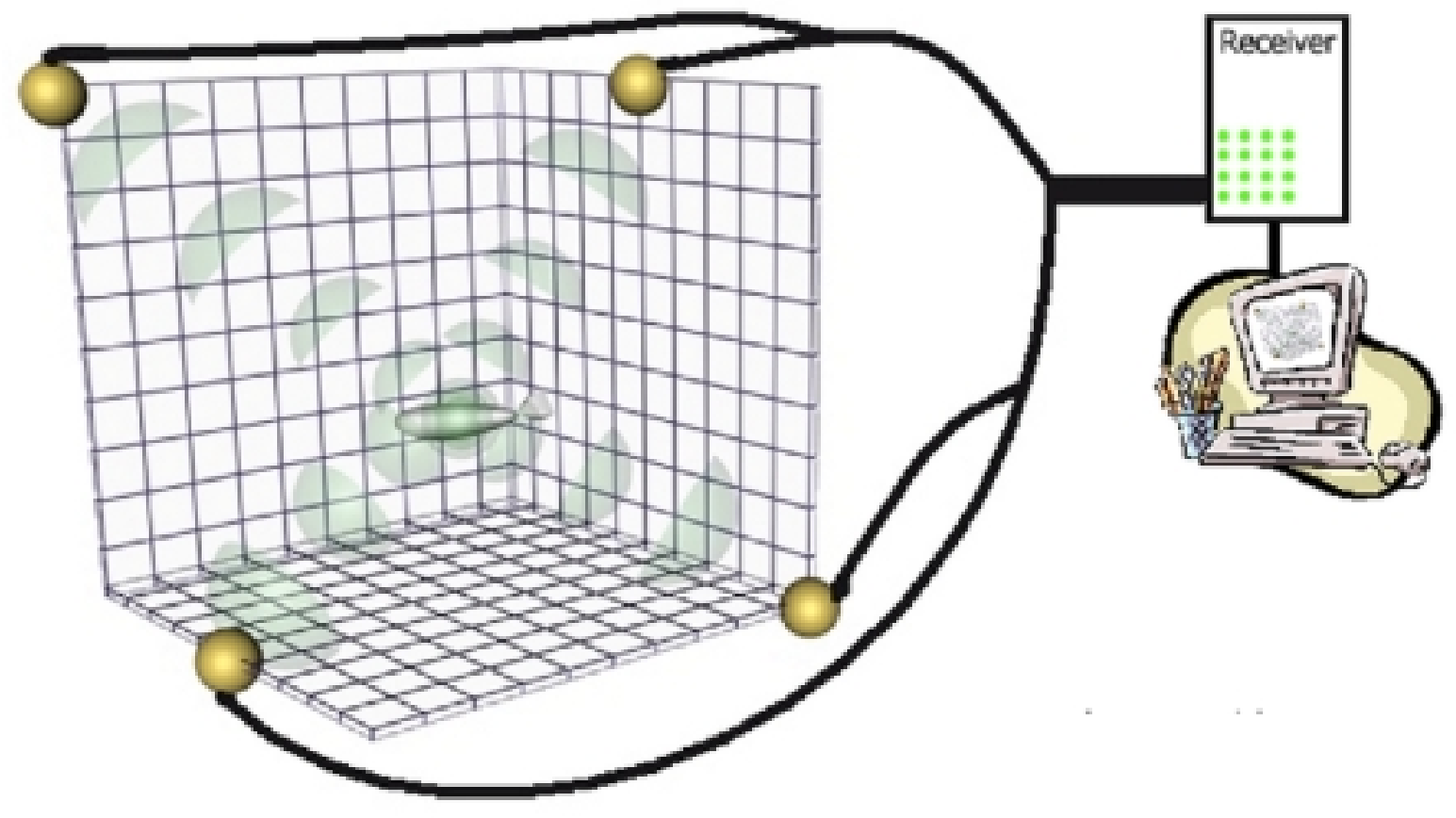

Propagating Sound Wave

Ultra-Sonic Tagged Juvenile Salmon $\simeq$ ?

Hydrophone $\odot$

Figure 6. Ideal Array of Hydrophones to Receive Ultrasonic Signals for 3D Positioning of Fish 


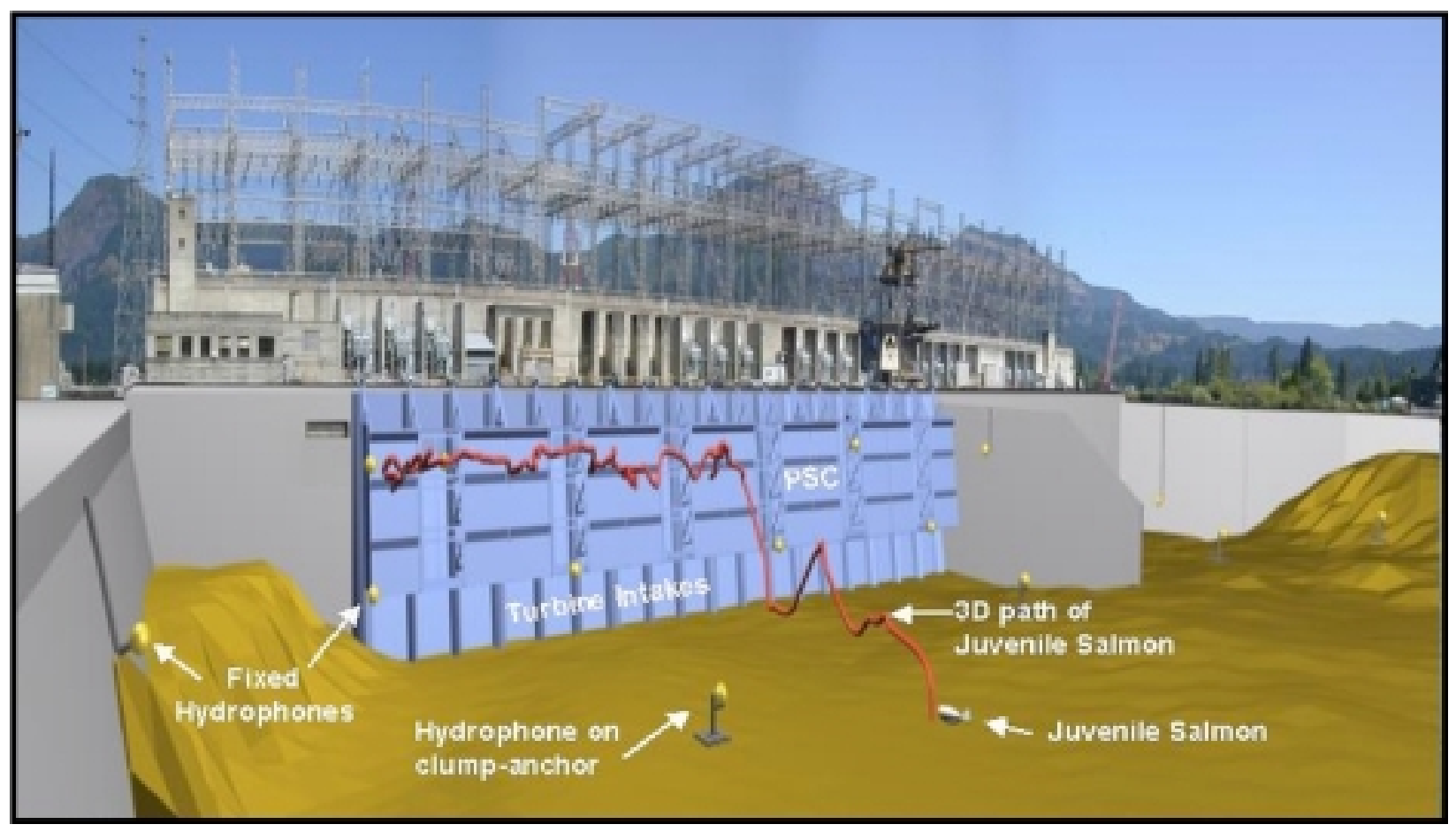

Figure 7. Baseline Hydrophone Array at Powerhouse I Showing a Tracked Juvenile Salmon as It Enters the Array 


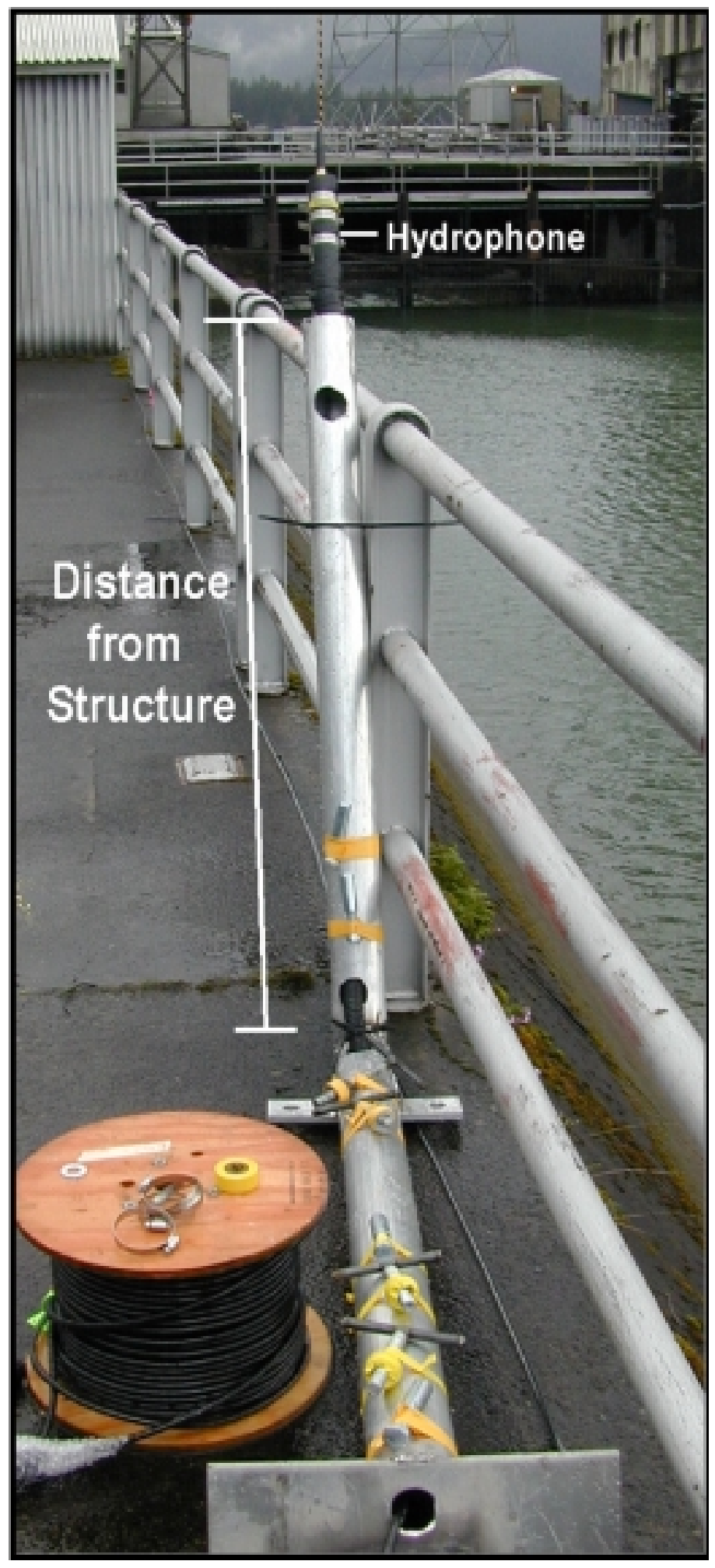

Figure 8. Fixed Hydrophone Mount 


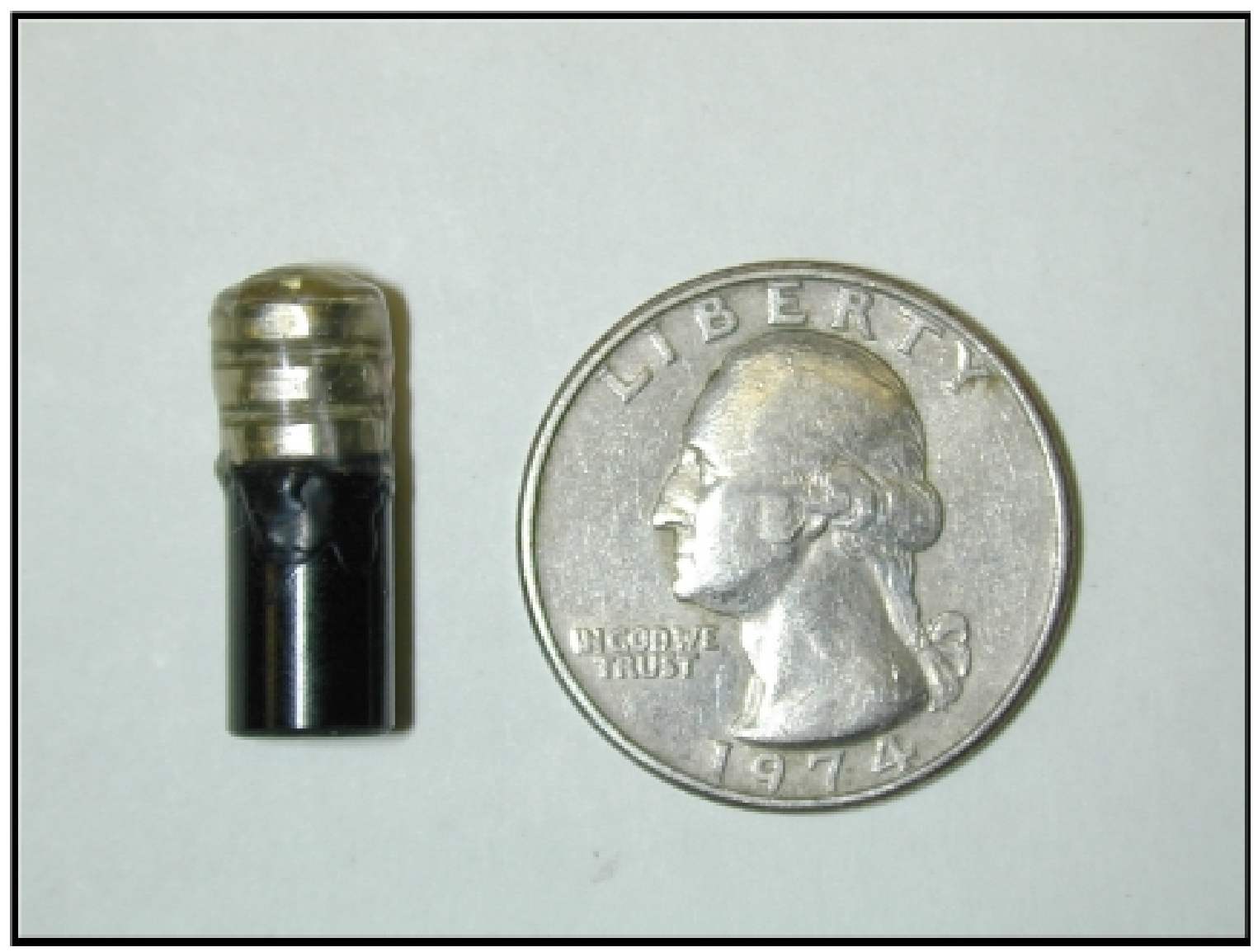

Figure 9. Ultrasonic Tag

Fig.9 


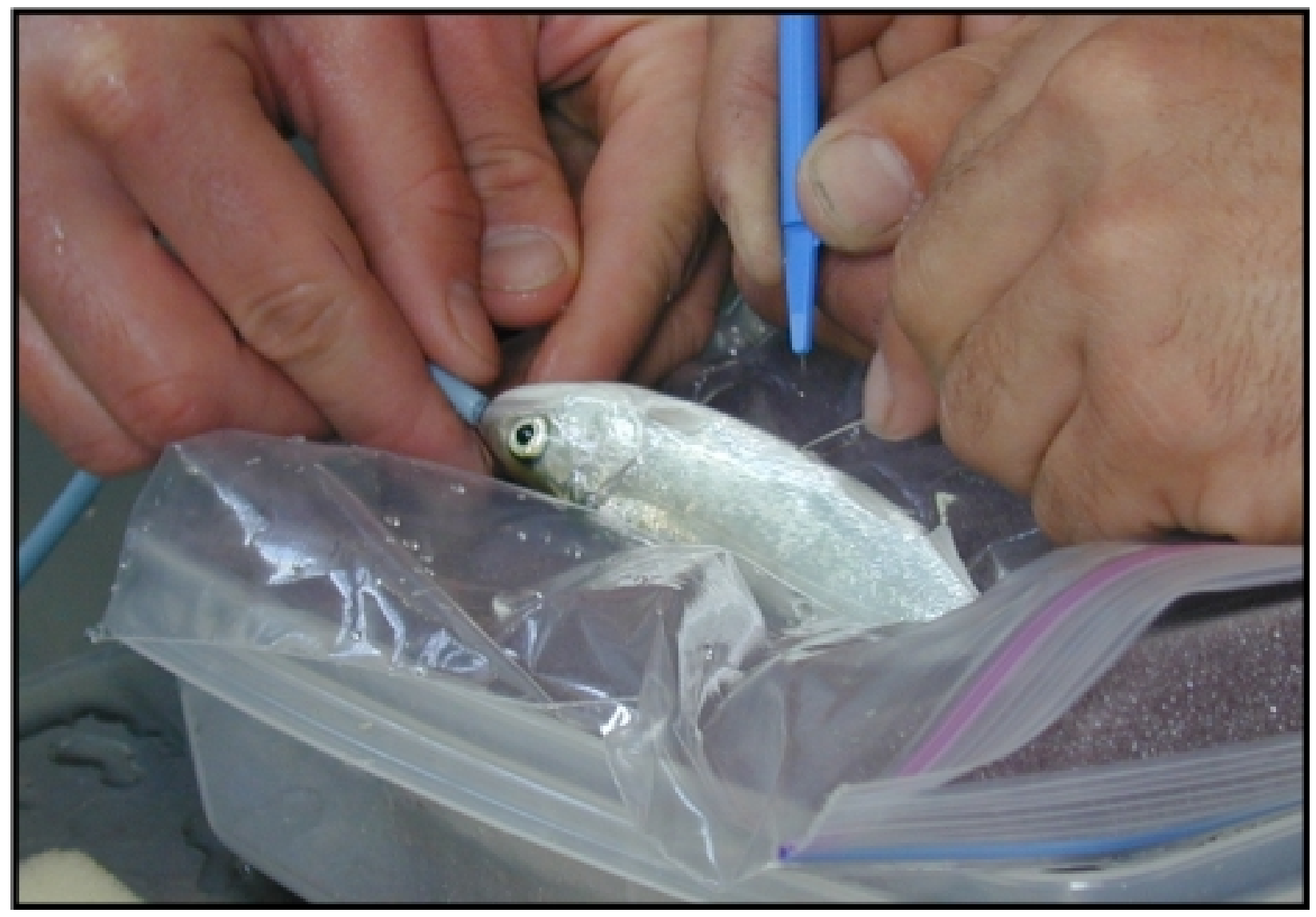

Figure 10. Surgical Incision of Yearling Chinook 


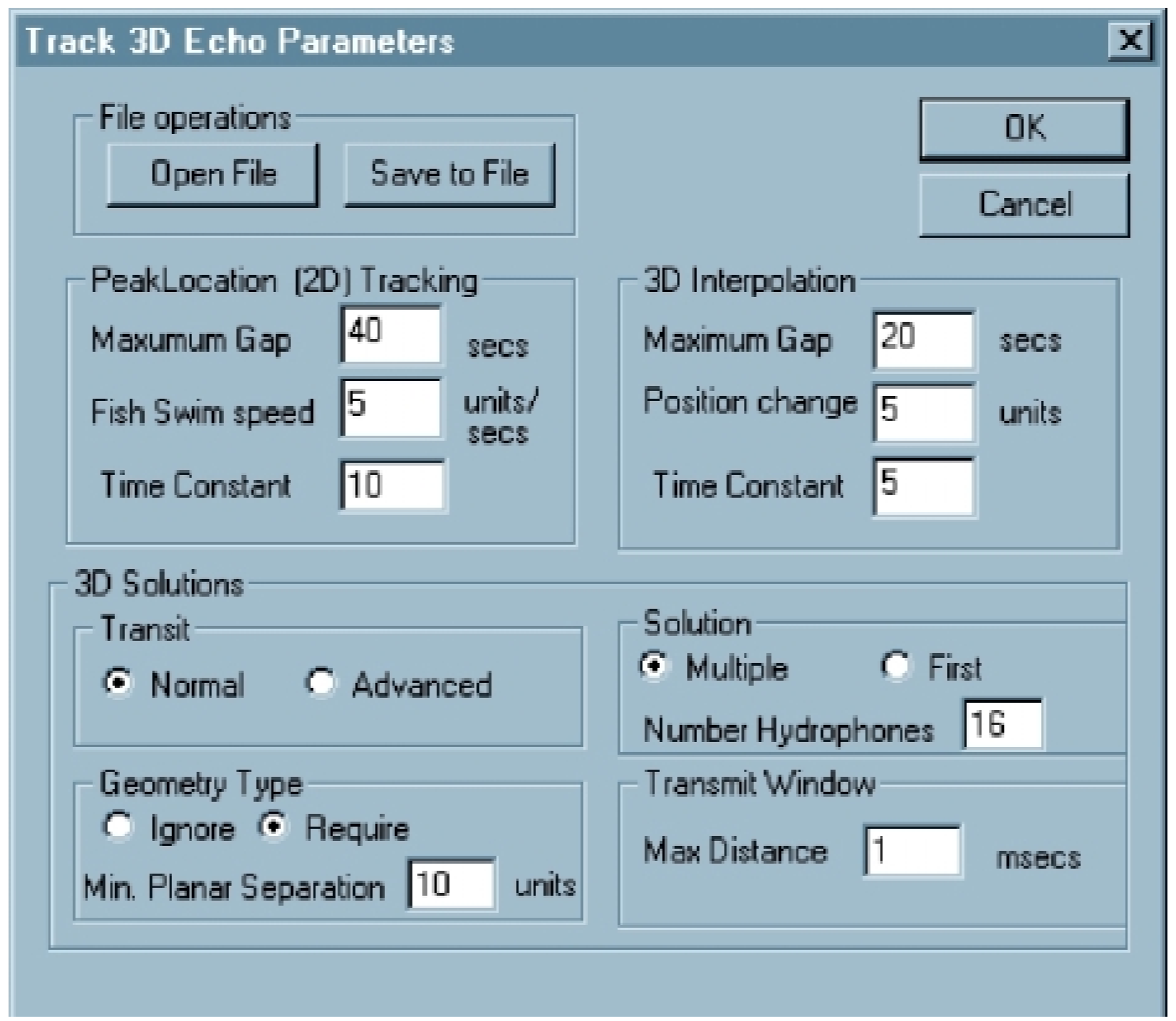

Figure 11. Parameters for Using 3D Positioning Algorithm 


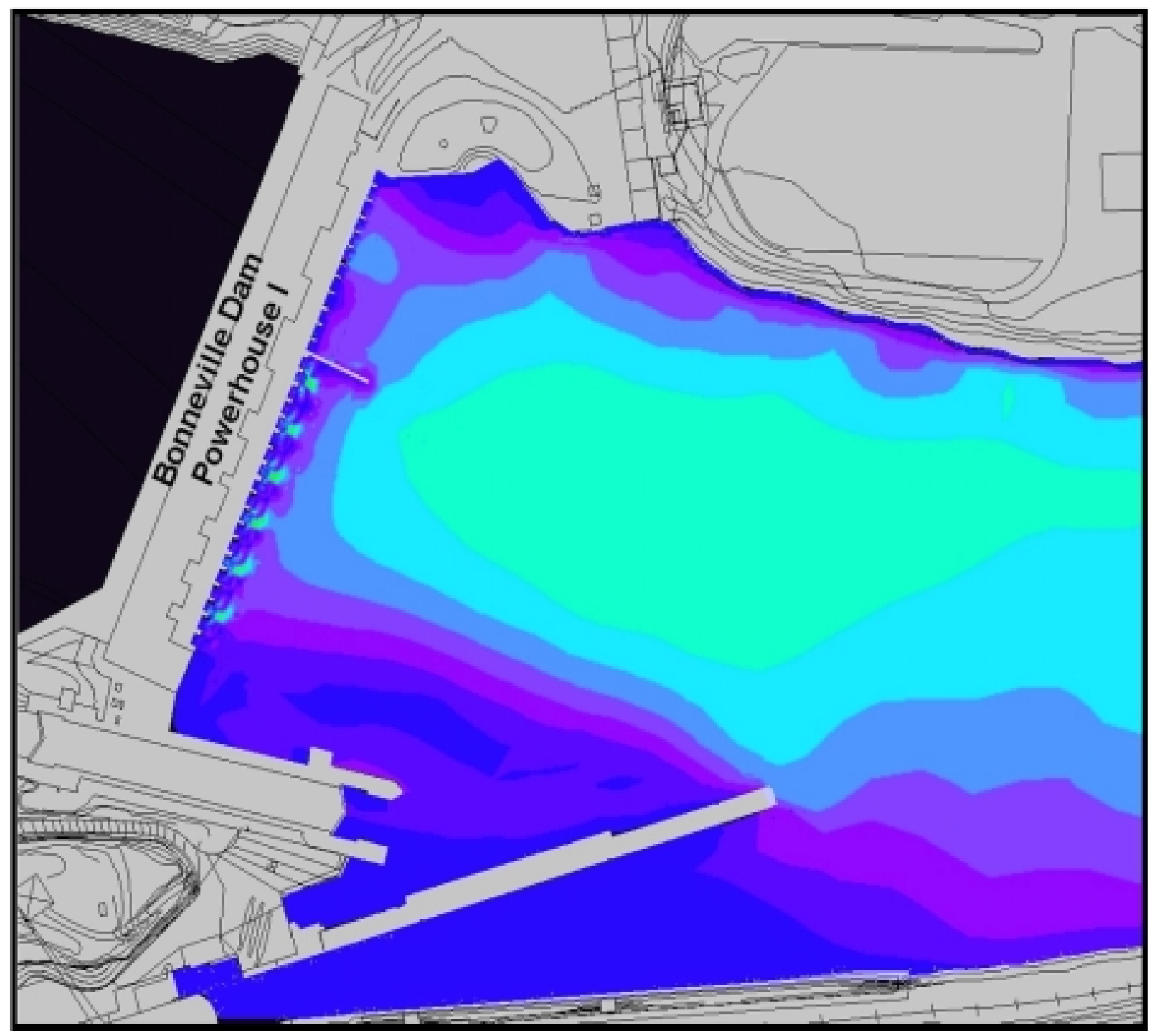

Figure 12. Water Velocity Output from CFD Model (velocity magnitude) 

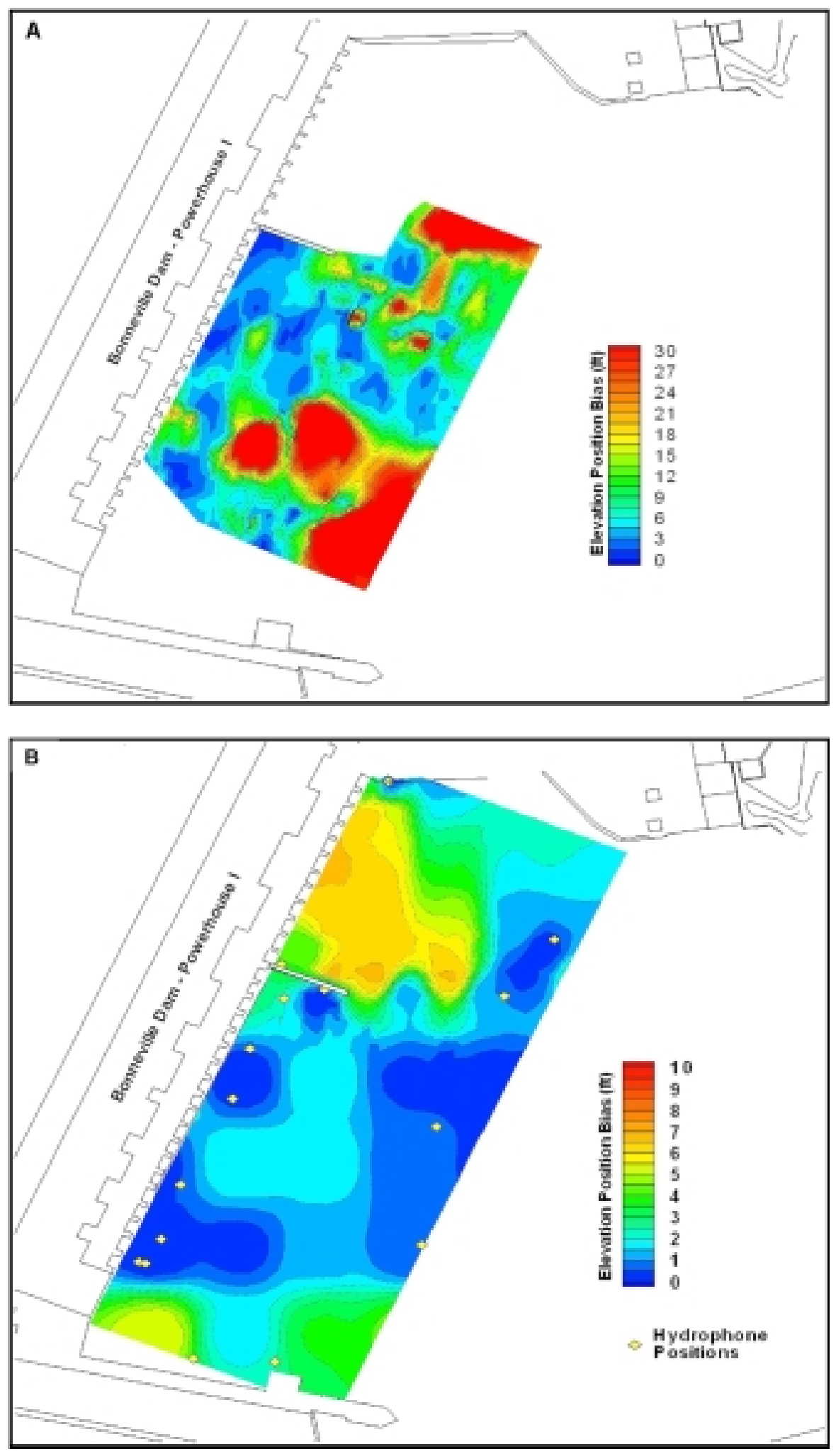

Figure 13. Absolute Value of Elevation (Z) Bias for Position Estimates at the 70-ft Elevation (A - Empirical from GPS drogues and fixed tags, B - Calculated using UW Solver.) 


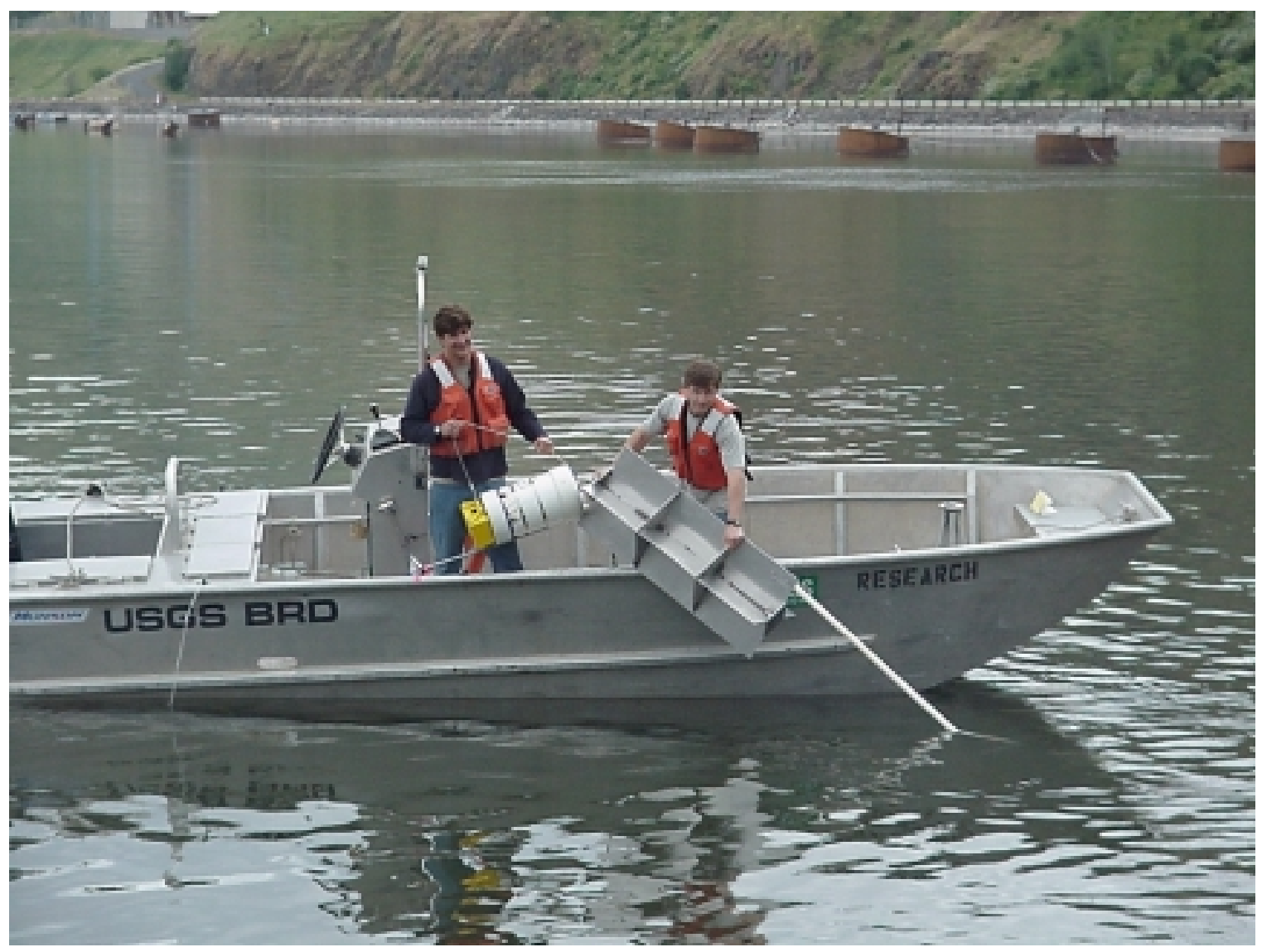

Figure 14. Deployment of GPS Drogue with Ultrasonic Tag Attached below Flow Vane 

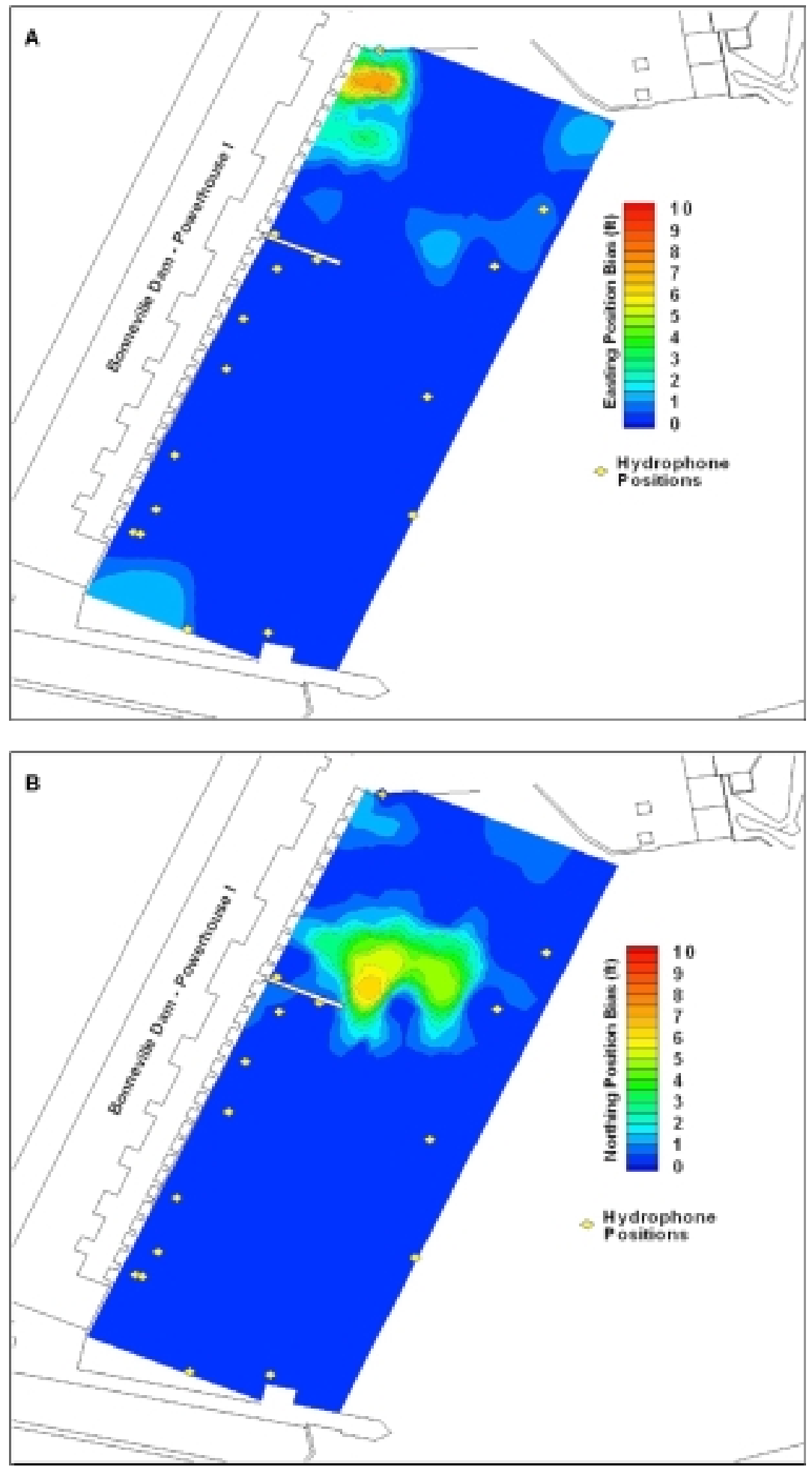

Figure 15. Predicted Bias in Positioning Estimates for Easting (A) and Northing (B) at the 70-ft Elevation from University of Washington's Monte Carlo Simulation 


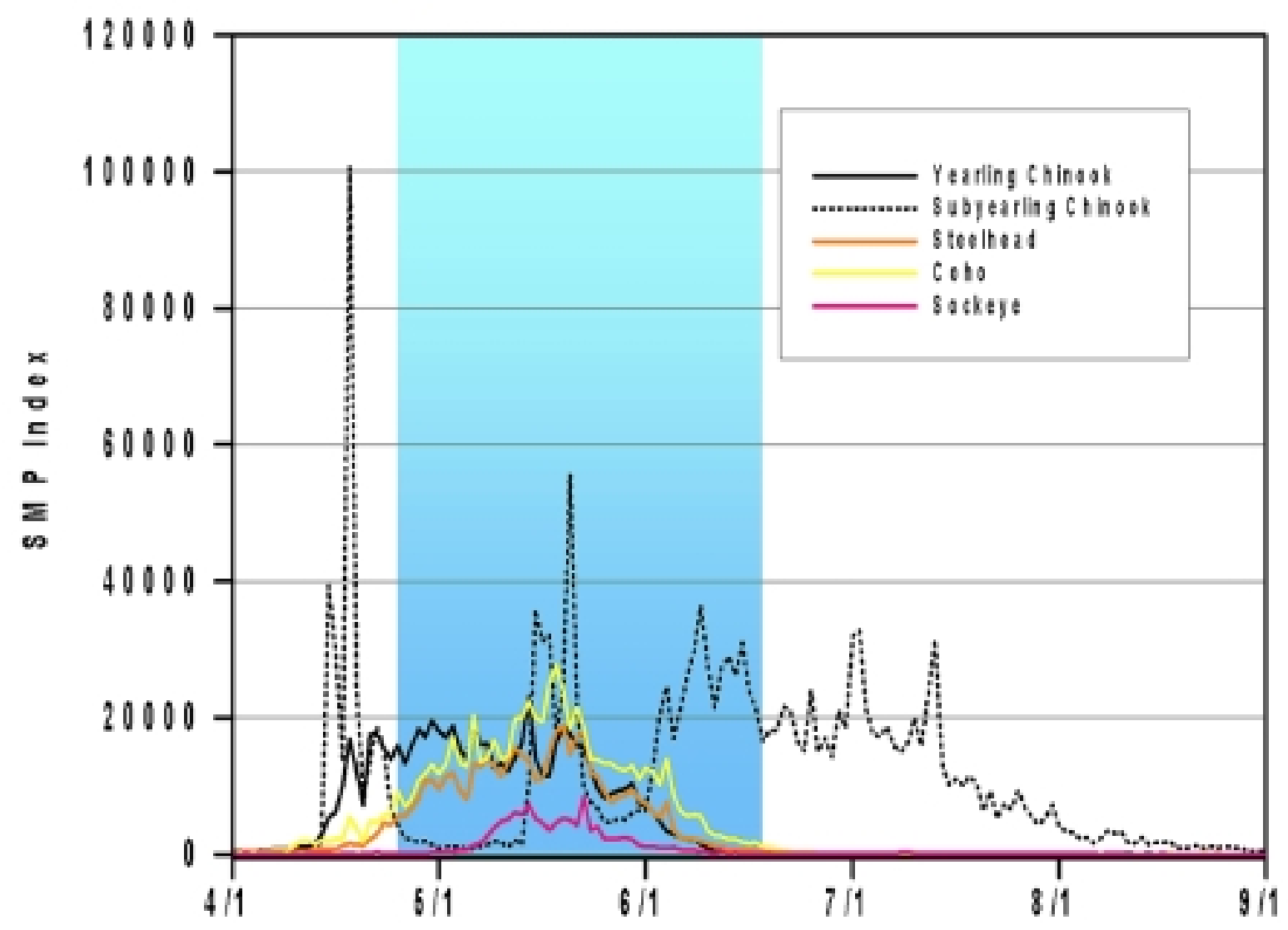

Figure 16. Average Daily Passage at Bonneville Dam by Species from 1995-1999 (FPC, 1995-1999). Shaded area is time period of 3D acoustic monitoring. 


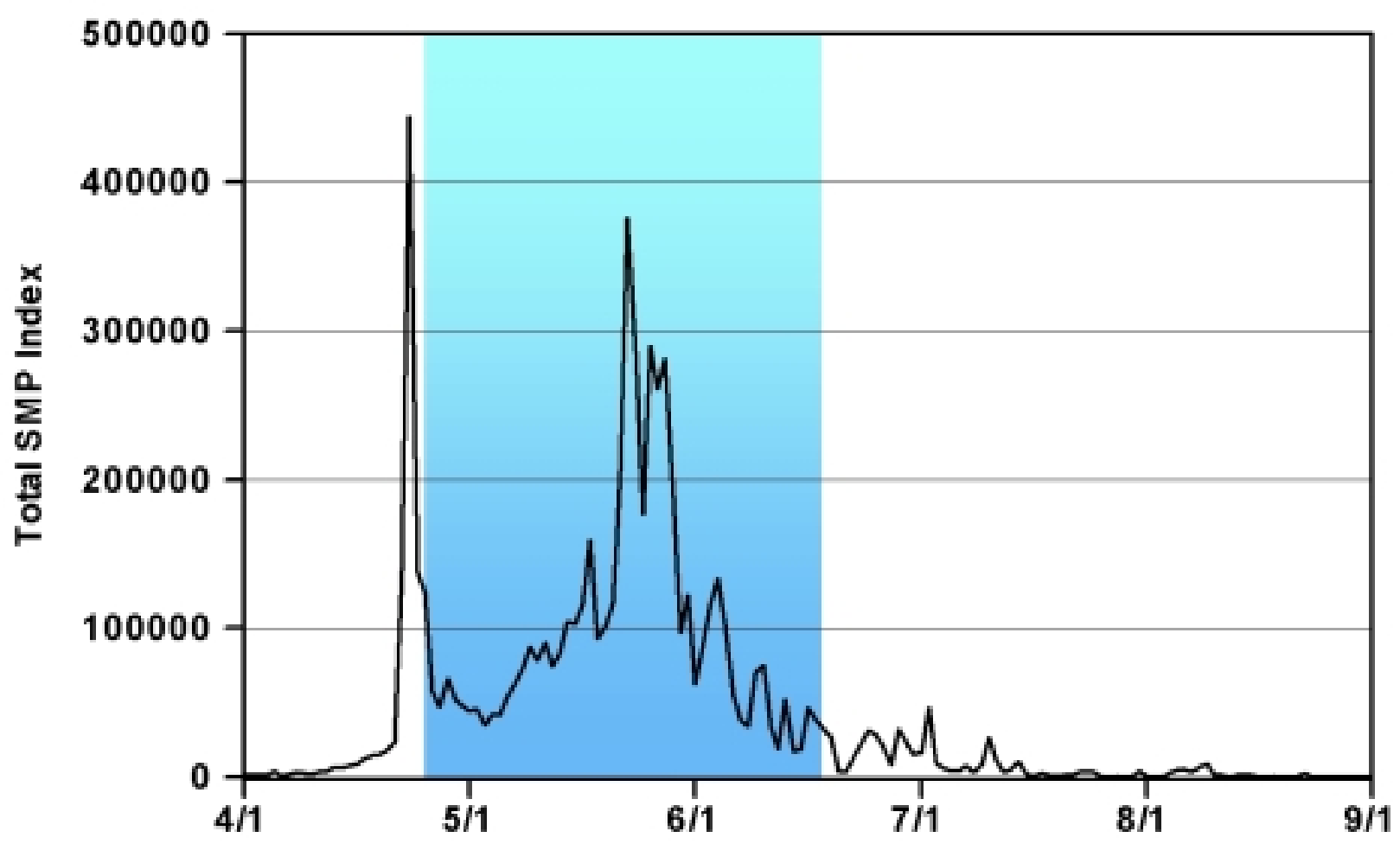

Figure 17. Total Smolt Passage Index for Juvenile Salmon and Steelhead at Bonneville Dam from April 1 to September 1, 2000 (FPC, 2000). Area shaded is the study period for Bonneville $3 \mathrm{D}$ acoustic telemetry studies. 

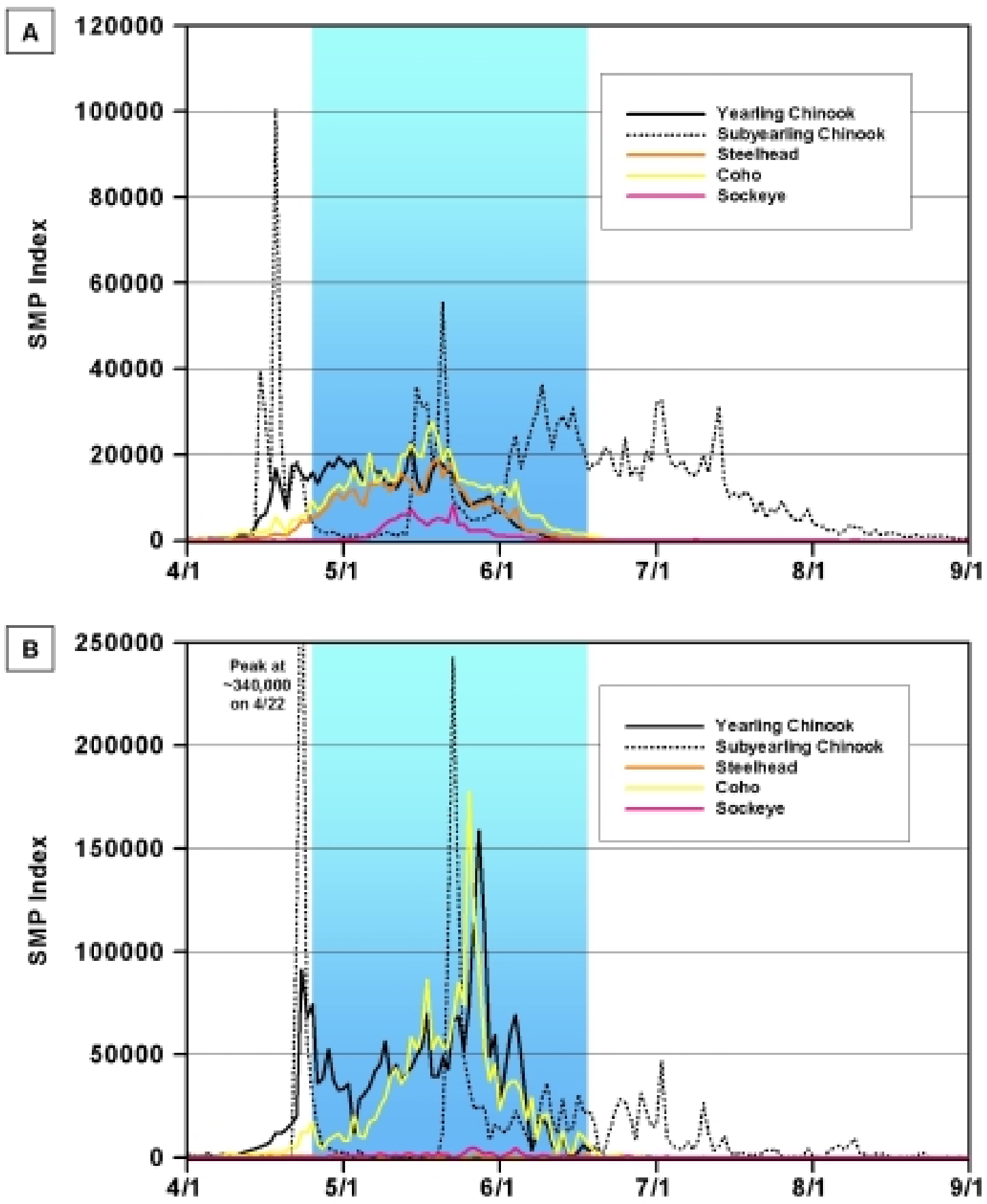

Figure 18. Average Daily Passage Indices by Species at Bonneville Dam from 1995 to 1999 (A, FPC, 2000) and Run Timing by Species at Bonneville Dam from April 1 to September 1, 2000 (B, FPC, 2000). Area shaded is the study period for Bonneville $3 \mathrm{D}$ acoustic telemetry studies. 

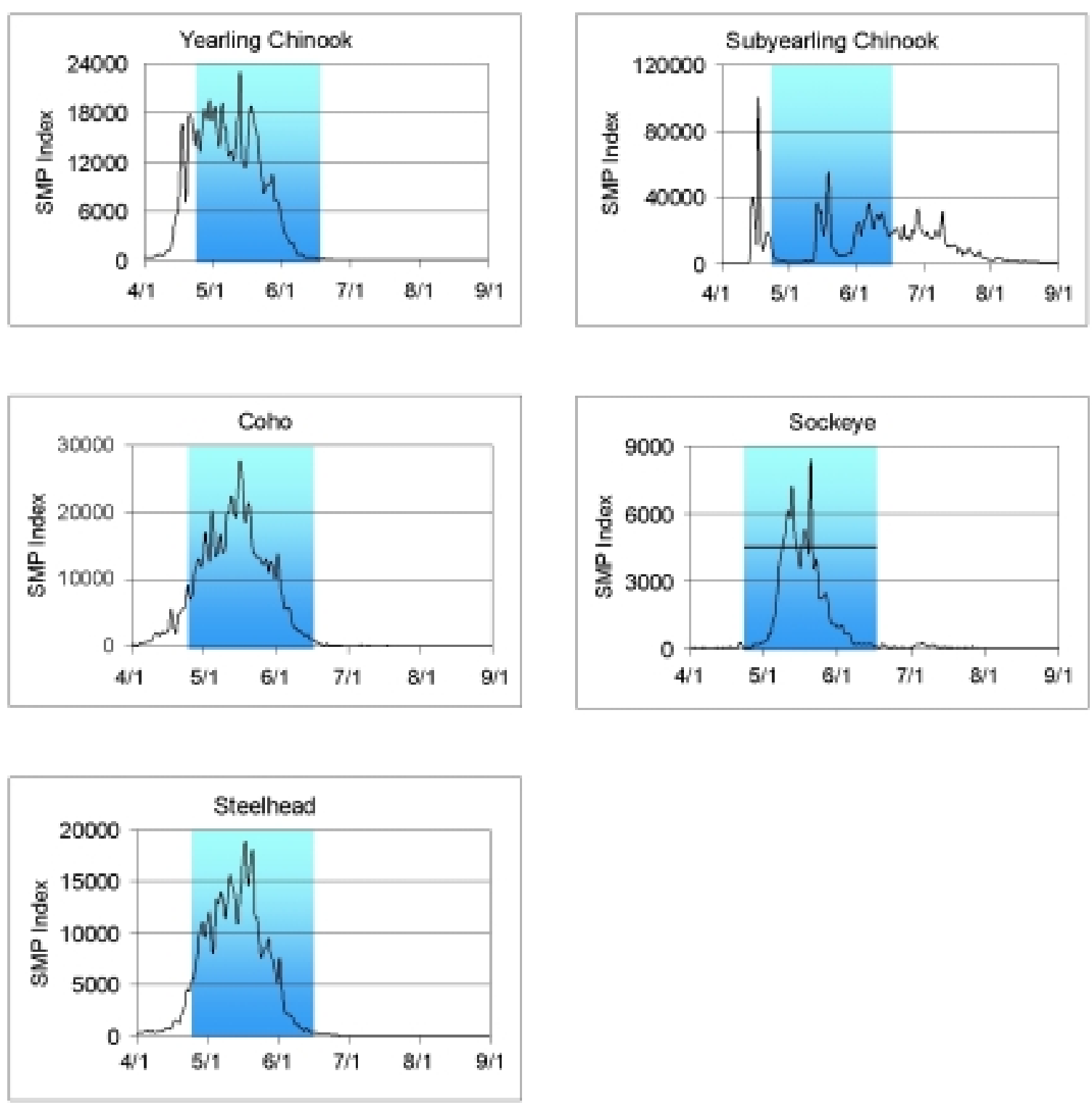

Figure 19. Average Daily Passage Indices by Species at Bonneville Dam from 1995 to 1999. Note the index scales differ among graphs. 


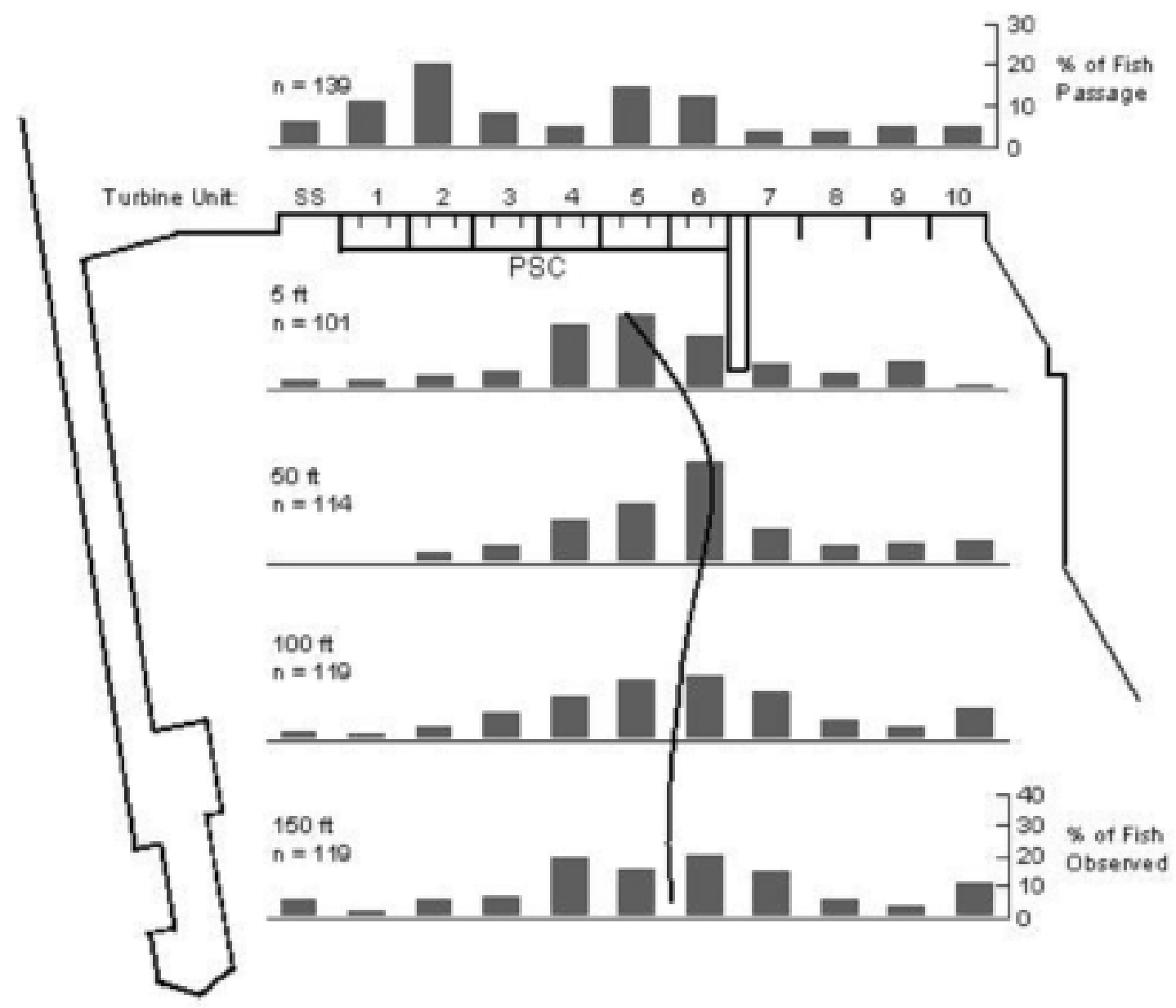

Figure 20. Approach and Passage Distribution of All Tracked Juvenile Steelhead and Yearling Chinook 


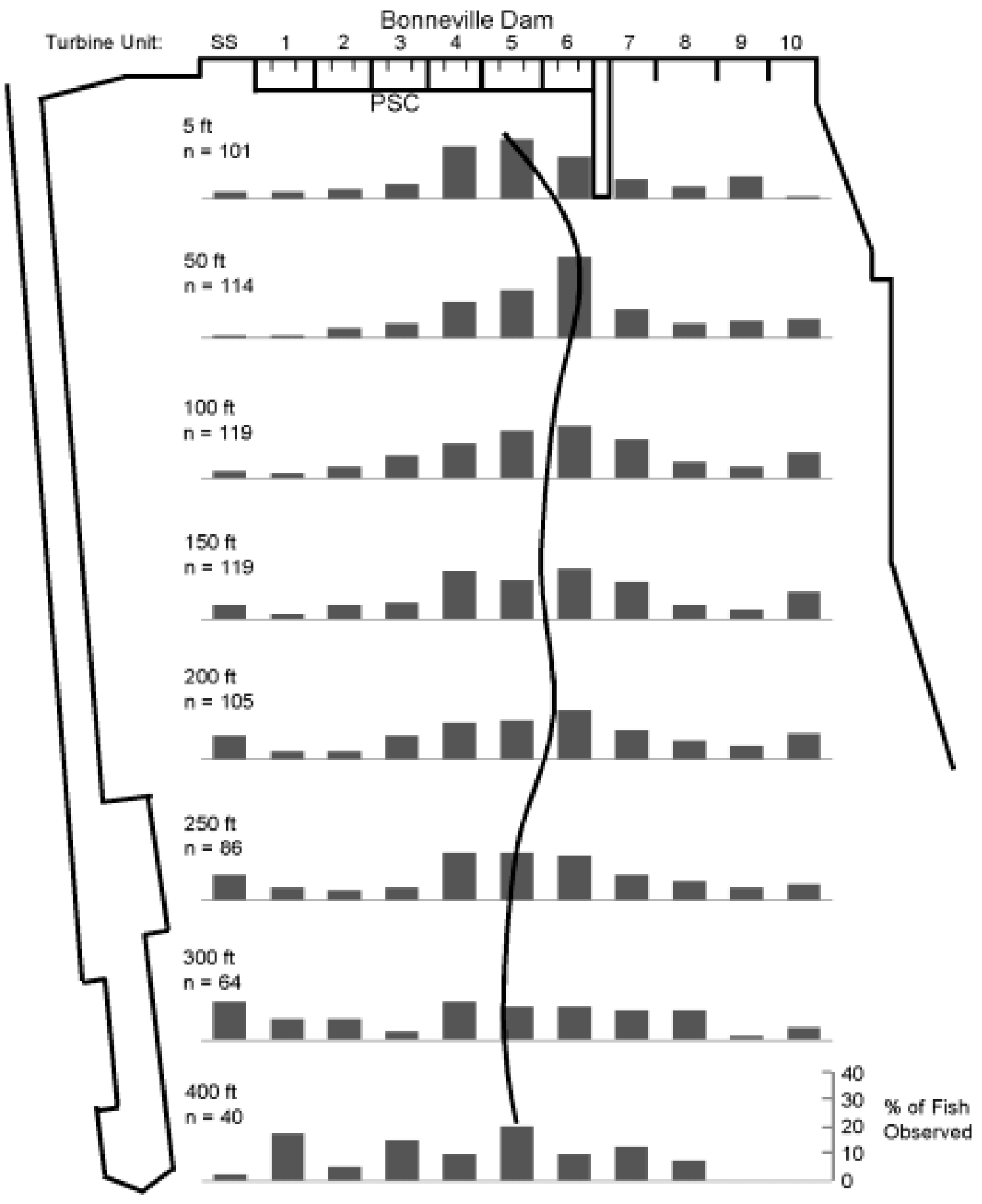

Figure 21. Horizontal Distribution of Juvenile Steelhead and Yearling Chinook Entering the Forebay of Bonneville Dam, Powerhouse I. All graphs are the same scale. Line represents $50 \%$ fish path entry. Distances are measured from the PSC to a plane parallel to the face of the PSC. Bars are separated by turbine unit. 


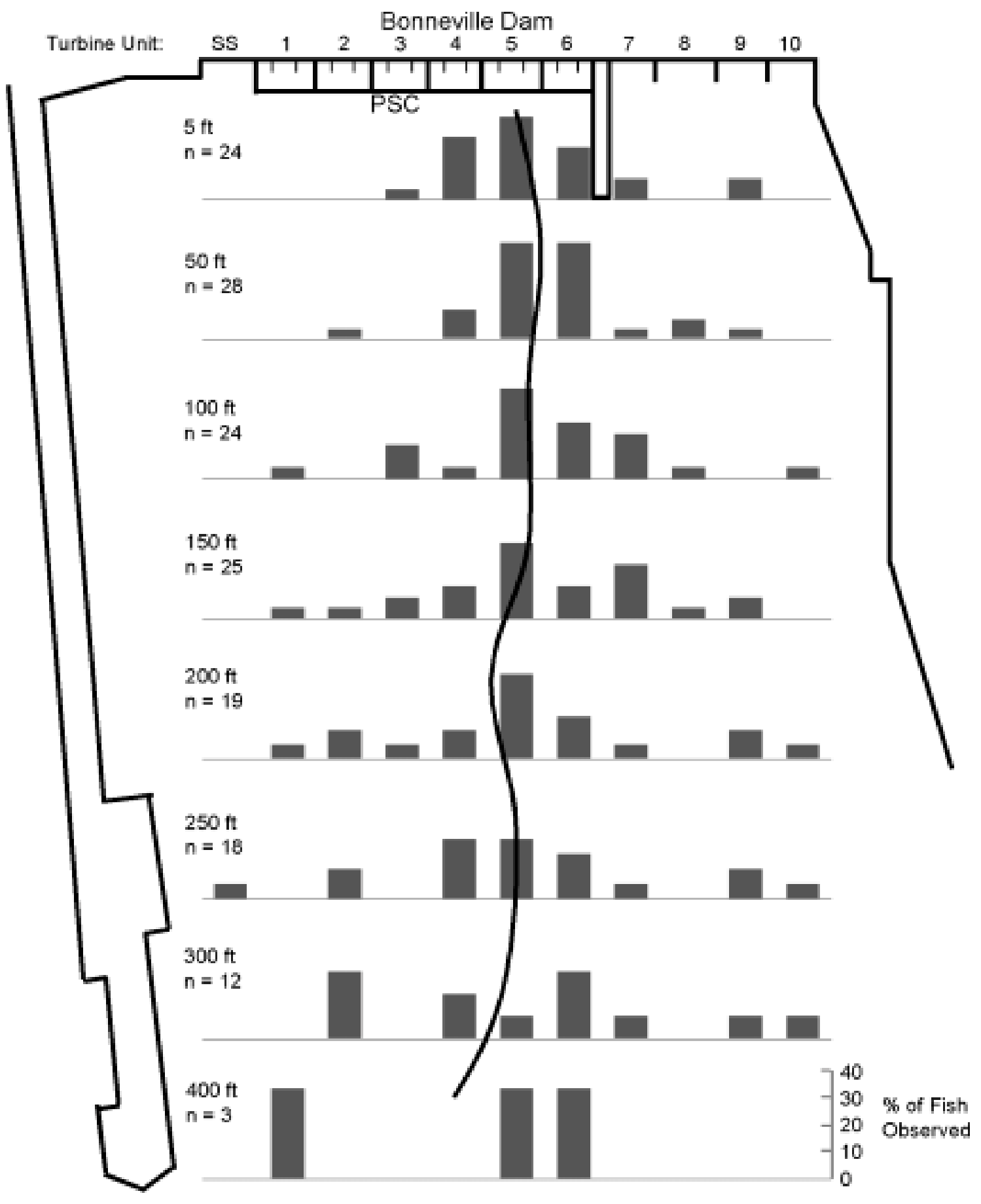

Figure 22. Horizontal Distribution of Yearling Chinook Entering the Forebay of Bonneville Dam, Powerhouse I. All graphs are the same scale. Line represents 50\% fish entry path. Distances are measured from the PSC to a plane parallel to the face of the PSC. Bars are separated by turbine unit. 


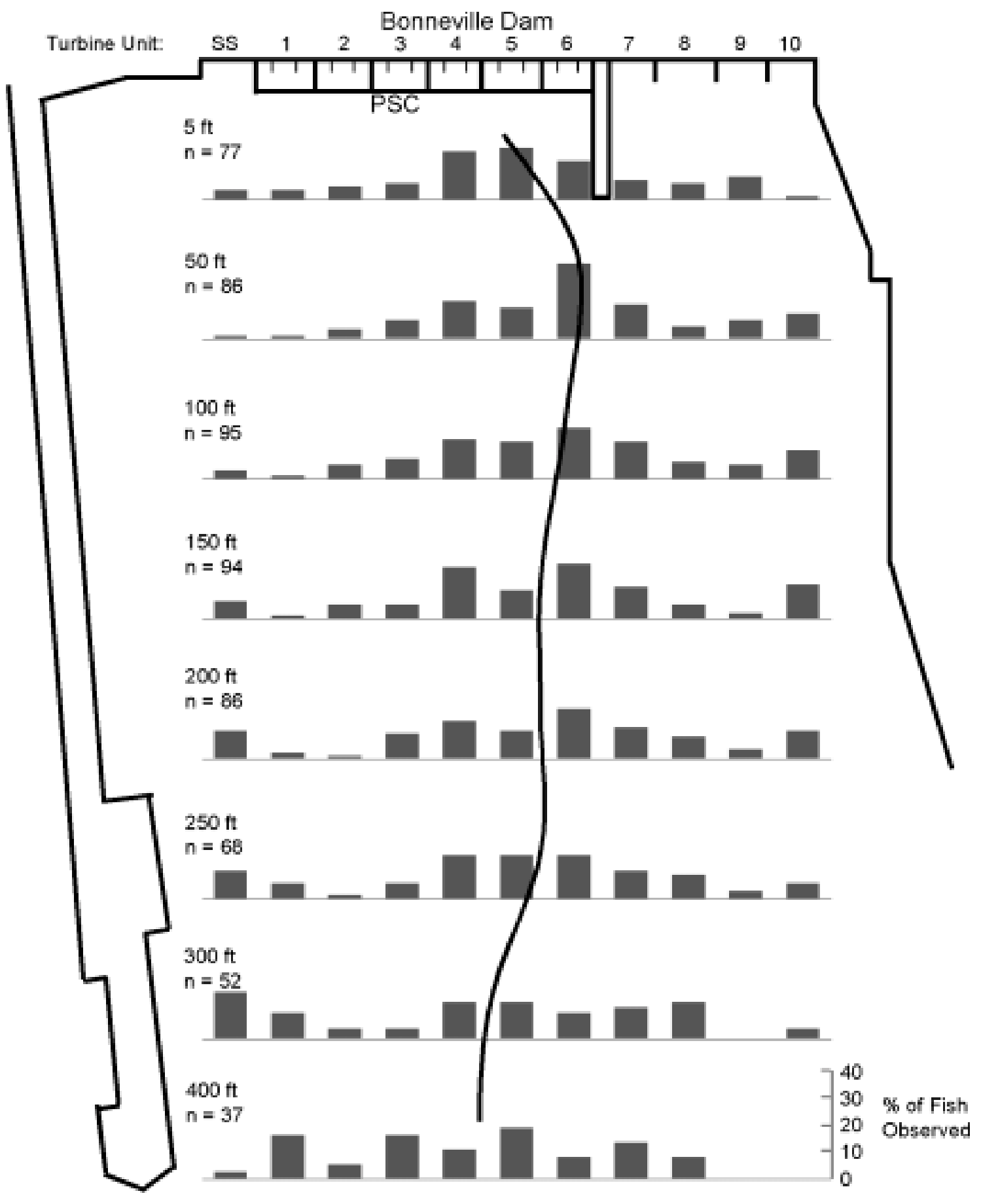

Figure 23. Horizontal Distribution of Juvenile Steelhead Entering the Forebay of Bonneville Dam, Powerhouse I. All graphs are the same scale. Line represents 50\% fish entry path. Distances are measured from the PSC to a plane parallel to the face of the PSC. Bars are separated by turbine unit. 


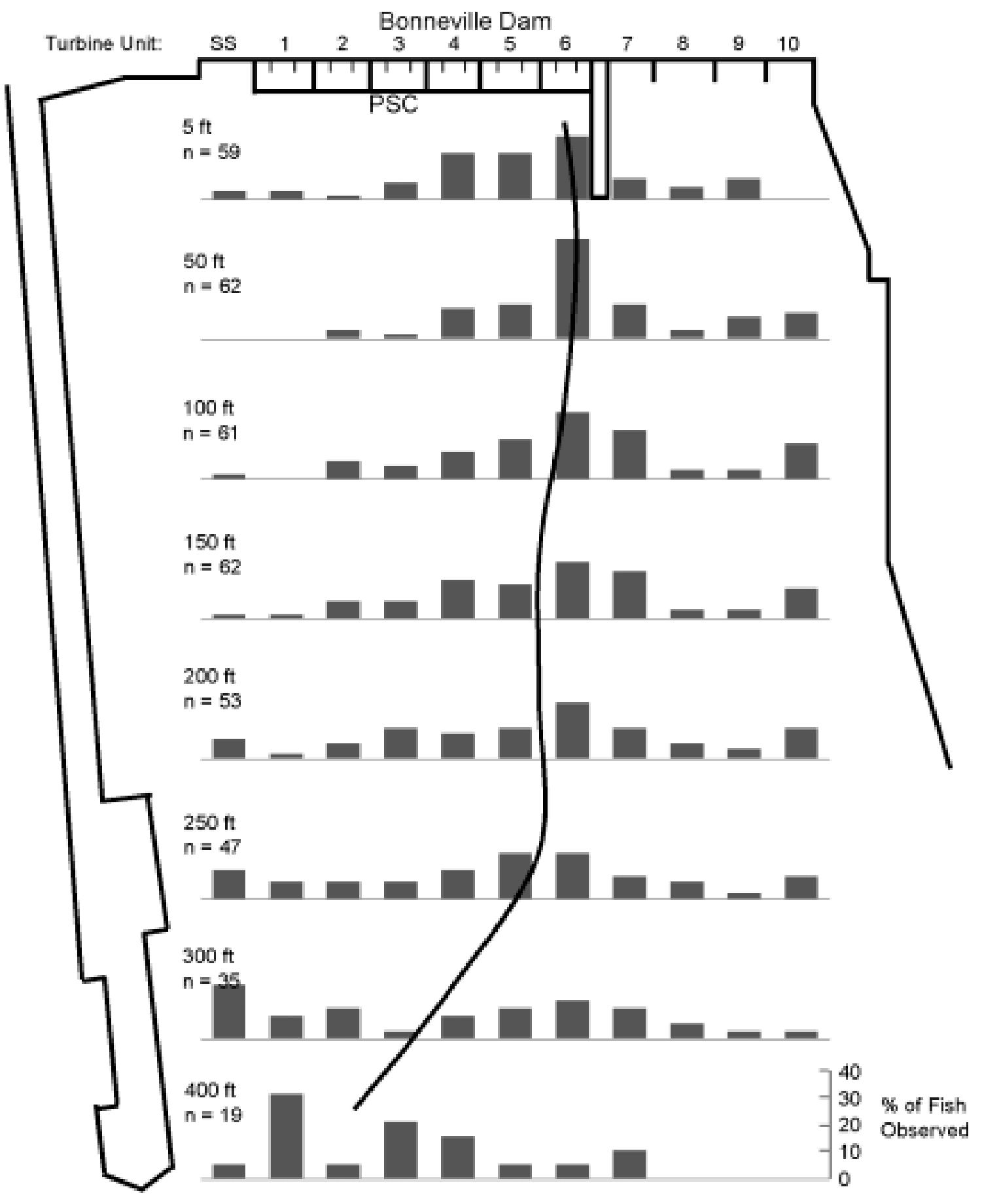

Figure 24. Horizontal Distribution of Juvenile Steelhead and Yearling Chinook Entering the Forebay of Bonneville Dam, Powerhouse 1, During Daylight Hours. All graphs are the same scale. Line represents $50 \%$ fish entry separated by turbine unit. 


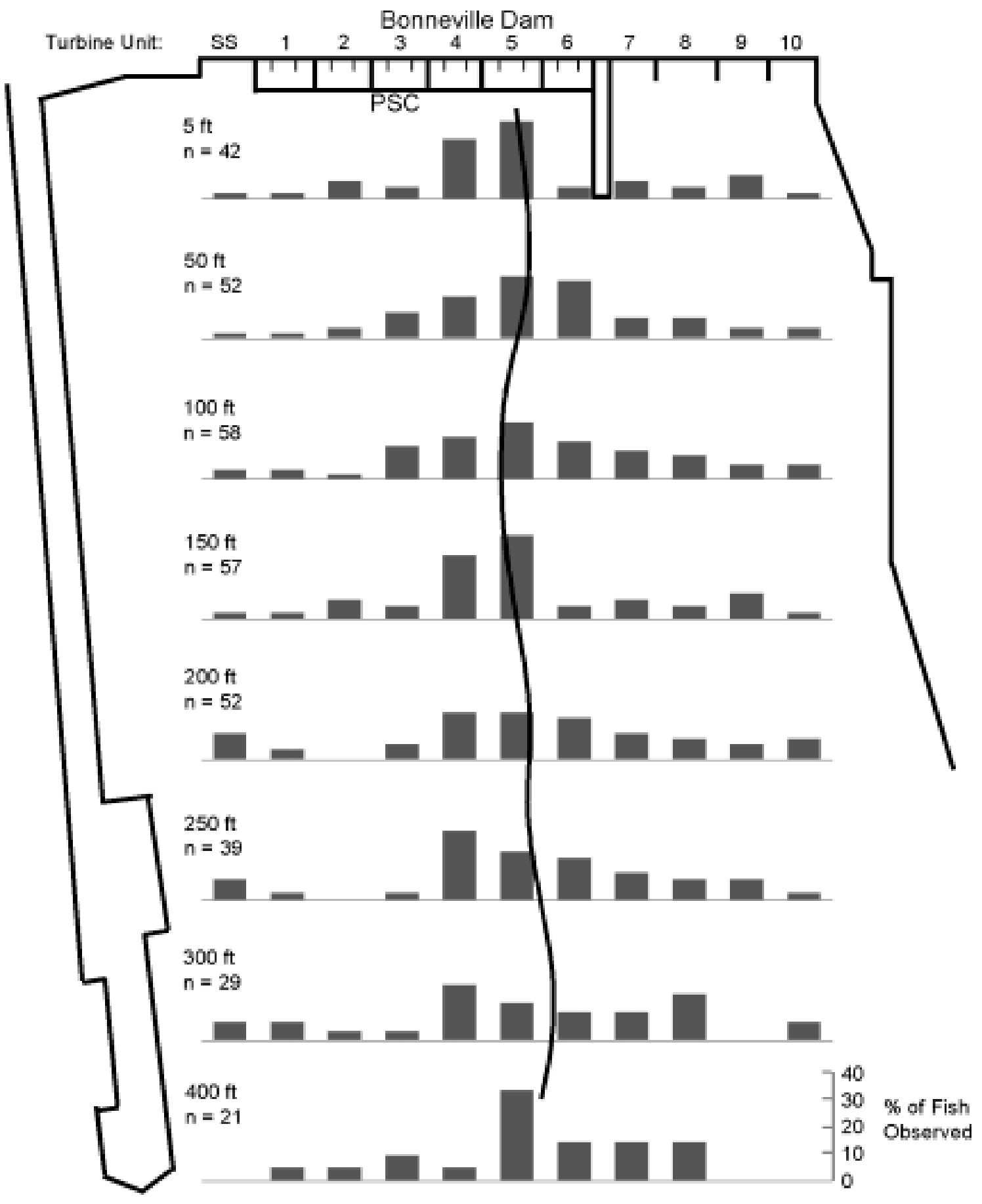

Figure 25. Horizontal Distribution of Juvenile Steelhead and Yearling Chinook Entering the Forebay of Bonneville Dam, Powerhouse 1, During Night Hours. All graphs are the same scale. Line represents $50 \%$ fish entry separated by turbine unit. 


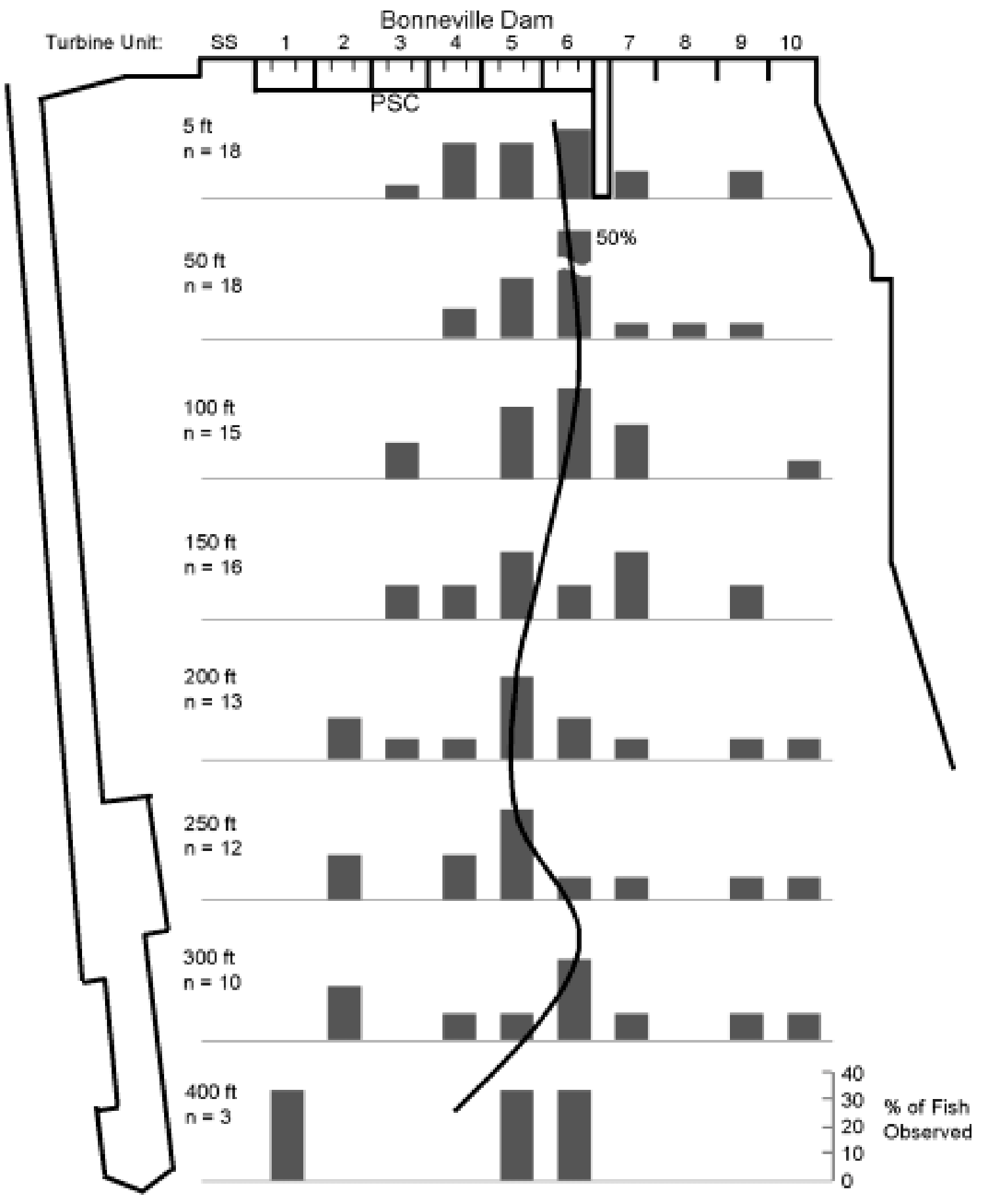

Figure 26. Horizontal Distribution of Yearling Chinook Entering the Forebay of Bonneville Dam, Powerhouse 1, During Daylight Hours. All graphs are the same scale. Line represents $50 \%$ fish entry path. Distances are measured from the PSC to a plane parallel to the face of the PSC. Bars are separated by turbine unit. 


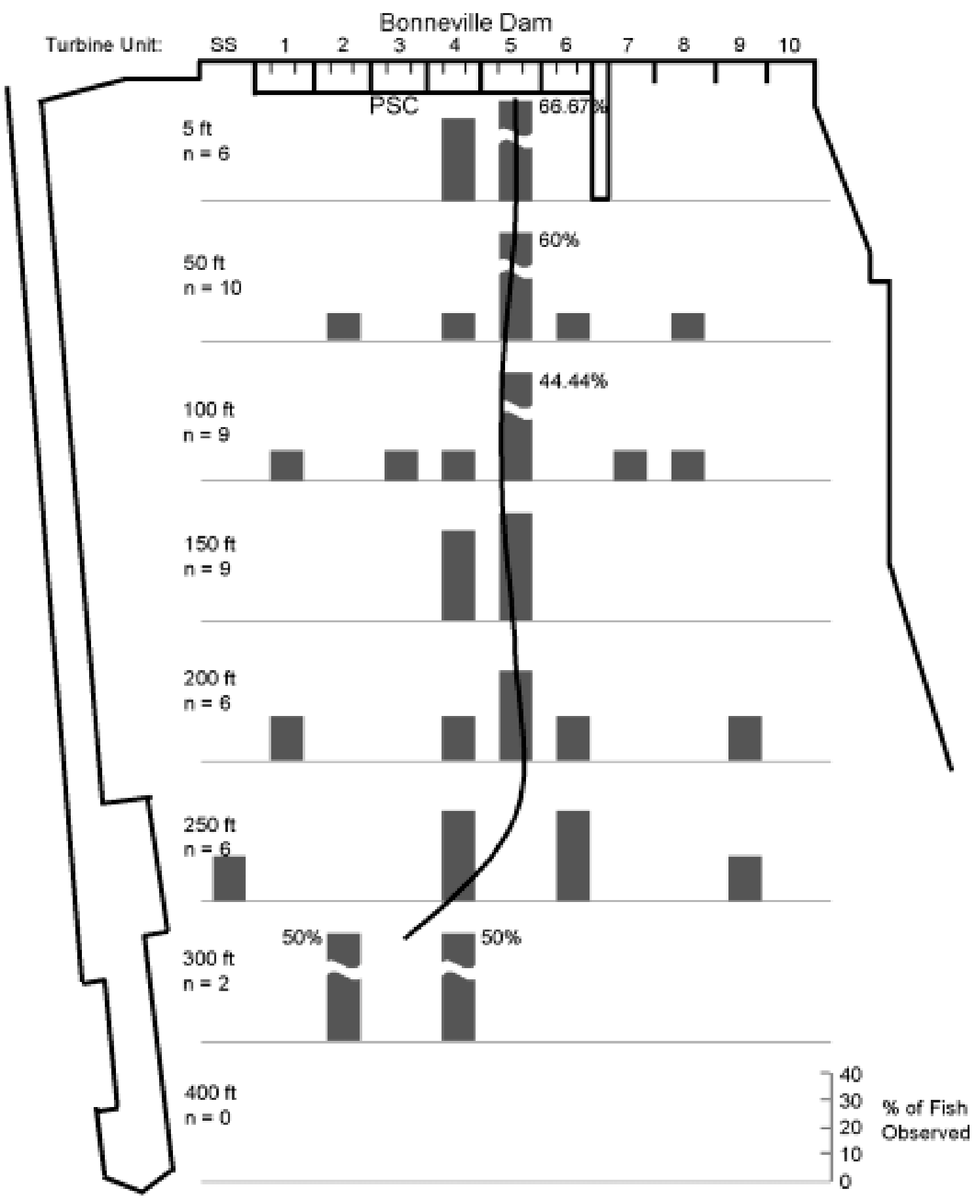

Figure 27. Horizontal Distribution of Yearling Chinook Entering the Forebay of Bonneville Dam, Powerhouse 1, During Night Hours. All graphs are the same scale. Line represents $509 \%$ fish entry path. Distances are measured from the PSC to a plane parallel to the face of the PSC. Bars are separated by turbine unit. 


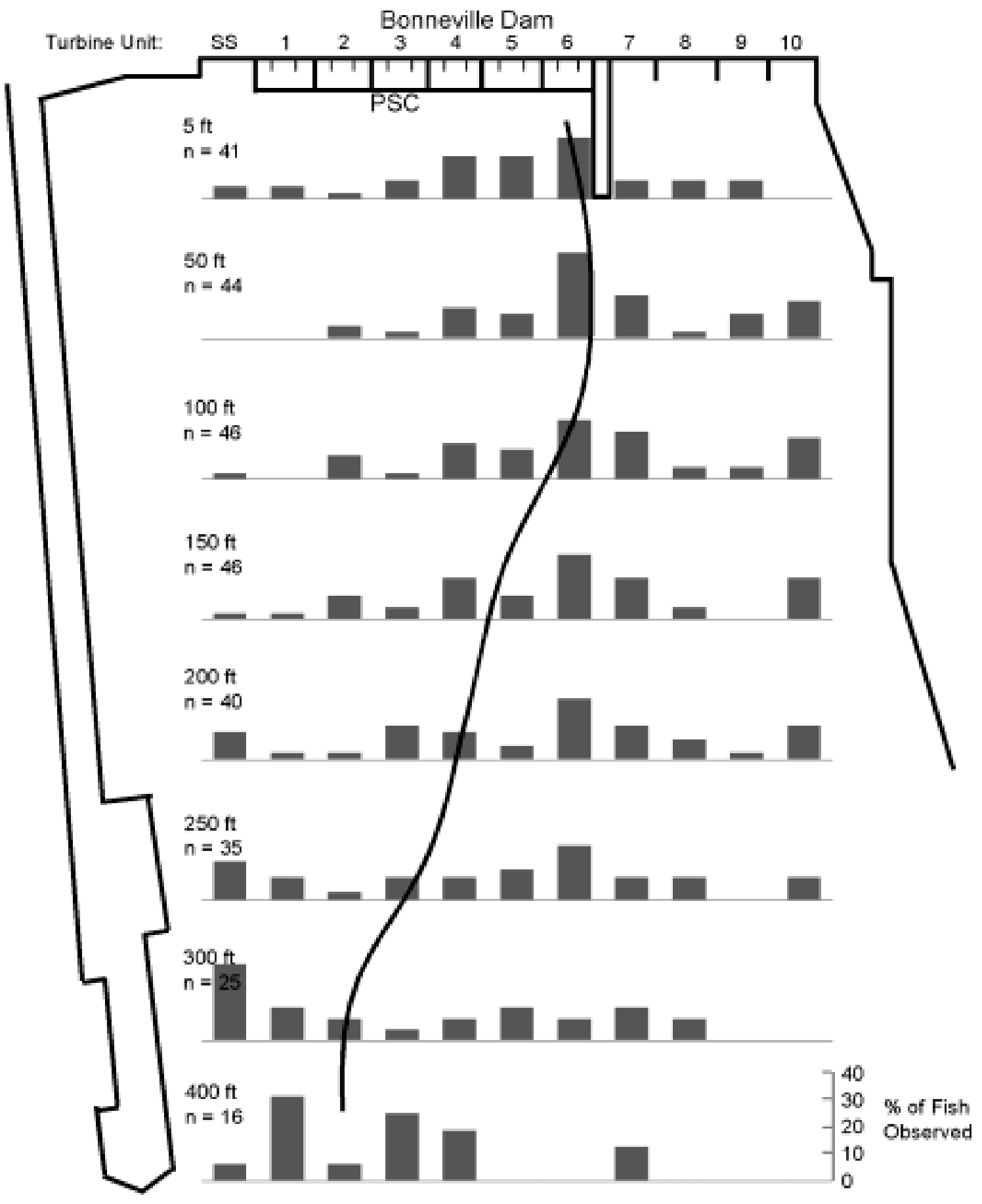

Figure 28. Horizontal Distribution of Juvenile Steelhead Entering the Forebay of Bonneville Dam, Powerhouse 1, During Daylight Hours. All graphs are the same scale. Line represents $50 \%$ fish entry path. Distances are measured from the PSC to a plane parallel to the face of the PSC. Bars are separated by turbine unit. 


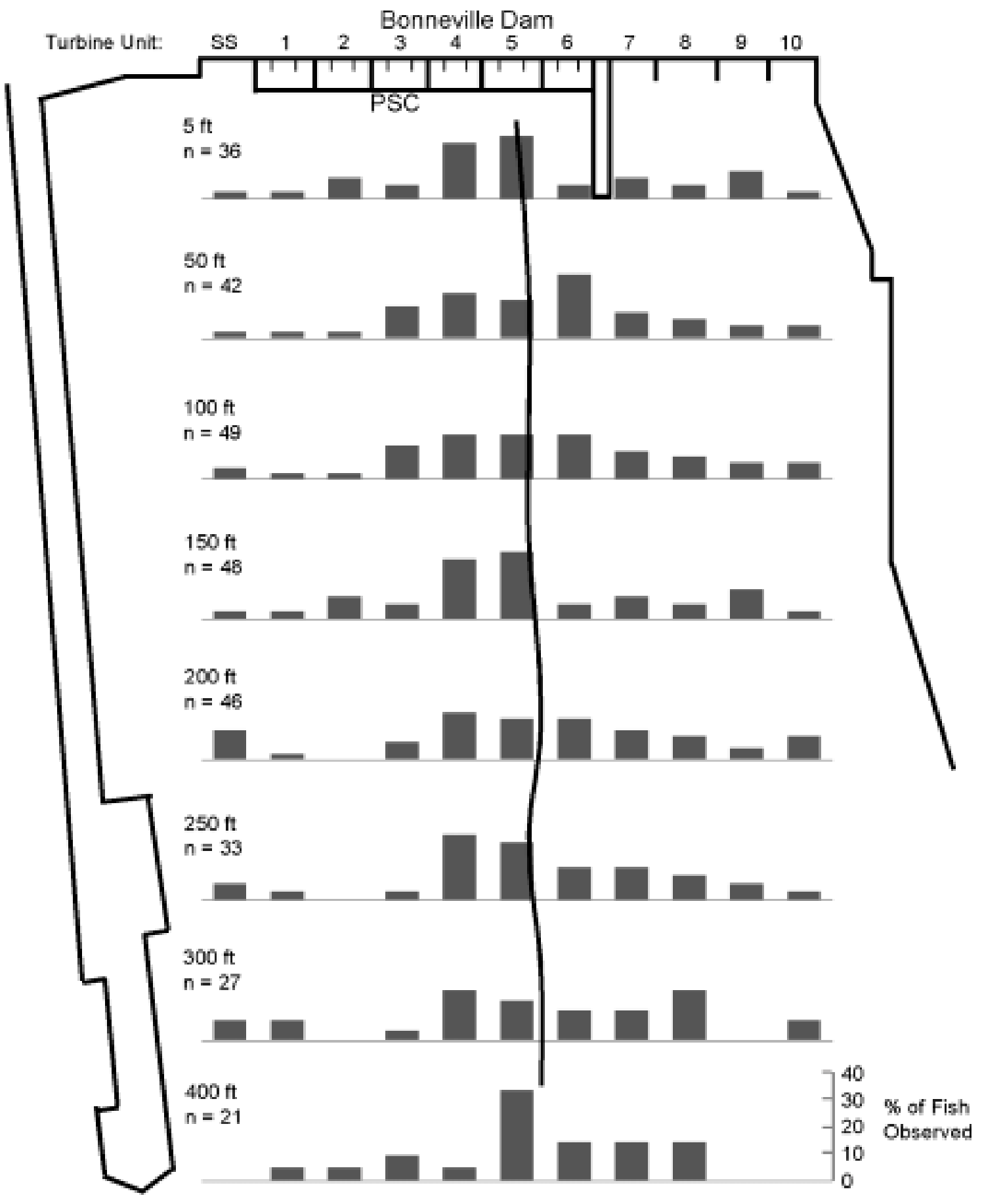

Figure 29. Horizontal Distribution of Juvenile Steelhead Entering the Forebay of Bonneville Dam, Powerhouse 1, During Night Hours. All graphs are the same scale. Line represents 50\% fish entry path. Distances are measured from the PSC to a plane parallel to the face of the PSC. Bars are separated by turbine unit. 

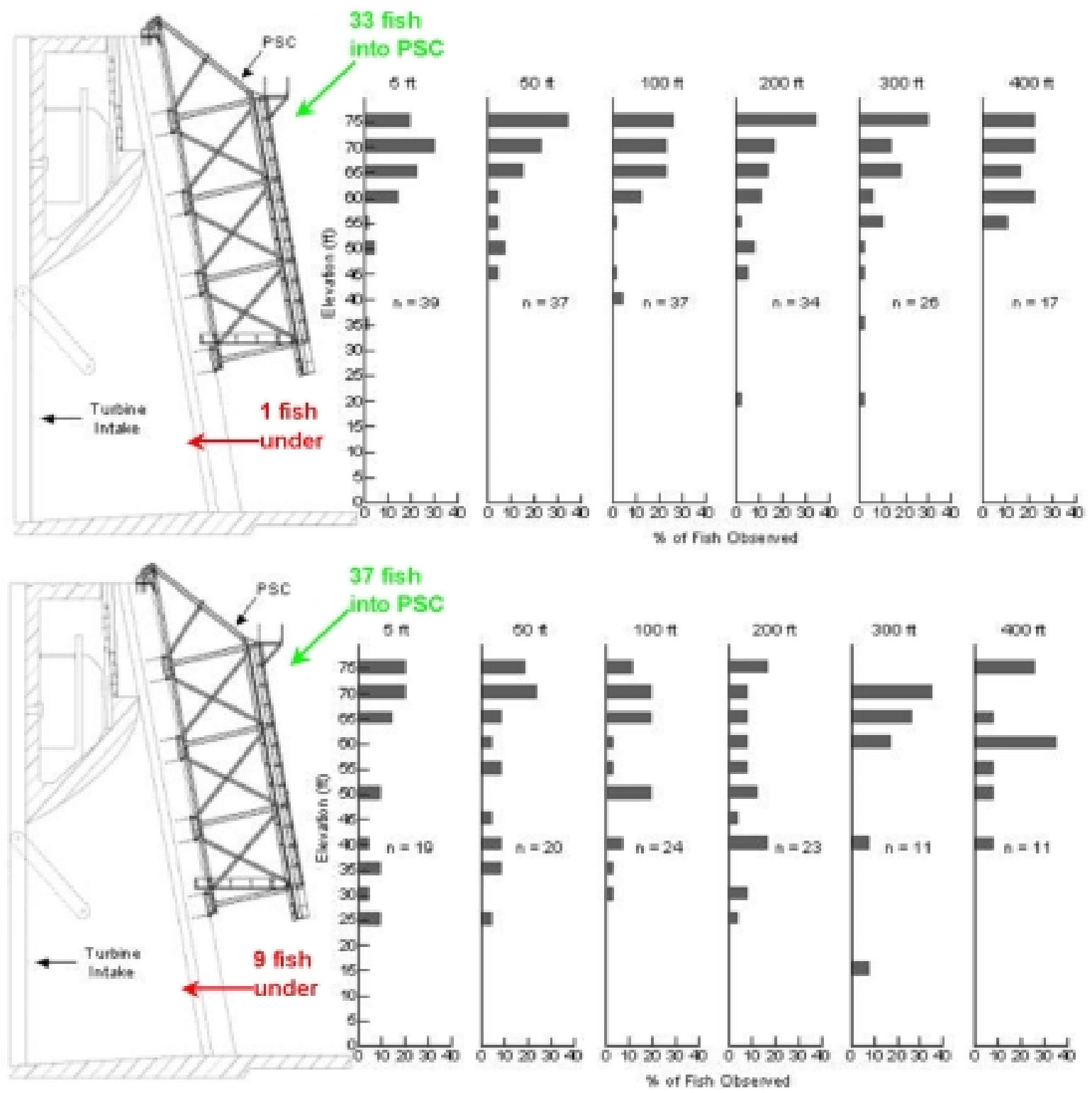

Figure 30. Vertical Distribution and Passage of Tagged Juvenile Steelhead at the PSC for Daytime and Nighttime Hours for April, May, and June 2000 

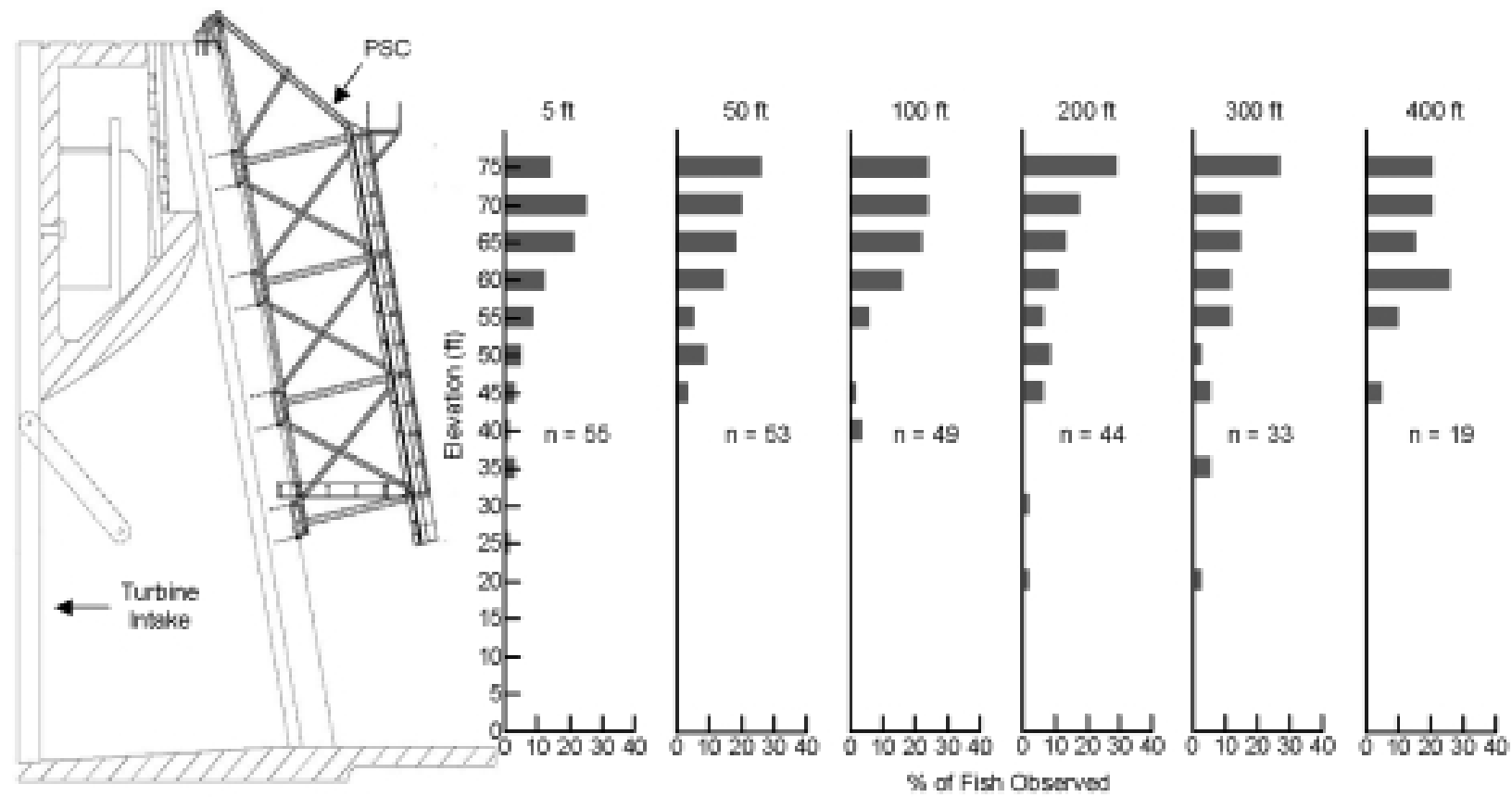

Figure 31. Vertical Distribution (elevation, $\mathrm{ft}$ ) of Yearling Spring Chinook and Juvenile Steelhead Approaching the PSC (Turbine Units 1-6) at Bonneville Dam during Daylight Hours. Percent of fish observed intercepting each plane at 5, 50, 100, 200, 300, and $400 \mathrm{ft}(1.5$, $15.2,30.5,61,91.5,122 \mathrm{~m}$ ) from the face of the PSC. 

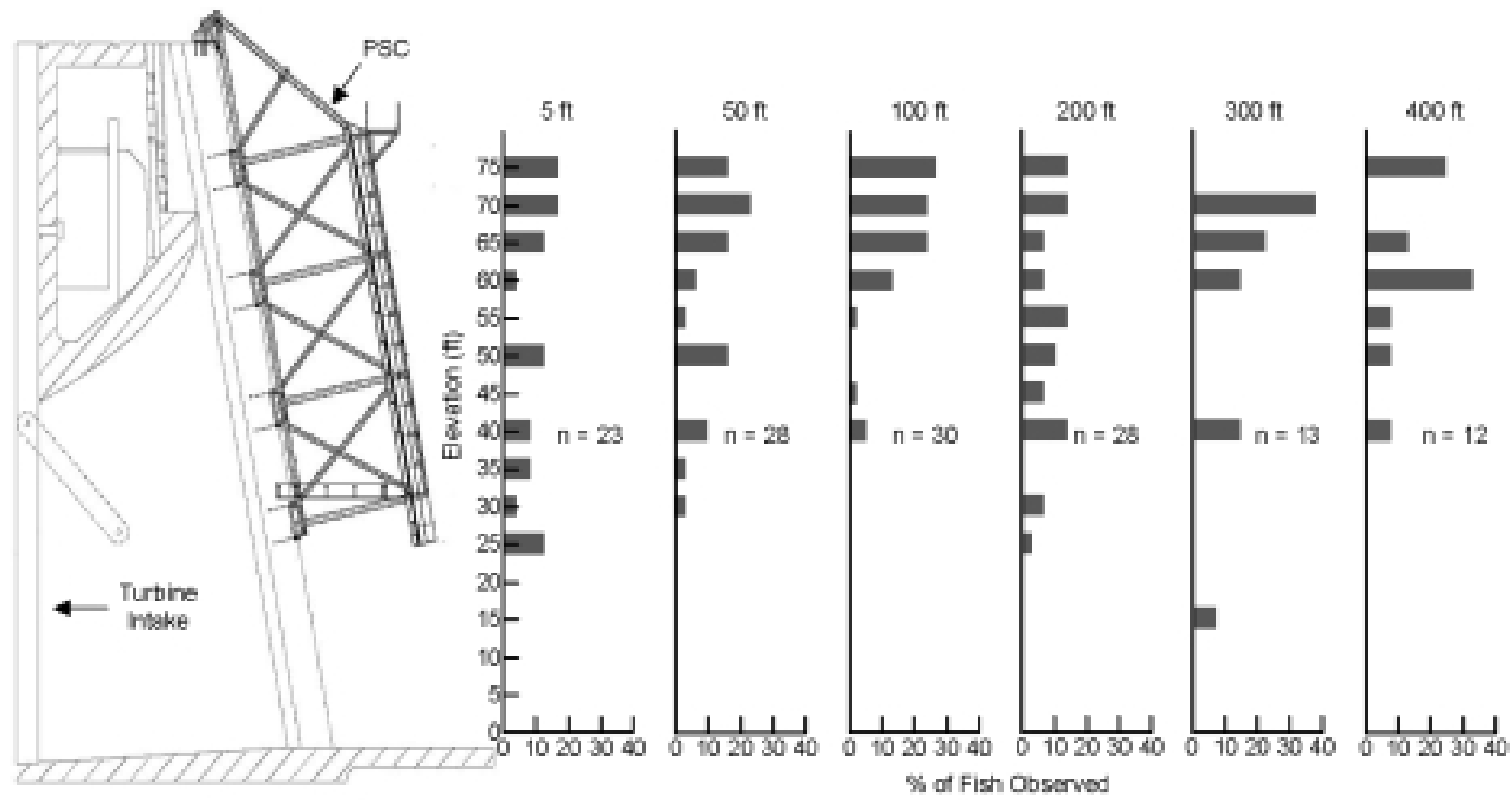

Figure 32. Vertical Distribution (elevation, ft) of Yearling Spring Chinook and Juvenile Steelhead Approaching the PSC (Turbine Units 1-6) at Bonneville Dam During Night Hours. Percent (\%) of fish observed intercepting each plane at 5, 50, 100, 200, 300, and $400 \mathrm{ft}(1.5,15.2$, $30.4,61,91.5,122 \mathrm{~m}$ ) from the face of the PSC. 

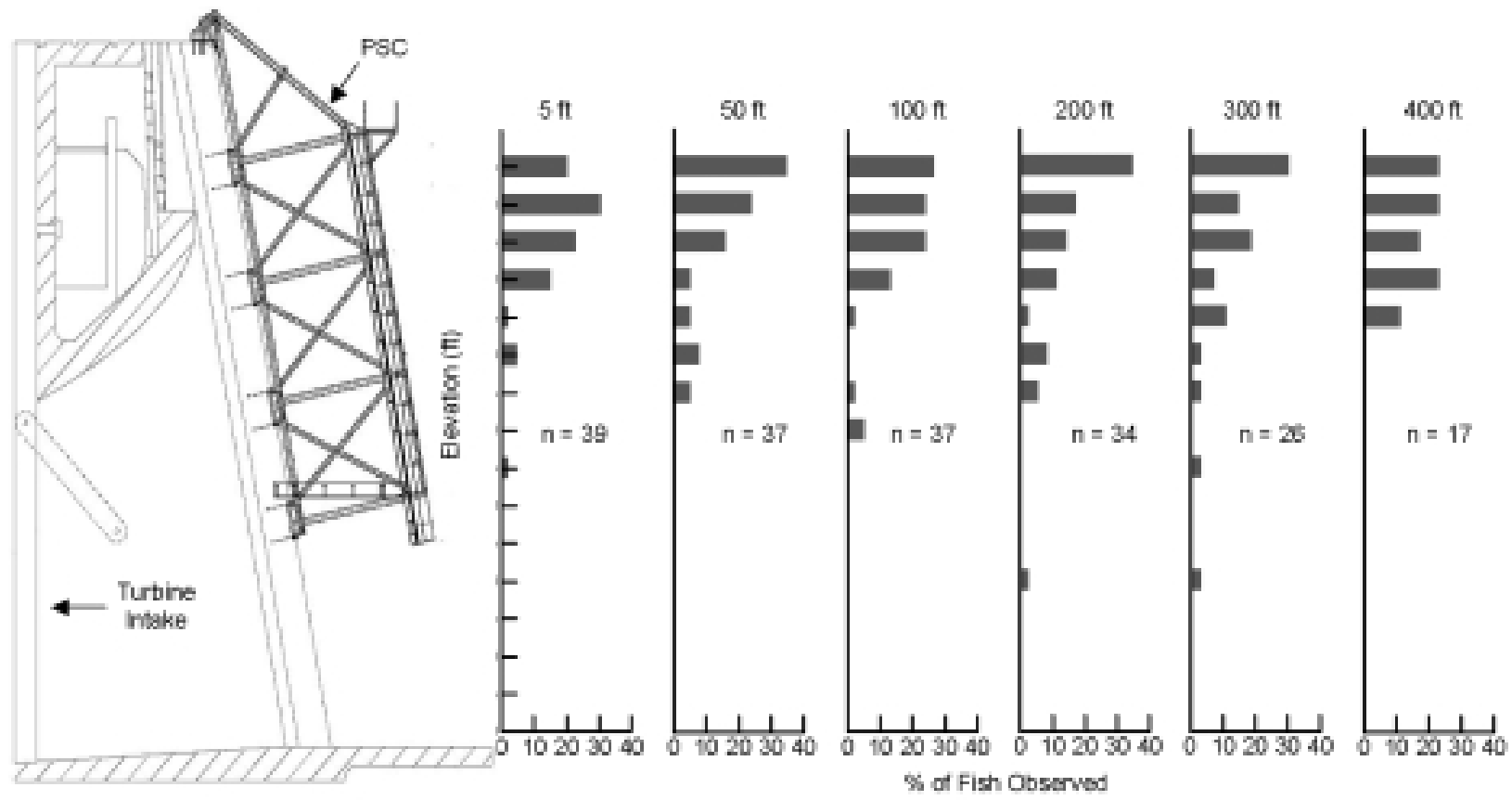

Figure 33. Vertical Distribution of Juvenile Steelhead Approaching the PSC (Turbine Units 1-6) at Bonneville Dam During Daylight Hours. Percent (\%) of fish observed intercepting each plane at 5, 50, 100, 200, 300, and $400 \mathrm{ft}(1.5,15.2,30.4,61,91.5,122 \mathrm{~m})$ from the face of the PSC. 

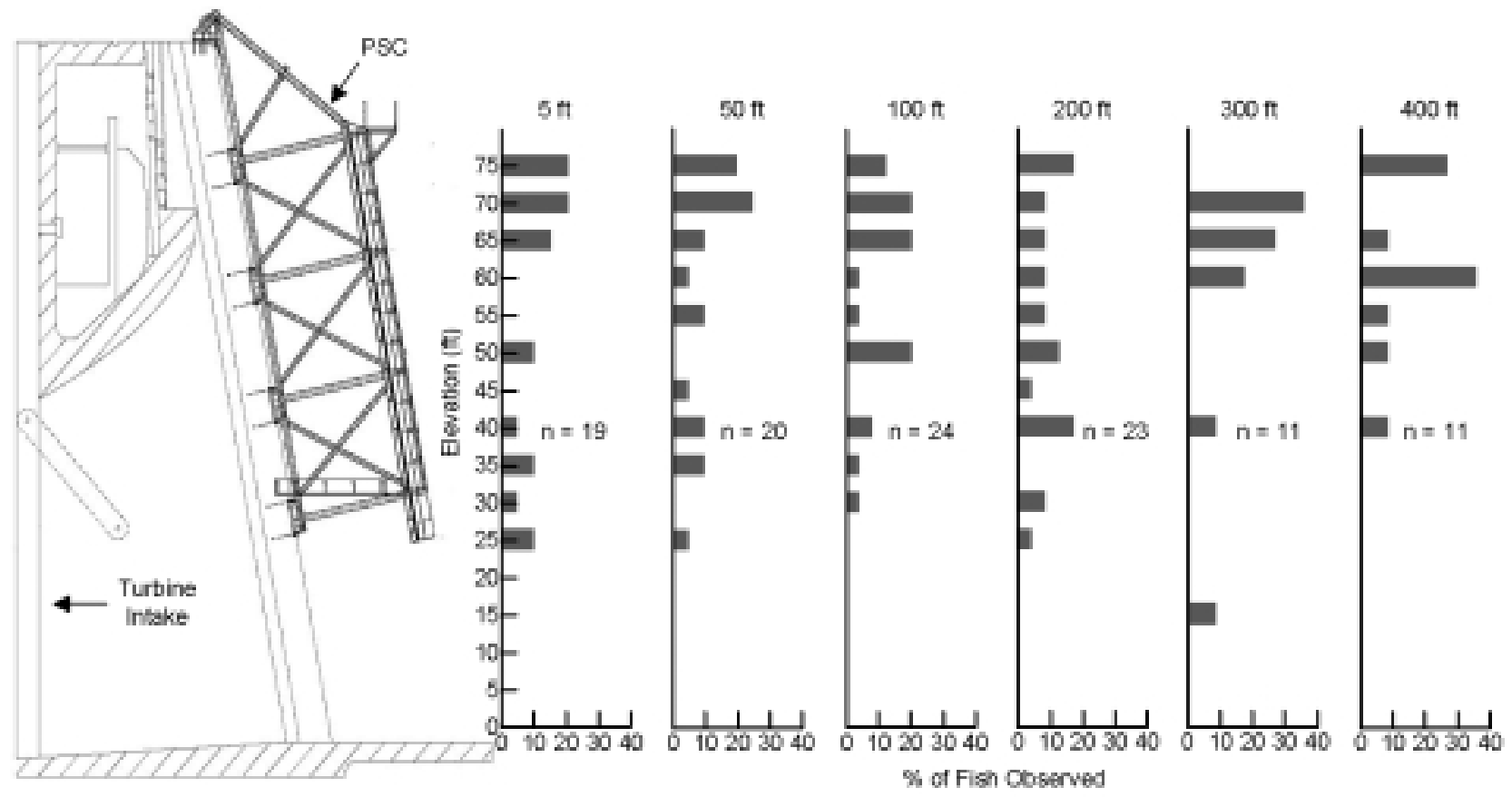

Figure 34. Vertical Distribution of Juvenile Steelhead Approaching the PSC (Turbine Units 1-6) at Bonneville Dam During Nighttime Hours. Percent (\%) of fish observed intercepting each plane at 5, 50, 100, 200, 300, and $400 \mathrm{ft}(1.5,15.2,30.5,61,91.5,122 \mathrm{~m})$ from the face of the PSC. 

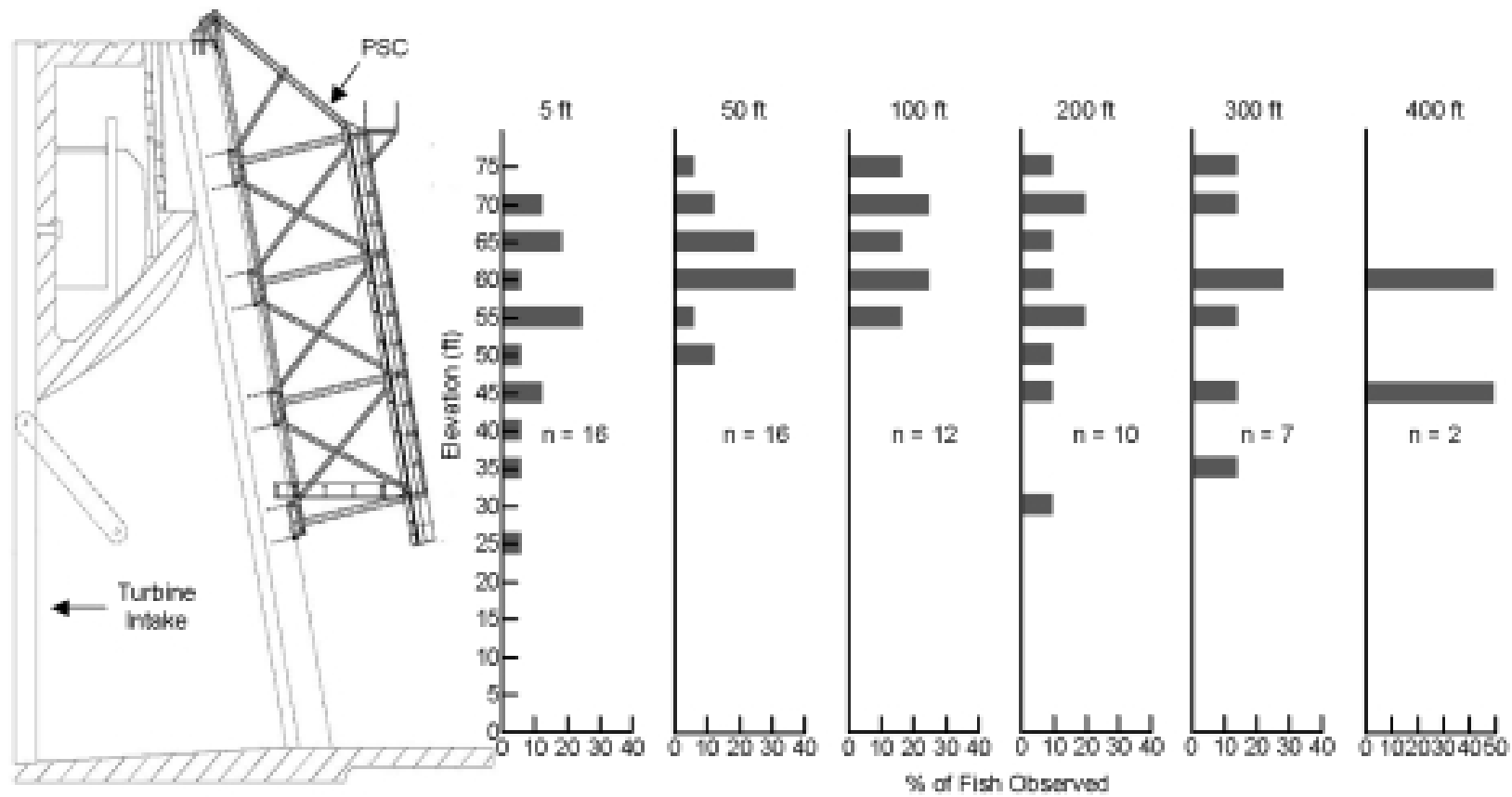

Figure 35. Vertical Distribution of Yearling Spring Chinook Approaching the PSC (Turbine Units 1-6) at Bonneville Dam During Daylight Hours. Percent (\%) of fish observed intercepting each plane at 5, 50, 100, 200, 300, and $400 \mathrm{ft}(1.5,15.2,30.5,61,91.5,122 \mathrm{~m})$ from the face of the PSC. Notice scales may differ among graphs. 

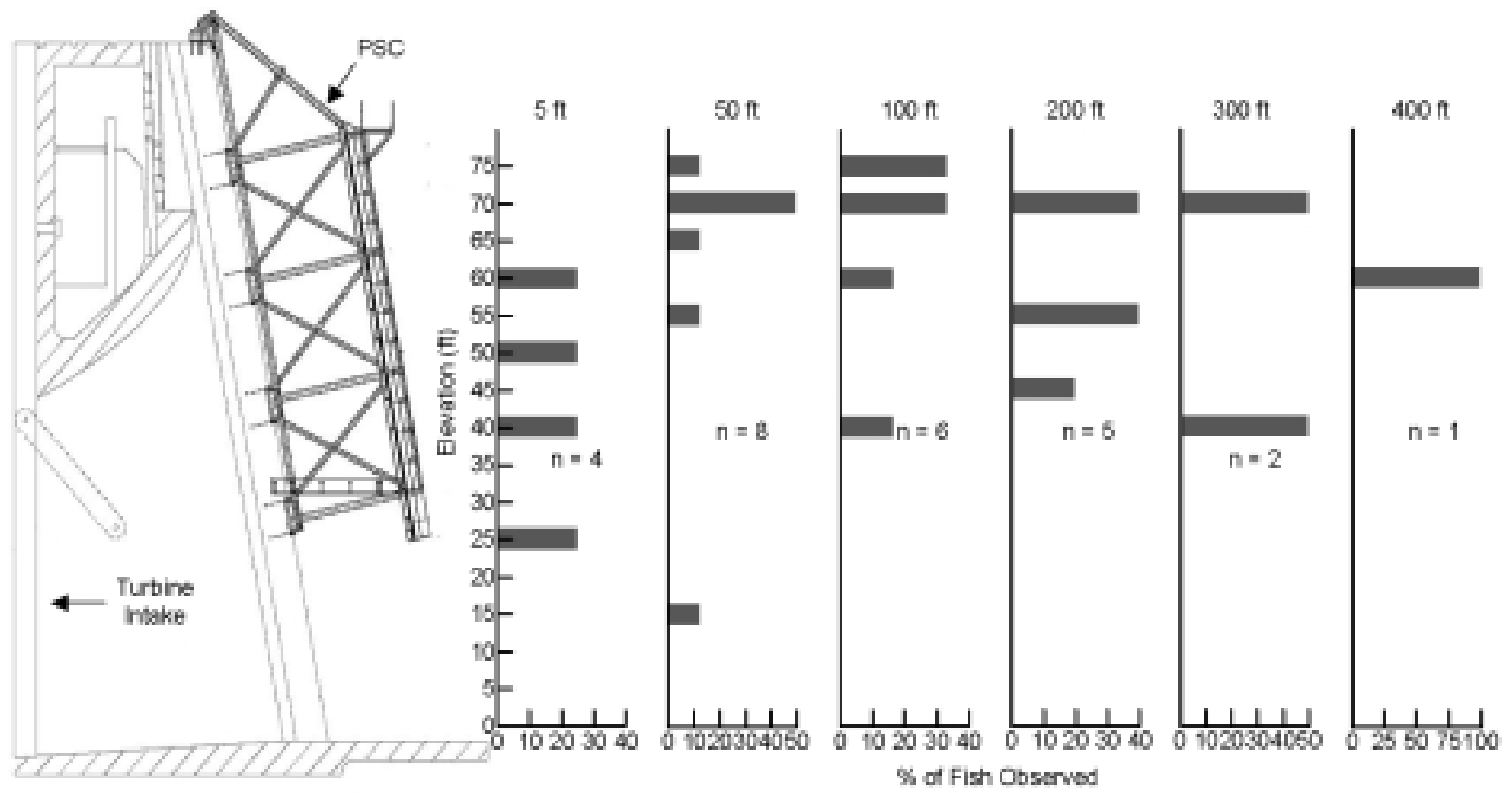

Figure 36. Vertical Distribution of Yearling Spring Chinook Approaching the PSC (Turbine Units 1-6) at Bonneville Dam During Nighttime Hours. Percent (\%) of fish observed intercepting each plane at 5, 50, 100, 200, 300, and $400 \mathrm{ft}(1.5,15.2,30.5,61,91.5,122 \mathrm{~m})$ from the face of the PSC. Note scales may differ among graphs. 


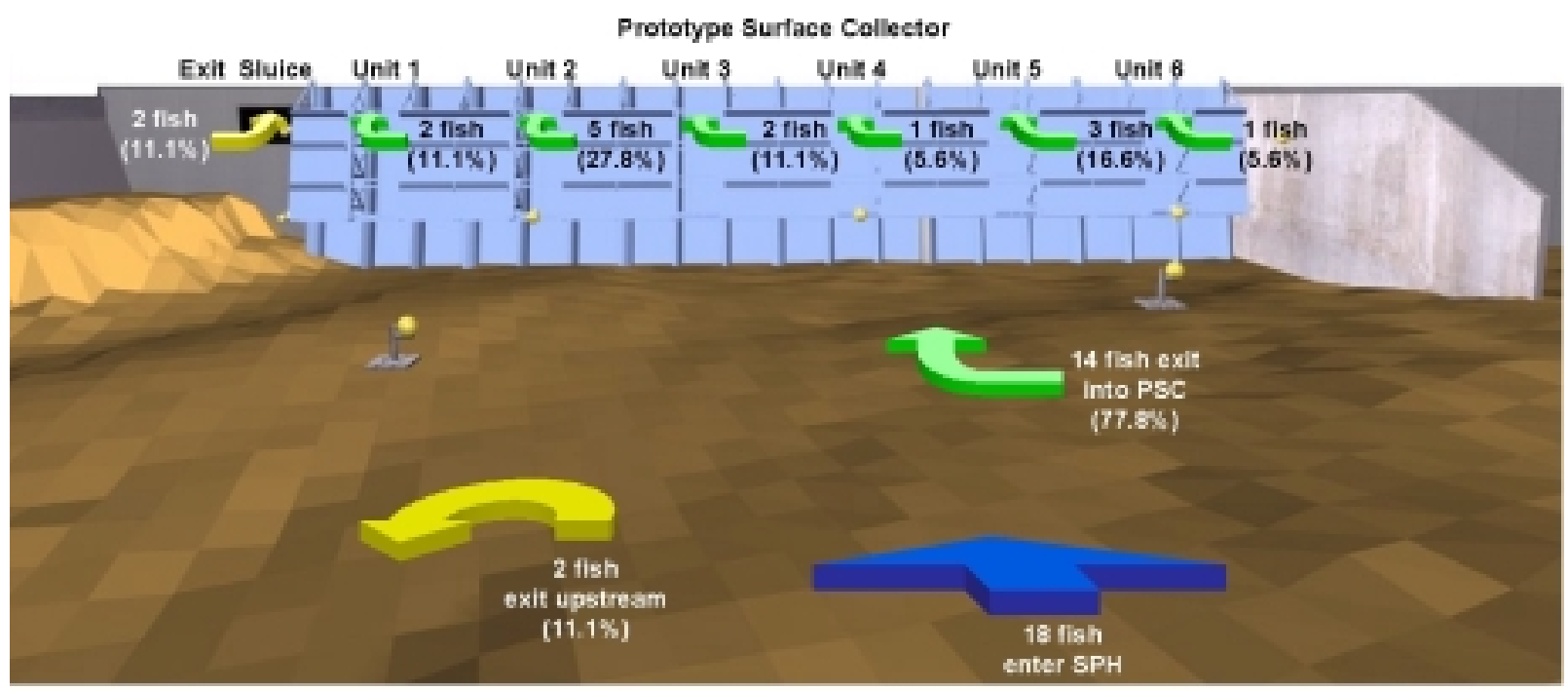

Figure 37. Migrating Yearling Spring Chinook Exiting South Side of Powerhouse I (SPH) at Bonneville Dam During Daylight Hours. Fish passage routes include: into and under PSC for Turbine Units 1-6, south sluice, and upstream. Statistics show exiting fish numbers and percents of total fish that entered SPH. No arrows indicates no fish passage. 


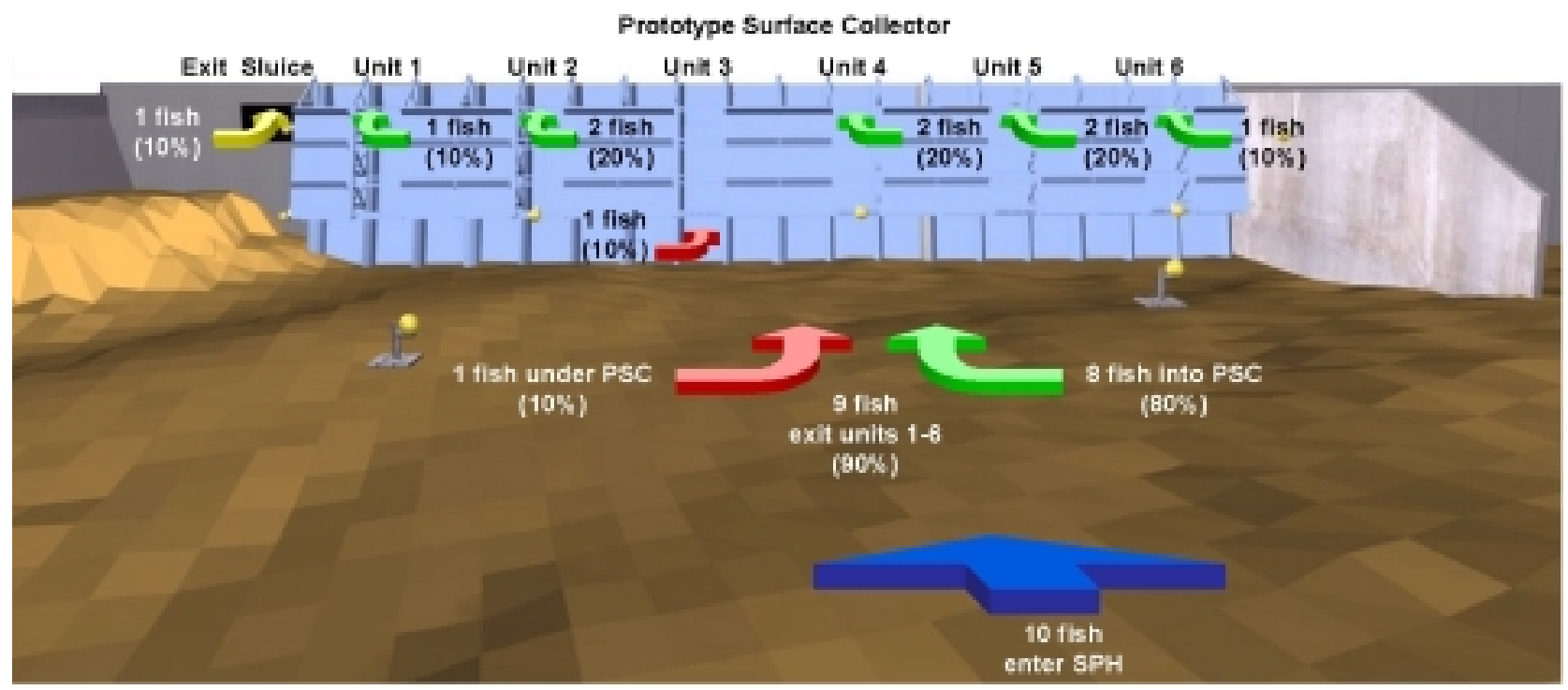

Figure 38. Migrating Yearling Spring Chinook Exiting South Side of Powerhouse I (SPH) at Bonneville Dam During Night Hours. Fish passage routes include into and under PSC for Turbine Units 1-6, south sluice, and upstream. Statistics show exiting fish numbers and percents of total fish that entered SPH. No arrows indicates no fish passage. 


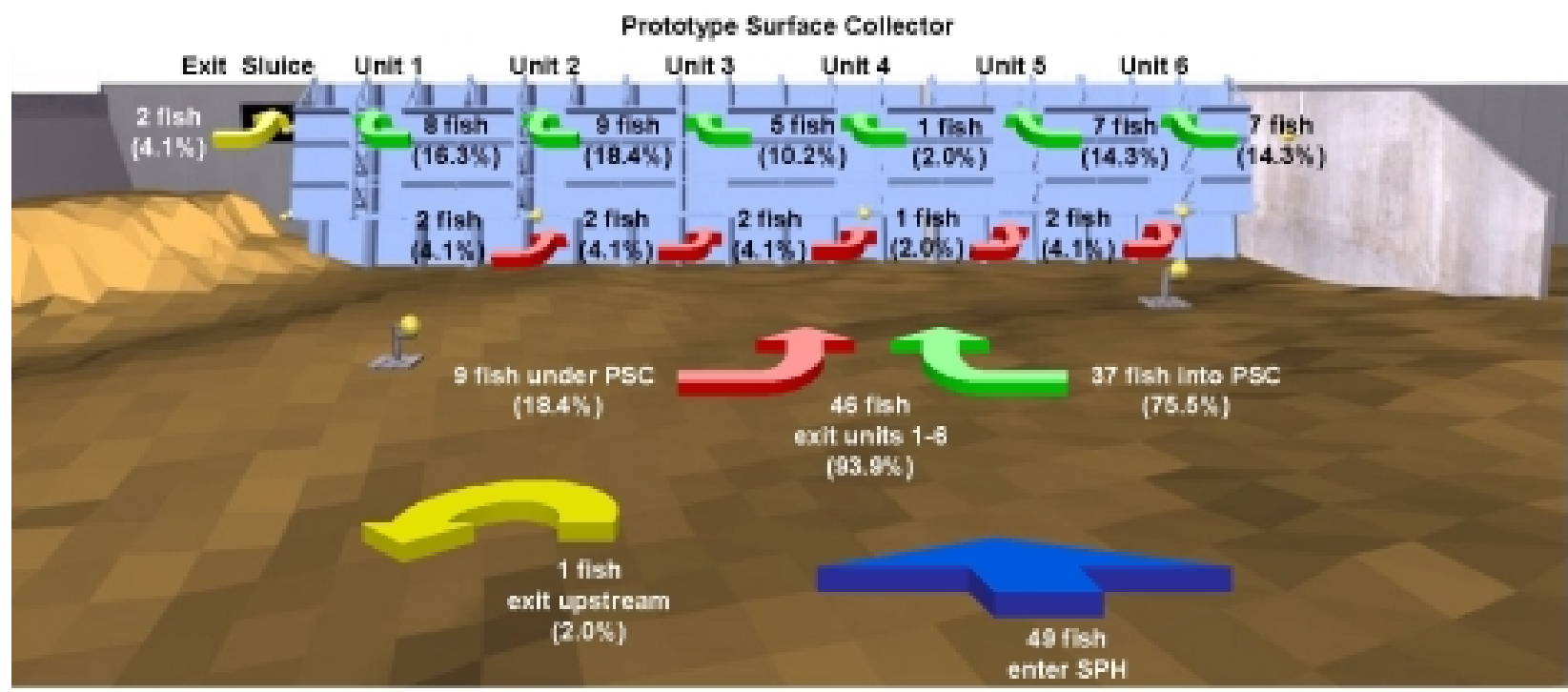

Figure 39. Migrating Juvenile Steelhead Exiting South Side of Powerhouse I (SPH) at Bonneville Dam During Daylight Hours. Fish passage routes include into and under PSC for Turbine Units 1-6, south sluice, and upstream. Statistics show exiting fish numbers and percents of total fish that entered SPH. No arrows indicates no fish passage. 


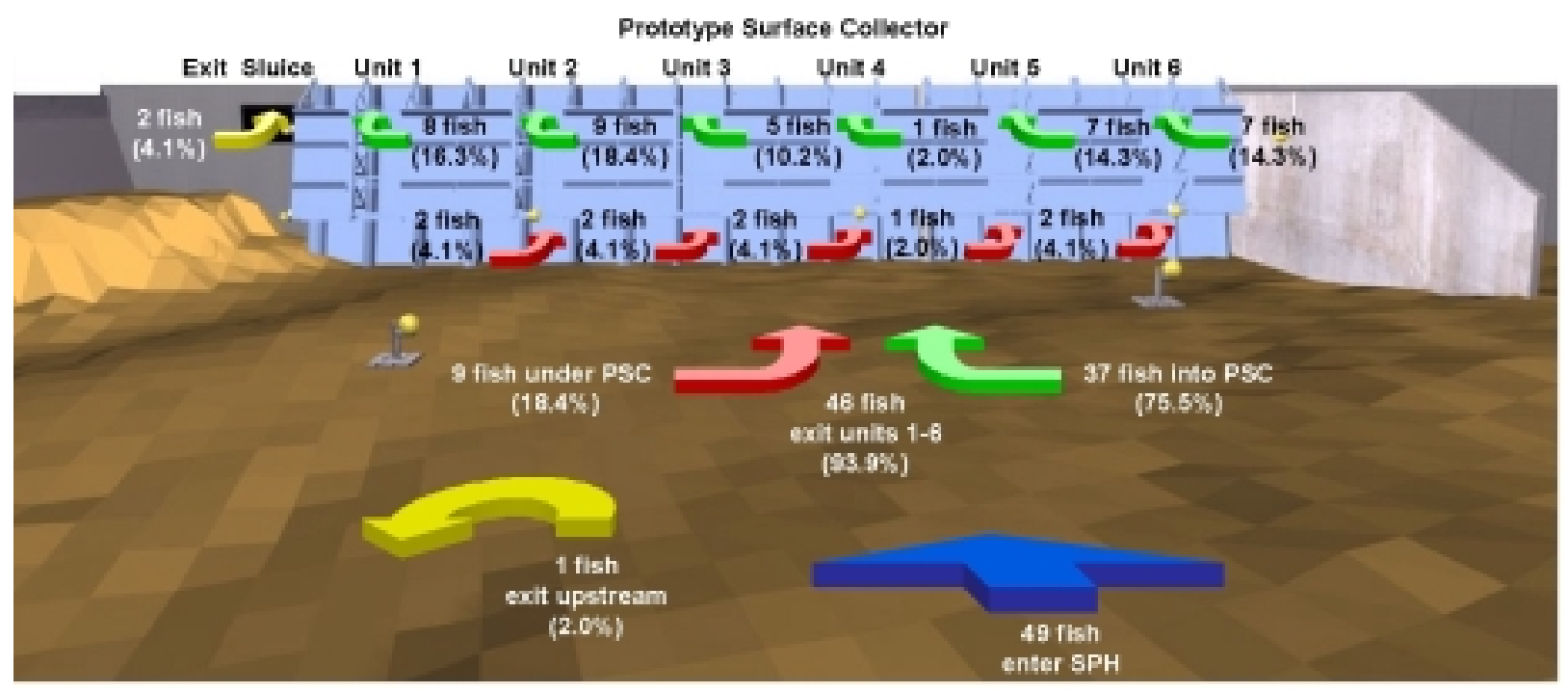

Figure 40. Migrating Juvenile Steelhead Exiting South Side of Powerhouse I (SPH) at Bonneville Dam During Night Hours. Fish passage routes include into and under PSC for Turbine Units 1-6, south sluice, upstream. Statistics show exiting fish numbers and percents of total fish that entered SPH. No arrows indicates no fish passage. 

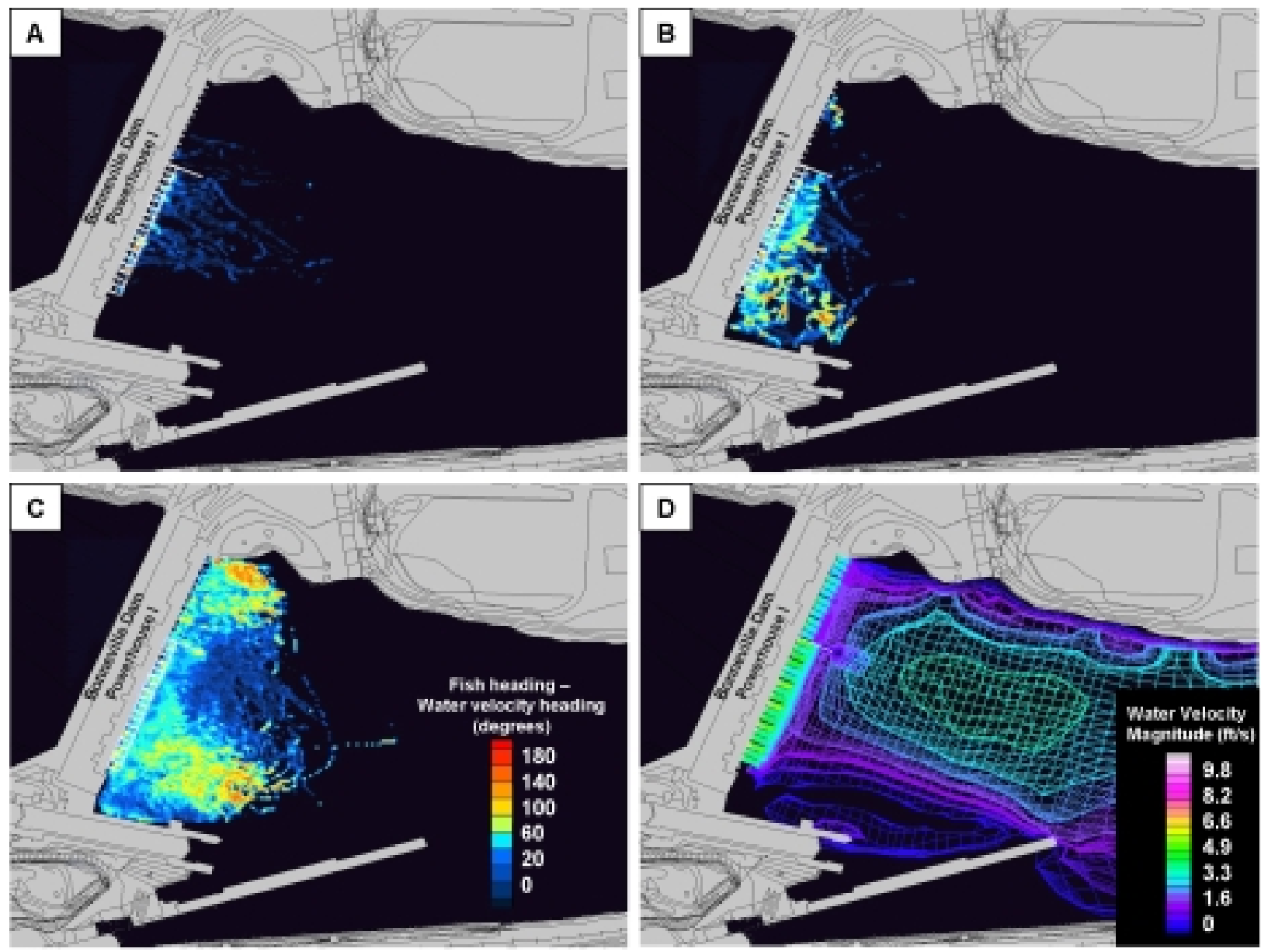

Figure 41. Angular Difference in Water Velocity Direction from Fish Direction for (A) Direct Pass Fish, (B) Searching Fish, and (C) Milling Fish. Modeled water velocity contours are also displayed showing steady turbine loading for all units (D) 

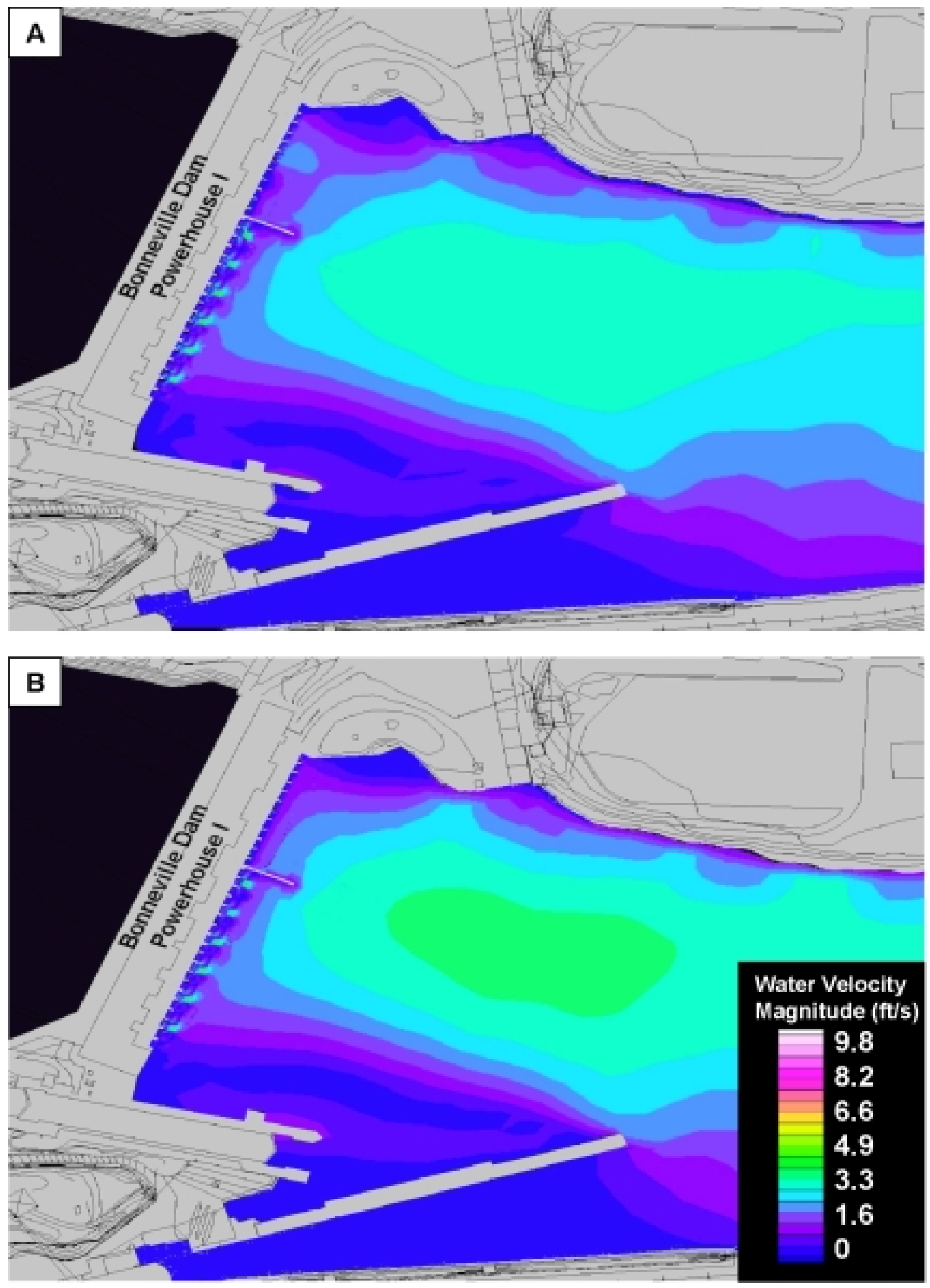

Figure 42. Modeled Water Velocity Contours Showing (A) Steady Turbine Loading Unit 8 Off and (B) Steady Turbine Loading Unit 8 On 

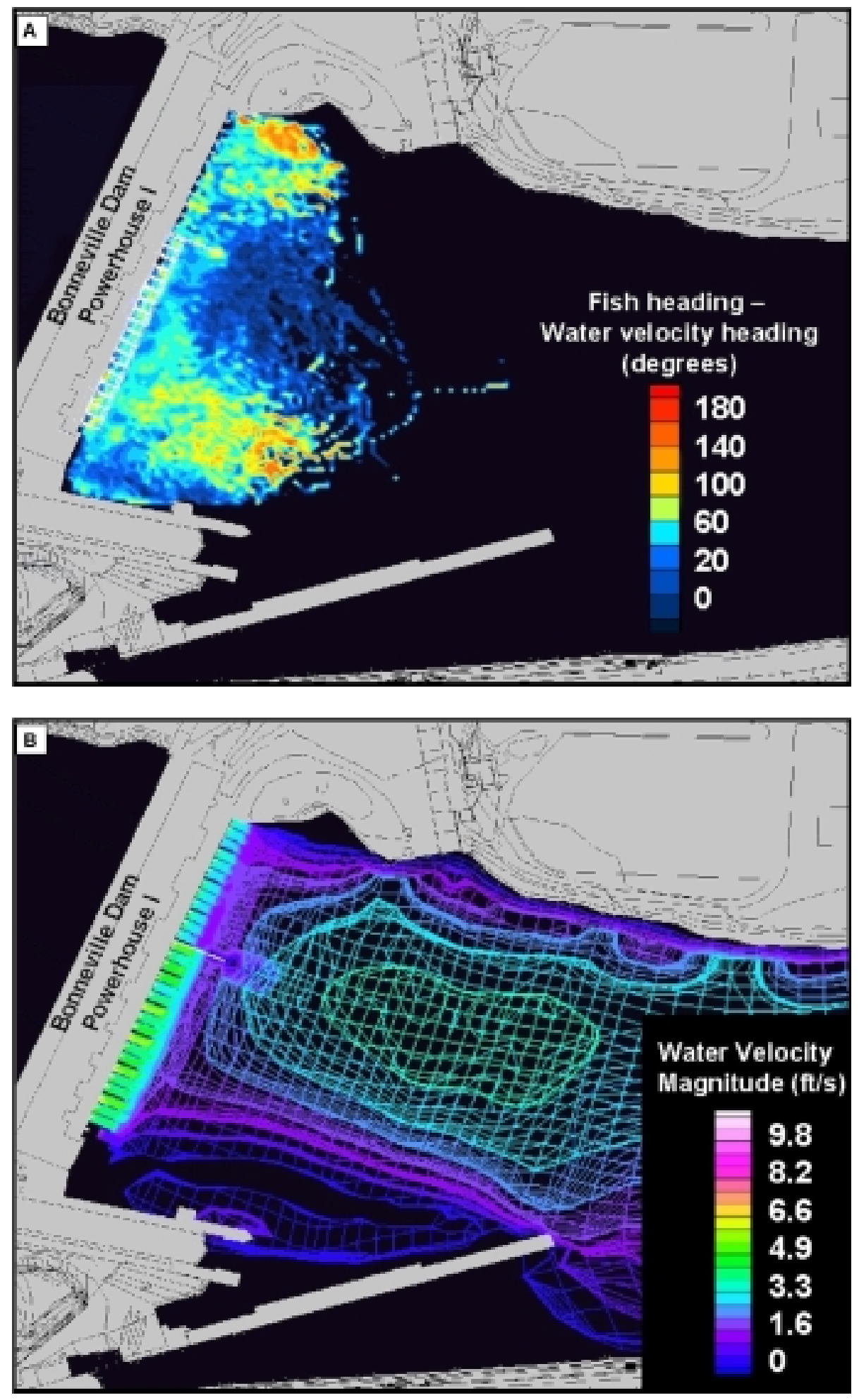

Figure 43. Milling Fish Movement with Respect to (A) Flow and (B) Water Velocity Magnitude Output from CFD Model 


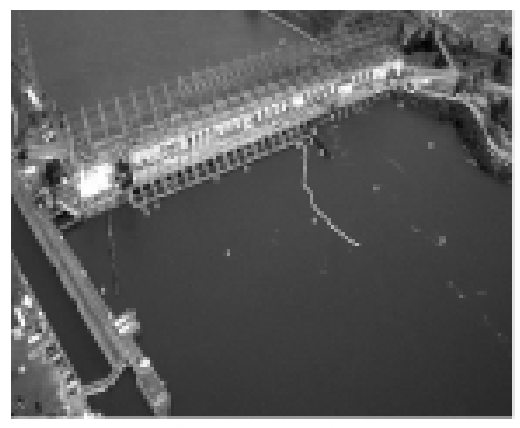

Direct Pass

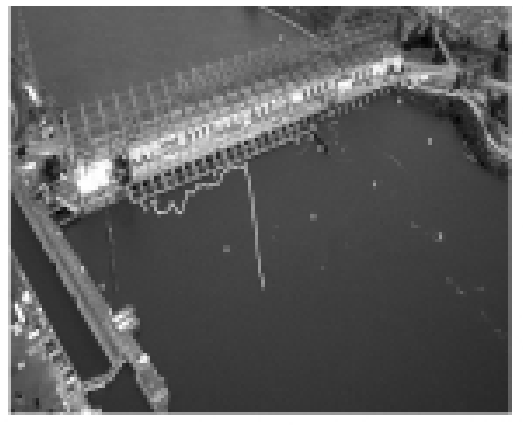

Searching

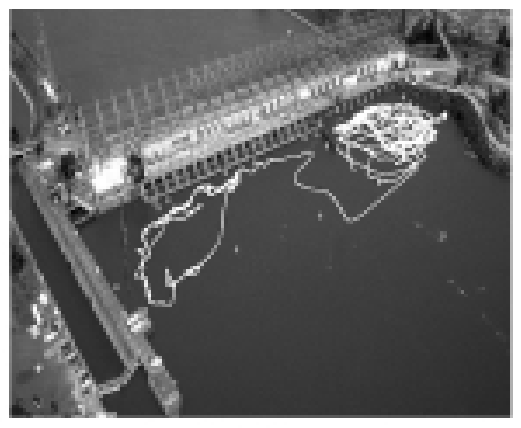

Miling

\begin{tabular}{|c|c|c|c|c|c|}
\hline Species & Entry Time & Direct Pass & Soarching & Milling & Total \\
\hline \multirow{3}{*}{$\begin{array}{l}\text { Combined Yearling } \\
\text { Chinook and } \\
\text { Juvenile Steelhead }\end{array}$} & All hours & $27.6 \%(47 / 170)$ & $20.0 \%[34 / 170]$ & $52.4 \%(89470)$ & $100.06 \%(170 / 170)$ \\
\hline & Day hours & $8.4 \%(895)$ & $27.3 \%(2685)$ & $642 \%(61 / 95)$ & $100.0 \%(9695)$ \\
\hline & Nght hours & S2.DN [39/75) & $10 \notin x(8 / 75)$ & $37.3 \%(28 / 75)$ & $100.0 \%(75775)$ \\
\hline \multirow{3}{*}{ Yearling Chinook } & All ho. & $26.8 \%(8 / 31)$ & $35.056(11 / 31)$ & $38 \pi \mathrm{T}\langle 12 / 31\}$ & $100.0 \%$ [31/31) \\
\hline & Dsy hours & $120 \%(4 / 21)$ & $429 \%(921)$ & $38.1 \%, 821\}$ & $100.0 \%(21 / 21)$ \\
\hline & Night hours & $40.05(4 / 10)$ & $200 \%(2 / 10)$ & $40 \mathrm{DF}(4 \mathrm{MO})$ & $100.0 \%(10 / 10)$ \\
\hline \multirow{3}{*}{ Juve nile Steelhead } & All hours & $28.1 \%(38139)$ & $16.5 \%[22 / 139]$ & $56.4 \%(77 / 439)$ & $100.0 \%(139 / 138)$ \\
\hline & Day hours & $5.4 \%(4 / 74)$ & $230 \%(17 / 74)$ & $71.6 \%(53 / 74)$ & $100.0 \%(74 / 74)$ \\
\hline & Night hours & $53.8 \times[35 / 66)$ & $9.2 \%\{6.65\}$ & $36.9 \%(2465)$ & $100.0 \%$ (65)65) \\
\hline
\end{tabular}

Figure 44. Sample Tracks of Fish Behavior Types in the Forebay of Bonneville Dam, Powerhouse 1. Direct pass behavior is characterized by a residence time outside of the PSC of 1 hour or less. Searching behavior is characterized by a residence time between 1 and 4 hours. Residence time for milling fish is greater than 4 hours. Statistics show percent of fish in each behavior pattern. Day and night are determined by time of entry into the array. 

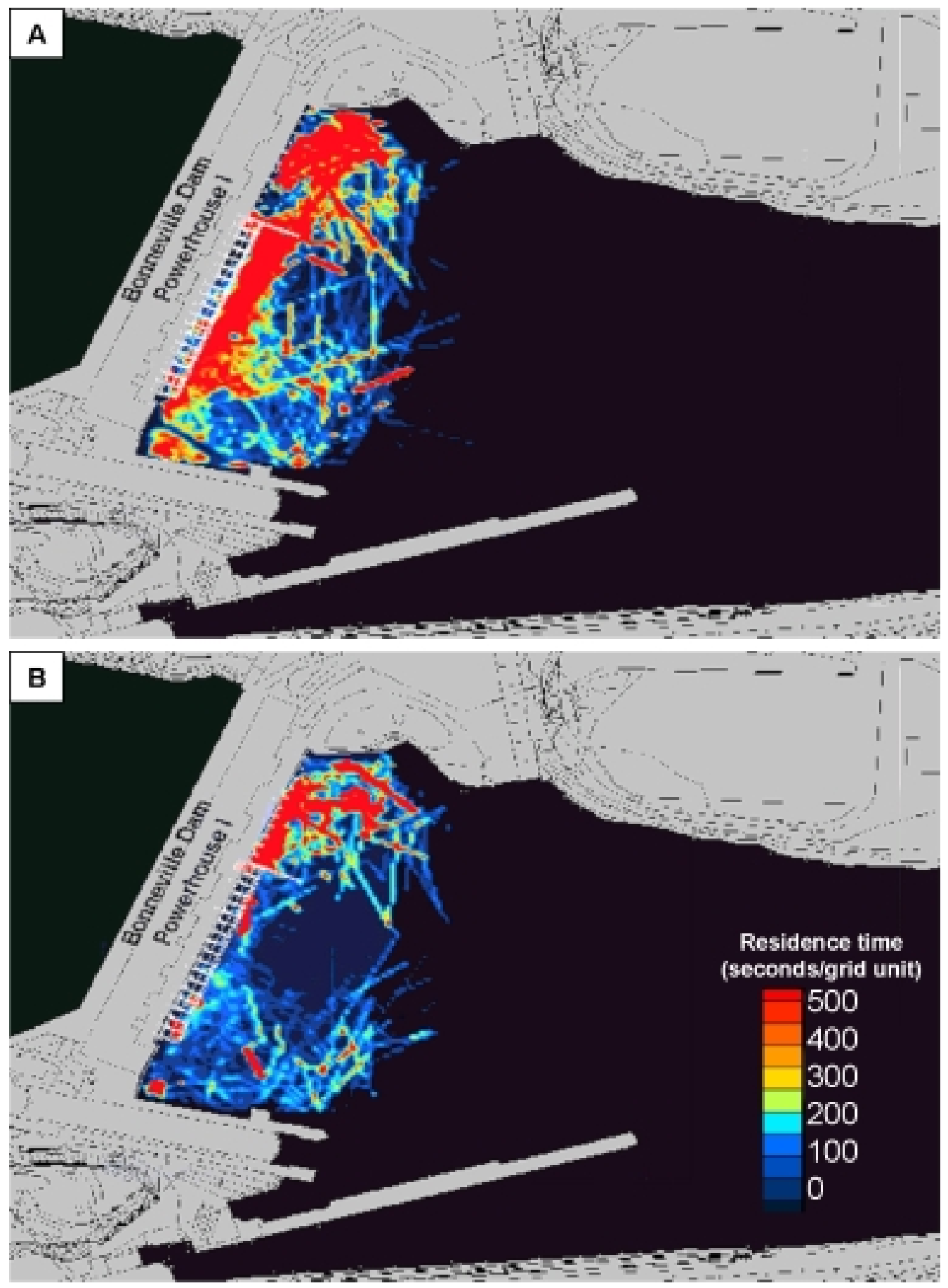

Figure 45. (A) Daytime and (B) Nighttime Average Residence Times of Both Yearling Chinook and Juvenile Steelhead. Residence times are displayed as an average time spent in $10 \mathrm{ft} \times 10 \mathrm{ft}(3 \mathrm{~m} \times 3 \mathrm{~m})$ grid unit for all fish that entered the forebay hydrophone array from 8 am to $8 \mathrm{pm}$ (daytime) or $8 \mathrm{pm}$ to 8 am (nighttime). 


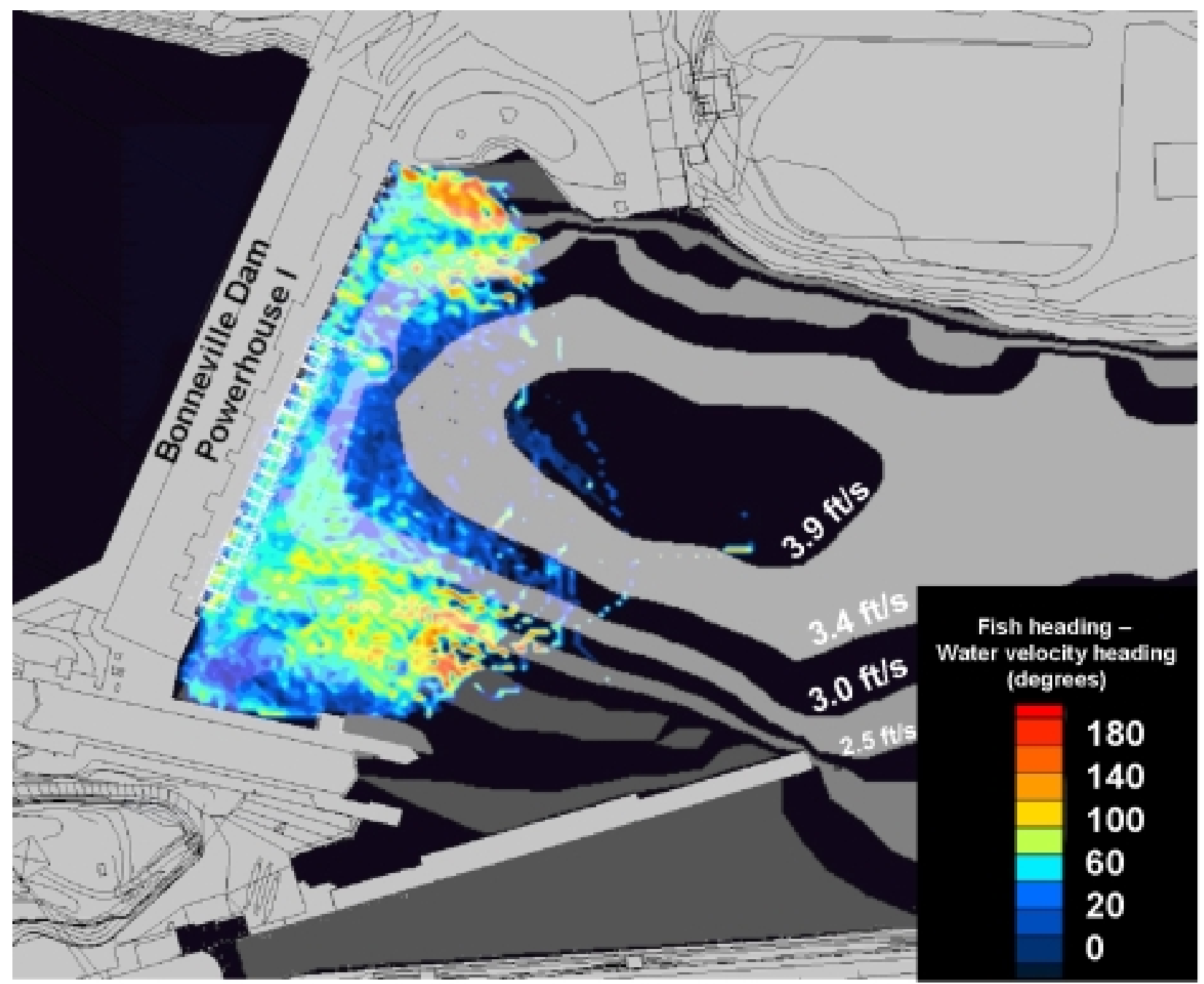

Figure 46. Modeled Water Velocity Contours (ft/s) Showing Steady Turbine Loading Unit 8 (on zebra contour zones) as Well as Milling Fish Movement Separated by $10 \mathrm{ft}$ x $10 \mathrm{ft}$ (3 m x $3 \mathrm{~m}$ ) Grid Unit; Fish Heading with Respect to Water Velocity Heading. Cool colors (i.e., blue, green) indicate fish were moving with flow while warm colors (i.e. red, yellow) indicate fish were moving against flow. 

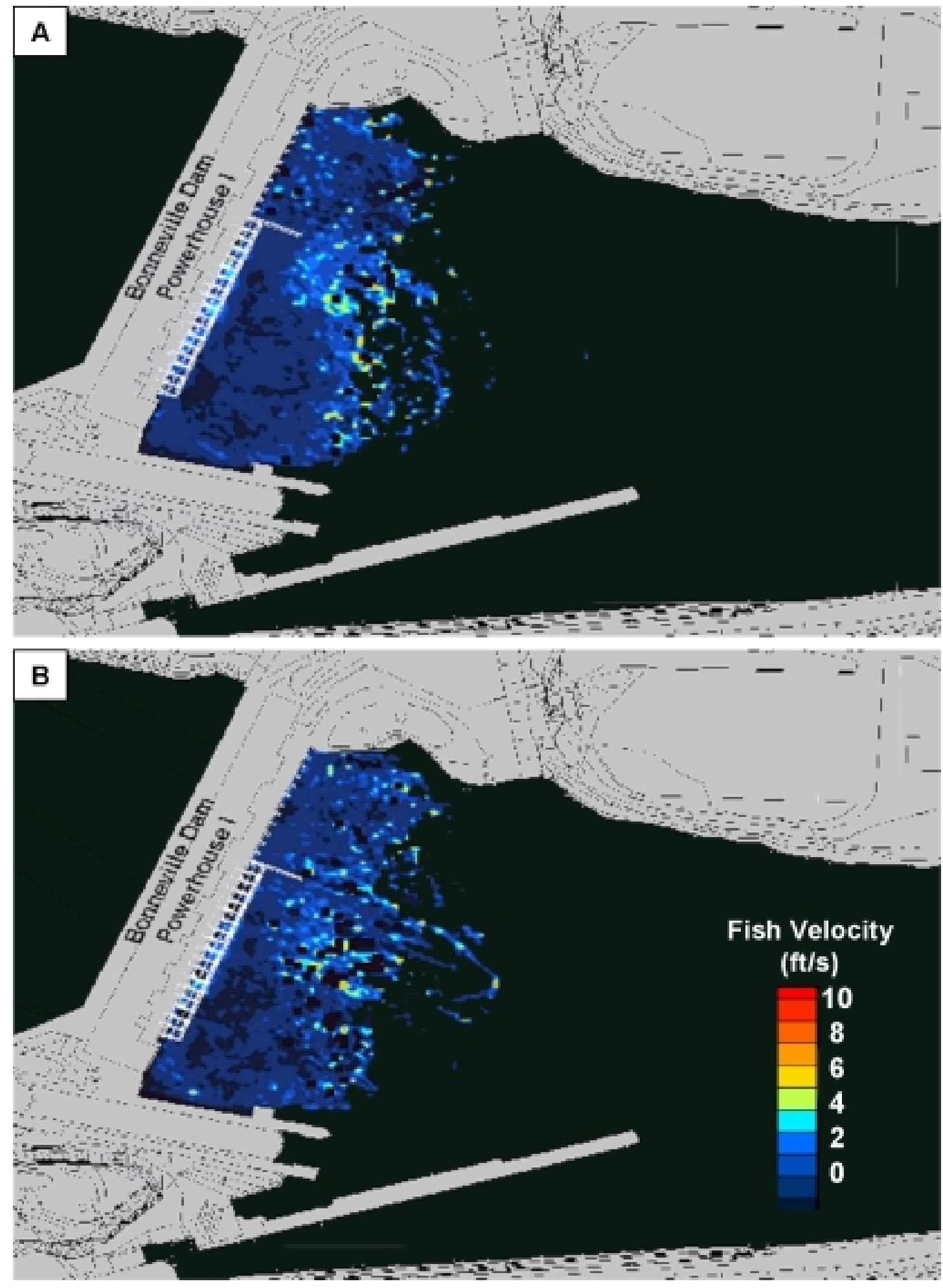

Figure 47. (A) Daytime and (B) Nighttime Average Fish Speed of Both Yearling Chinook and Steelhead. Speed is displayed as an average velocity of all contacts in a $10 \mathrm{ft} \times 10 \mathrm{ft}$ ( $3 \mathrm{~m} \times 3 \mathrm{~m}$ ) grid unit for all fish that entered the forebay hydrophone array from 8 am to $8 \mathrm{pm}$ (daytime) or $8 \mathrm{pm}$ to 8 am (nighttime). 
Table 1. Fate of Yearling Chinook and Juvenile Steelhead Entering Powerhouse I 3D Hydrophone Array at Bonneville Dam

\begin{tabular}{|c|c|c|c|c|c|c|c|}
\hline Species & $\begin{array}{c}\text { PSC } \\
\text { Passage }\end{array}$ & $\underset{1-6}{\text { Turbine Units }}$ & $\begin{array}{c}\text { Turbine Units } \\
7-10\end{array}$ & Sluice & Upstream & Unknown & Total \\
\hline $\begin{array}{c}\text { Combined yearling } \\
\text { chinook and juvenile } \\
\text { steelhead }\end{array}$ & $\begin{array}{l}\text { Into } \\
\text { Under }\end{array}$ & $\begin{array}{l}92(54.1 \%) \\
11(6.5 \%)\end{array}$ & $\begin{array}{c}26 \\
(15.3 \%)\end{array}$ & $\begin{array}{c}9 \\
(5.3 \%)\end{array}$ & $\begin{array}{c}30 \\
(17.6 \%)\end{array}$ & $\begin{array}{c}2 \\
(1.2 \%)\end{array}$ & $\begin{array}{c}170 \\
\langle 100 \%\rangle\end{array}$ \\
\hline Yearling chinook & $\begin{array}{l}\text { Into } \\
\text { Under }\end{array}$ & $\begin{array}{c}22(71.0 \%) \\
1(3.2 \%)\end{array}$ & $\begin{array}{c}2 \\
(6.4 \%)\end{array}$ & $\begin{array}{c}3 \\
(97 \%)\end{array}$ & $\begin{array}{c}3 \\
(9.7 \%)\end{array}$ & 0 & $\begin{array}{c}31 \\
\langle 100 \%)\end{array}$ \\
\hline Juvenile steelhead & $\begin{array}{l}\text { Into } \\
\text { Under }\end{array}$ & $\begin{array}{l}70(50.4 \%) \\
10(7.2 \%)\end{array}$ & $\begin{array}{c}24 \\
(17.3 \%)\end{array}$ & $\begin{array}{c}6 \\
(4.3 \%)\end{array}$ & $\begin{array}{c}27 \\
(19.4 \%)\end{array}$ & $\begin{array}{c}2 \\
(1.4 \%)\end{array}$ & $\begin{array}{c}139 \\
(100 \%)\end{array}$ \\
\hline
\end{tabular}

Table 2. Migrating Yearling Chinook and Juvenile Steelhead Exiting South Side of Powerhouse I (SPH) at Bonneville Dam During Daylight Hours

\begin{tabular}{|c|c|c|c|c|c|c|c|c|c|c|}
\hline \multirow{2}{*}{ Species } & \multirow{2}{*}{$\begin{array}{c}\text { PSC } \\
\text { Passage }\end{array}$} & \multicolumn{6}{|c|}{ Turbine units } & \multirow{2}{*}{ Sluice } & \multirow{2}{*}{ Upstraam } & \multirow{2}{*}{ Total } \\
\hline & & 1 & 2 & 3 & 4 & 5 & 6 & & & \\
\hline \multirow{2}{*}{$\begin{array}{l}\text { Combined yearling } \\
\text { chinook and } \\
\text { juvenile steethead }\end{array}$} & Into & $\stackrel{7}{7}^{(11.1 \%)}$ & $\begin{array}{c}16 \\
(25.4 \%)\end{array}$ & $\stackrel{4}{4}$ & $\stackrel{2}{2}$ & $\begin{array}{c}11 \\
\{17.0 \mathrm{~W}\}\end{array}$ & $\stackrel{7}{7}^{111.1 \%)}$ & \multirow{2}{*}{$\begin{array}{c}8 \\
(8.5 \%)\end{array}$} & \multirow{2}{*}{$\stackrel{9}{9}$} & \multirow{2}{*}{$\begin{array}{c}60 \\
(100 \%\end{array}$} \\
\hline & Under & 0 & 0 & 0 & 0 & 0 & $\begin{array}{c}1 \\
(106)\end{array}$ & & & \\
\hline \multirow{2}{*}{ Yesrling chinook } & Into & $\begin{array}{c}2 \\
(11.1 \%)\end{array}$ & $\stackrel{5}{5}$ & $\stackrel{2}{2}$ & $\begin{array}{c}1 \\
\text { (5.6x) }\end{array}$ & $\left(10 \frac{3}{7} \times\right)$ & $\begin{array}{c}1 \\
(5.656)\end{array}$ & \multirow{2}{*}{$\begin{array}{c}2 \\
(11.1 x)\end{array}$} & \multirow{2}{*}{$\begin{array}{c}2 \\
(11.1 \%)\end{array}$} & \multirow{2}{*}{$\begin{array}{c}18 \\
\langle 100 \%\end{array}$} \\
\hline & Under & 0 & 0 & 0 & 0 & 0 & 0 & & & \\
\hline \multirow{2}{*}{ Juvenile steelhead } & Into & $\stackrel{5}{(11.1 \%)}$ & $\begin{array}{c}11 \\
(24.4 \%)\end{array}$ & $\begin{array}{c}2 \\
(4.4 \times)\end{array}$ & $\stackrel{1}{1}$ & $\stackrel{8}{8}$ & $\begin{array}{c}6 \\
(13.3 \%)\end{array}$ & \multirow{2}{*}{$\stackrel{4}{48.9 \%)}$} & \multirow{2}{*}{$\stackrel{7}{7}$} & \multirow{2}{*}{$\begin{array}{c}45 \\
\langle 100 \%\end{array}$} \\
\hline & Under & 0 & 0 & 0 & 0 & 0 & $\frac{1}{(226)}$ & & & \\
\hline
\end{tabular}

Table 3. Migrating Yearling Chinook and Juvenile Steelhead Exiting South Side of Powerhouse I (SPH) at Bonneville Dam During Night Hours

\begin{tabular}{|c|c|c|c|c|c|c|c|c|c|c|}
\hline \multirow{2}{*}{ Species } & \multirow{2}{*}{$\begin{array}{c}\text { PSC } \\
\text { Passage }\end{array}$} & \multicolumn{6}{|c|}{ Turbine units } & \multirow{2}{*}{ Sluíce } & \multirow{2}{*}{ Upsetream } & \multirow{2}{*}{ Total } \\
\hline & & 1 & 2 & 3 & 4 & 5 & 6 & & & \\
\hline \multirow{2}{*}{$\begin{array}{l}\text { Combinod yearling } \\
\text { chinook and } \\
\text { juvenile steelhead }\end{array}$} & Into & $\frac{9}{(16.3 \%)}$ & $\begin{array}{c}11 \\
\text { (18.0\%) }\end{array}$ & $\begin{array}{c}5 \\
(8.6 *)\end{array}$ & $\stackrel{3}{(5.1 \%)}$ & $\stackrel{9}{\{15.3 \%)}$ & $\begin{array}{c}8 \\
(13.6 \%)\end{array}$ & \multirow{2}{*}{$\begin{array}{c}3 \\
(5.1 \%)\end{array}$} & \multirow{2}{*}{$\begin{array}{c}1 \\
(1.78)\end{array}$} & \multirow{2}{*}{$\begin{array}{c}50 \\
(100 \%)\end{array}$} \\
\hline & Under & 0 & (3.4\%) & $\begin{array}{c}3 \\
(5.1 \%)\end{array}$ & $\begin{array}{c}2 \\
\langle 3.4 \%\rangle\end{array}$ & $\begin{array}{c}1 \\
(1.7 \%)\end{array}$ & $\begin{array}{c}2 \\
(3.4 \%)\end{array}$ & & & \\
\hline \multirow[b]{2}{*}{ Yoarling chinook } & Into & $\frac{1}{100(x)}$ & $\frac{2}{(x)+s)}$ & 0 & $2^{2}$ & $\stackrel{2}{2}^{2}$ & $\stackrel{1}{1}$ & \multirow{2}{*}{$\begin{array}{c}1 \\
(10.0 \mathrm{~s})\end{array}$} & \multirow[b]{2}{*}{0} & \multirow{2}{*}{$\begin{array}{c}10 \\
\text { (100\%) }\end{array}$} \\
\hline & Under & 0 & 0 & $\begin{array}{c}1 \\
(10.0 \%)\end{array}$ & 0 & 0 & 0 & & & \\
\hline \multirow{2}{*}{ Juvenile steelhead } & Into & $\stackrel{8}{(16.3 \%)}$ & $\begin{array}{c}9 \\
\text { (18.4\%) }\end{array}$ & $\frac{5}{(10.2 \%)}$ & $\begin{array}{c}1 \\
\langle 2.0 \mathrm{~N}\rangle\end{array}$ & $\begin{array}{c}7 \\
\{14.3 \times)\end{array}$ & $\begin{array}{c}7 \\
(14.3 \%)\end{array}$ & \multirow{2}{*}{$\begin{array}{c}2 \\
(4.1 \%)\end{array}$} & \multirow{2}{*}{$\begin{array}{c}1 \\
(2.056)\end{array}$} & \multirow{2}{*}{$\begin{array}{c}49 \\
(100 \times)\end{array}$} \\
\hline & Under & 0 & $\left.{ }^{2}+4 \%\right)$ & $\begin{array}{c}2 \\
(4.1 \%)\end{array}$ & $\begin{array}{c}2 \\
(4.1 x)\end{array}$ & $\begin{array}{c}1 \\
(20 x)\end{array}$ & $\begin{array}{c}2 \\
(4.1 \%)\end{array}$ & & & \\
\hline
\end{tabular}


Table 4. Summary of Acoustic Telemetry Data Relative to Bonneville Dam, Powerhouse 1 (Powerhouse I) and the PSC

\begin{tabular}{|c|c|c|c|}
\hline \multirow{2}{*}{ Metric } & \multirow{2}{*}{ Equation } & \multicolumn{2}{|c|}{ Species } \\
\hline & & Yearling Chinook & Juvenile Steelhead \\
\hline Travel Time & $T T=\sum_{i=1}^{n} T T i / n$ & 18 hours 22 minutes & 17 hours 9 minutes \\
\hline Percent Contact & $P C=R_{\text {cont }} / R_{\text {fot }}$ & $\begin{aligned} P C & =31 / 163 \\
& =19 \%\end{aligned}$ & $\begin{aligned} P C & =139 / 331 \\
& =42 \%\end{aligned}$ \\
\hline $\begin{array}{l}\text { PSC Passage } \\
\text { Efficiency }\end{array}$ & $P E_{1-8}=P_{1-8} / P_{1-8}+U_{1-8}$ & $\begin{aligned} P E_{1 \cdot 6} & =22 /(22+1) \\
& =22 / 23 \\
& =95.7 \%\end{aligned}$ & $\begin{aligned} P E_{1-6} & =70 /(70+10) \\
& =70 / 80 \\
& =87.5 \%\end{aligned}$ \\
\hline $\begin{array}{l}\text { PSC Entrance } \\
\text { Efficiency }\end{array}$ & $E E_{t-6}=P_{1-6} / W_{t-6}$ & $\begin{aligned} E E_{t \cdot 6} & =22 / 23 \\
& =96 \%\end{aligned}$ & $\begin{aligned} E E_{1-8} & =70 / 74 \\
& =95 \%\end{aligned}$ \\
\hline $\begin{array}{l}\text { PSC Discovery } \\
\text { Efficiency }\end{array}$ & $D E=W_{1.6} / T$ & $\begin{aligned} D E & =23 / 28 \\
& =82 \%\end{aligned}$ & $\begin{aligned} D E & =74 / 1110 \\
& =67 \%\end{aligned}$ \\
\hline $\begin{array}{l}\text { PSC Passage } \\
\text { Effectiveness }\end{array}$ & $P F=P E / F p s c /(F p s c+F u)$ & $\begin{array}{c}P F=0.957 / \\
3114 /(31 n+0235) \\
=0.957 / 0.333 \\
=2.87\end{array}$ & $\begin{array}{c}P F=0.875 \\
3+14 /(3144-6235) \\
=0.8750 .333 \\
=2.63\end{array}$ \\
\hline $\begin{array}{c}\text { Forebay } \\
\text { Residence Time }\end{array}$ & $R T=\sum_{i=1}^{n} R T i m$ & 6 hours 56 minutes & 11 hours 37 minutes \\
\hline
\end{tabular}

Summary of Variables:

$\mathrm{TT}=$ Mean travel time from Hood River release site to detection at B1 array

$R_{\text {con }}=$ Number of fish contacted from release site

$R_{\text {mit }}=$ Total number of fish released at Hood River

$\mathrm{P}_{1-6}=$ Total passage into the PSC (turbine units 1-6)

$U_{1-6}=$ Total passage under the PSC (turbine units 1-6)

$W_{1-8}=$ Total passage rate within 3 meters of PSC entrances 1-6

$T=$ Total number of fish entering B1 forebay that passed at B1 someplace

$\mathrm{F}_{\mathrm{psc}}=$ Flow into the PSC

$\mathrm{E}_{\mathrm{T}}=$ Flow under the PSC

$\mathrm{RT}=$ Mean time spent in B1 forebay prior to passing at B1 
Evaluation of Fish Behavior at the PSC at Bonneville Powerhouse I

Fig.50 


\section{Distribution}

PNNL-13526

No. of

Copies

ONSITE

22 Pacific Northwest National Laboratory

T.J. Carlson (10) BPO

D.M. Faber (5) BPO

T.L. Gilbride BPO

R.A. Moursund K6-85

M.A. Weiland (5) BPO

\section{OFFSITE}

Blaine Eberts $(20+2$ unbound $)$

U.S. Army Corps of Engineers, Portland District

Rock Peters

U.S. Army Corps of Engineers, Portland District

Noah Adams

U.S. Geological Survey, Biological Resources Division

Dennis Rondorf

U.S. Geological Survey, Biological Resources Division 
Evaluation of Fish Behavior at the PSC at Bonneville Powerhouse I

Dist.2 